\title{
INFLUENCE OF PERMEATING IONS ON Kv1.5 CHANNEL BLOCK BY NIFEDIPINE
}

\author{
by \\ SHUNPING LIN \\ M.D., Beijing Medical University, 1992 \\ A THESIS SUBMITTED IN PARTIAL FULFILMENT OF \\ THE REQUIREMENTS FOR THE DEGREE OF \\ MASTER OF SCIENCE \\ in \\ THE FACULTY OF GRADUATE STUDIES \\ (Department of Physiology; School of Medicine; Master of Science) \\ We accept this thesis as conforming \\ to the Tequired standard
}

THE UNIVERSITY OF BRITISH COLUMBIA

November, 2000

(c) Shunping Lin, 2000 
In presenting this thesis in partial fulfilment of the requirements for an advanced degree at the University of British Columbia, I agree that the Library shall make it freely available for reference and study. I further agree that permission for extensive copying of this thesis for scholarly purposes may be granted by the head of my department or by his or her representatives. It is understood that copying or publication of this thesis for financial gain shall not be allowed without my written permission.

Department of Physiology

The University of British Columbia

Vancouver, Canada

Date Nov/2i/2000 


\begin{abstract}
Nifedipine antagonizes current flow through both cardiovascular L-type $\mathrm{Ca}^{2+}$ channels and voltage-gated $\mathrm{K}^{+}(\mathrm{Kv})$ channels. Work from our lab has shown that nifedipine blocks human heart Kv1.5 current when channels are expressed in HEK cells, and an open channel block mechanism was suggested. Here, the potency of nifedipine block of $\mathrm{K}^{+}, \mathrm{Rb}^{+}$, and $\mathrm{Cs}^{+}$currents was investigated, and found to be different with $\mathrm{K}_{d}$ 's of $7.3,16.0$, and $26.9 \mu \mathrm{M}$, respectively, when internal and external $\mathrm{K}^{+}$were replaced with equimolar $\mathrm{Rb}^{+}$or $\mathrm{Cs}^{+}$. The voltagedependence of block was unaffected and block with all three ions conformed to a single binding site block model. Varying ion species at the intracellular and extracellular sides of the channel, and using a non-conducting W472F-Kv1.5 mutant, demonstrated that block was conditioned by the ion permeating the pore, and to a lesser extent by the extracellular ion species alone. In $\mathrm{Kv} 1.5$ the outer pore mutant $\mathrm{R} 487 \mathrm{~V}$ reduced nifedipine potency close to that of $\mathrm{Kv} 4.2$, and other $\mathrm{Kv}$ channels with an equivalent valine. Although changing this residue can affect C-type inactivation of $\mathrm{Kv}$ channels, the normalized reduction and time course of currents blocked by nifedipine in 5,135 , and $300 \mathrm{mM} \mathrm{K}^{+}$owas the same. Similarly, a mean recovery time constant from nifedipine block of $316 \mathrm{~ms}$ was unchanged $(332 \mathrm{~ms})$ after $5 \mathrm{~s}$ prepulses to allow C-type inactivation. This is consistent with the conclusion that nifedipine block and C-type inactivation in the Kv1.5 channel can coexist, but are mediated by distinct mechanisms coordinated by outer pore conformation.
\end{abstract}


TABLE OF CONTENTS

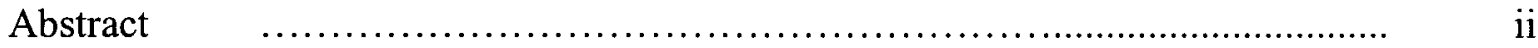

Table of contents $\quad$........................................................................ iii

List of tables $\quad$.........................................................

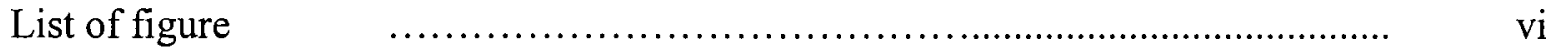

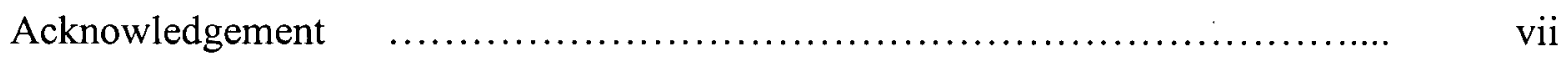

Statement about authorship $\quad$........................................................................... viii

CHAPTER I $\quad$ General introduction..................................... 1
\end{abstract}

CHPATER II Influence of permeating ions on Kv1.5 channel block by nifedipine

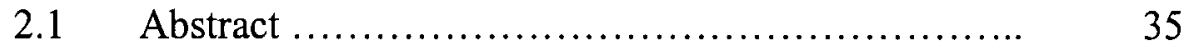

2.2 Introduction ................................... 36

$2.3 \quad$ Materials and methods ............................... 38

$2.4 \quad$ Results ........................................ 43

2.5 Discussion .................................... $\quad 71$

CHAPTER III Nifedipine block and C-type inactivation ................. 75

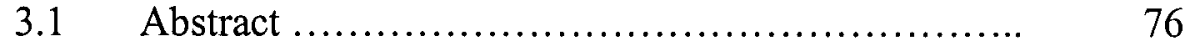

3.2 Introduction .................................... 77

3.3 Materials and methods .............................. $\quad 79$

$3.4 \quad$ Results ....................................... 81

3.5 Discussion ..................................... 92

CHAPTER IV $\quad$ General conclusions ...................................... 95

4.1 Conclusion ................................... 96

4.2 Nifedipine clinical use and possible $\mathrm{K}^{+}$channel block responsible for morbidity at high doses............................................ 96

4.3 Nifedipine binding sites in the potassium channel ... $\quad 99$ 
4.4 Permeating ions modulates nifedipine block of Kv1.5 ... 103

4.5 C-type inactivation is unrelated with nifedipine block .... 104

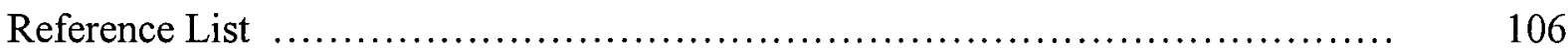




\section{LIST OF TABLES}

Table 1.1: Arrhythmic mechanism: vulnerable parameters and ionic currents involved ............................................................................ 7

Table 1.2: Vaughan Williams' classification of antiarrhythmic agents ............ 9

Table 1.3: The comparison of pore regions of different kind of channels ....... 19

Table 2.1: The time constants of Kv1.5 current decay in the absence and presence of nifedipine

Table 2.2: The time constants of Kv4.2 current decay in the absence or presence of nifedipine 


\section{LIST OF FIGURES}

Figure 1.1 Ionic and molecular basis of the cardiac action potential $\quad \ldots \ldots \ldots \ldots \quad 4$

Figure $1.2 \mathrm{~K}^{+}$channel structure, N-type and C-type inactivation mechanism .... 13

Figure 1.3 Proposed transmembrane topology of the delayed rectifier human

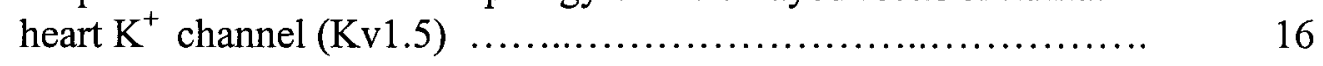

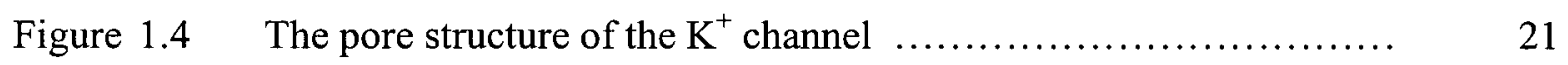

Figure 1.5 Chemical structures of nifedipine, verapamil and diltiazem, the three

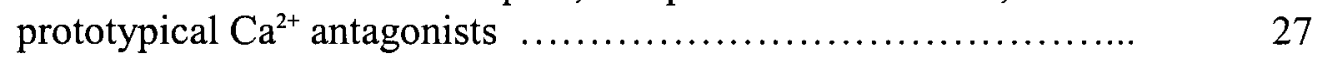

Figure 1.6 Dihydropyridine binding sites in sensitive $\mathrm{Ca}^{2+}$ channels .......... 29

Figure 2.1 Block of $\mathrm{Kv} 1.5 \mathrm{~K}^{+}, \mathrm{Rb}^{+}$, and $\mathrm{Cs}^{+}$currents in HEK cells by nifedipine ... 44

Figure 2.2 Steady-state $\mathrm{I}-\mathrm{V}$ relations for $\mathrm{K}^{+}, \mathrm{Rb}^{+}$, and $\mathrm{Cs}^{+}$current block by

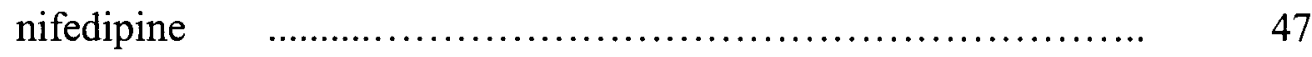

Figure 2.3 Concentration-dependence of nifedipine block of $\mathrm{Kv1} 1.5 \mathrm{~K}^{+}, \mathrm{Rb}^{+}$, and $\mathrm{Cs}^{+}$currents ................................................. 49

Figure 2.4 Decay time constant of $\mathrm{Kv1.5} \mathrm{K}^{+}, \mathrm{Rb}^{+}$, and $\mathrm{Cs}^{+}$currents in the presence of nifedipine .................................................... 53

Figure 2.5 Nifedipine block is modulated by the ion species occupying the pore ... 56

Figure 2.6 Quantification of permeating ion modulation of nifedipine block ....... 58

Figure 2.7 Ion modulation of nifedipine block of gating current in Kv1.5-W472F .. 61

Figure 2.8 An external pore R487V mutant reduces nifedipine block ........... 64

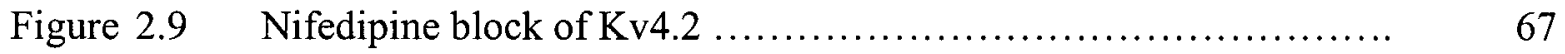

Figure 3.1 Nifedipine block and C-type inactivation of the Kv1.5 channel ....... 82

Figure 3.2 Summary of external $\mathrm{K}^{+}$-dependence of nifedipine block of Kv1.5 ... 85

Figure 3.3 The effect of nifedipine on recovery from C-type inactivation ........ 88

Figure 4.1 The proposed structure of the S5, P region and S6 segments of the Kv1.5 channel .................................................. 101 


\section{ACKNOWLEDGEMENTS}

I would like to express my deepest appreciation to my supervisor, Dr. David Fedida, for his supervision during the production of this thesis, especially for his patience in checking my thesis draft which originally contained a number of English errors, and for his advice and encouragement towards my education over the last three years.

My appreciation also extends to Dr. Zhuren Wang, who kindly showed me how to do whole-cell recordings and analysis the experimental data; Xue Zhang and Derek Schulze, who generously contributed some data which made this thesis more complete; Dr. Dave Steele and Neil Maruoka, who were kind enough to provide pcDNAs for transient expression; and to Christian Hesketh, Harley Kurata and Dr. Shetuan Zhang, who were very kind to discuss and answer my questions. 
CHAPTER I

GENERAL INTRODUCTION 
Ion channels are integral protein pores that mediate the transmembrane passage of ions down their electrochemical potential gradients. Ion channels are probably found in the membranes of all cells, and their known functions include establishing a resting membrane potential, shaping electrical signals, gating hormone response, and sensing mechanical change (Hille, 1992; Vega-Saenz de Miera et al., 1994). These channels are selectively permeable to different physiological monovalent and divalent ions, such as $\mathrm{H}^{+}, \mathrm{K}^{+}, \mathrm{Na}^{+}, \mathrm{Cl}^{-}$and $\mathrm{Ca}^{2+}$. Among these channels, $\mathrm{K}^{+}$channel proteins that preferentially pass $\mathrm{K}^{+}$probably represent the most diverse class in terms of function and structure. They are found in all organ systems, including heart, smooth muscle, brain, pancreas, kidney, lung and skeletal muscle. The key characteristic of ion channels is their gating, which is a conformational switching of the protein structure between "open" and "closed" states. These gates are controlled by different factors, such as membrane potential, ligands, and mechanical force (Rees et al., 2000). As a result of this channel diversity, $\mathrm{K}^{+}$channels play key roles in a wide range of cellular functions including excitability, secretion, ion transport and osmotic regulation (Hille, 1992; Vega-Saenz de Miera et al., 1994).

Because of the diversity of channel types and the presence of multiple overlapping $\mathrm{K}^{+}$ currents in native cells, investigation of the individual $\mathrm{K}^{+}$channel is difficult. Molecular cloning and cDNA expression technologies have made it possible to identify, characterize and then alter the primary structure of $\mathrm{K}^{+}$channels. In this study, ion modulation of nifedipine block of voltage-gated $\mathrm{K}^{+}$channels, Kv1.5 (Fedida et al., 1993) cloned from human heart and Kv4.2 (Baldwin et al., 1991) cloned from rat brain, but homologous to the heart isoform, has been analyzed in detail. 


\subsection{Diversity of cardiac currents and the mechanism of antiarrhythmic drugs}

\section{1a. Cardiac currents in native cardiac tissues}

The action potential waveform of heart is the net result of the finely tuned coordinated action of multiple ionic channels that activate and inactivate on different time scales (Fig. 1.1); $\mathrm{K}^{+}$currents are the most important and are involved in nearly all phases (Snyders, 1999).

The action potential of a heart cell is stimulated (phase 0 ) when the resting potential of the cell membrane reaches the threshold of $\mathrm{Na}^{+}$channels; the inward $\mathrm{Na}^{+}$current is much faster and inactivated quickly. It is followed by a partial early repolarization caused by transient outward $\mathrm{K}^{+}$currents $\left(\mathrm{I}_{\mathrm{TO}}\right)$ (phase 1 ), which are rapidly activated and inactivated at depolarizing voltages. Therefore, the extent of this early repolarization (notch) indirectly controls the action potential duration (APD). At same time, the inward L-type $\mathrm{Ca}^{2+}$ channels and outward $\mathrm{K}^{+}$ channels are activated, the delicate balance of inward (depolarizing) and outward (repolarizing) currents is responsible for the plateau phase of action potential (phase 2). The main influx force is a $\mathrm{Ca}^{2+}$ current, which slowly declines as $\mathrm{L}$-type $\mathrm{Ca}^{2+}$ channels inactivate, but some noninactivating $\mathrm{Na}^{+}$channels also play a role during the plateau phase. The $\mathrm{K}^{+}$efflux is due to activation of several different delayed rectifier channels $\left(\mathrm{I}_{\mathrm{K}}\right)$. Normally, there are three types of $\mathrm{I}_{\mathrm{K}}$ : $\mathrm{I}_{\mathrm{Kur}}$ (ultrarapid $\mathrm{I}_{\mathrm{K}}$ ), $\mathrm{I}_{\mathrm{Kr}}$ (rapid $\mathrm{I}_{\mathrm{K}}$ ), and $\mathrm{I}_{\mathrm{Ks}}$ (slow $\mathrm{I}_{\mathrm{K}}$ ) which are separated by the activation/inactivation properties and specific drug sensitivity. Inwardly rectifying $\mathrm{K}^{+}$channels $\left(I_{K 1}\right)$, which carry (almost) no current during the plateau phase, are mainly responsible for maintaining the resting membrane potential and mediating final repolarization (phase 3) (Snyders, 1999). $\quad \mathrm{I}_{\mathrm{f}}$ (funny current), the pacemaker current, is a voltage-activated current, in contrast to most channels, it is activated upon hyperpolarization and can conduct both $\mathrm{K}^{+}$and $\mathrm{Na}^{+}$ions. $I_{f}$ is responsible for the automaticity of pacemaker cells, which cause gradual 
Figure 1.1. Ionic and molecular basis of the cardiac action potential. This is a schematic indication of currents and the responding clones. Downward direction represents the depolarizing inward current and upward direction indicates the repolarizing outward currents. Each column depicts the name, the shape, and the role of a current, with the suggested clone responsible for this kind of current indicated (Snyders, 1999). 


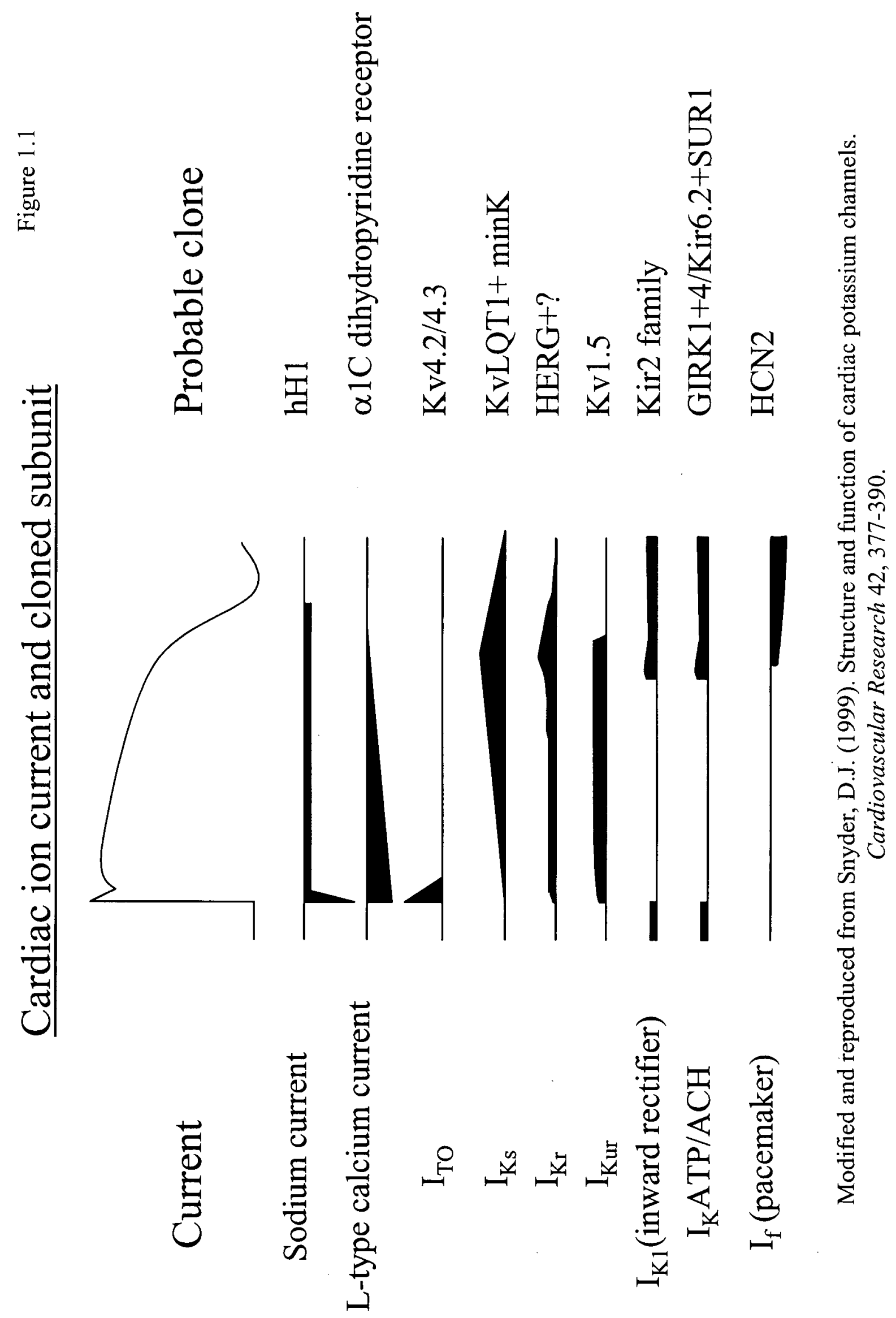


depolarization (phase 4) during the period between two action potentials (Snyders, 1999) (Carmeliet \& Mubagwa, 1998).

\section{1b. Mechanism of cardiac arrhythmias and the classification of antiarrhythmic}

\section{drugs}

Cardiac muscle possesses an intrinsic rhythmicity that allows the heartbeat to originate in the heart without extrinsic stimulation. Specialized strands of cardiac muscle tissue, the conduction system, coordinate cardiac events surrounding the filling and emptying of the chambers of the heart from atria to ventricles. The excitation in the heart is initiated by de novo spontaneous depolarization in the pacemaker cells of the sinus node, spreads to the atrium, conducts over the atrioventricular (AV) node and His-Purkinje system, and finally leads to the almost synchronous depolarization of the ventricle (Carmeliet \& Mubagwa, 1998; Braunwald, 1997). Cardiac arrhythmias may arise from disturbances of impulse initiation, conduction, or both (Table 1.1, shown below) (Carmeliet \& Mubagwa, 1998; Grant, 1992). The abnormal impulse initiation has two sources: automaticity and triggered activity. Sinus bradycardia and tachycardia is due to the sinus diseases or drugs that affect sympathetic or parasympathetic innervations to the SA node, but abnormal automatic arrhythmias arise from the ectopic pacemakers - cells located outside the SA node that assume a pacemaker function. These arrhythmias happen when the sinus node fails to initiate the cardiac cycle or the subsidiary pacemaker's automaticity is enhanced (Grant, 1992; Braunwald, 1997). Arrhythmias of the triggered rhythms, one kind of abnormal impulse initiation, are dependent on preceding membrane depolarization. Early afterdepolarizations (EAD) is a kind of arrhythmia resulting from a marked delay or complete failure of normal repolarization caused by slow heart rates and drugs that block the outward repolarizing $\mathrm{K}^{+}$currents. Torsades de pointes, the distinct polymorphic form of ventricular tachycardia, is believed to result from triggered activity (Grant, 1992). A nonspecific inward current, which is activated by an abnormal high intracellular $\mathrm{Ca}^{2+}$ 
Table 1.1. Arrhythmic mechanisms: vulnerable parameters and ionic currents involved

\begin{tabular}{|c|c|c|}
\hline Mechanisms of arrhythmia & Vulnerable parameter & Possible target current \\
\hline \multicolumn{3}{|l|}{ Abnormal impulse initiation } \\
\hline \multicolumn{3}{|l|}{ Automaticity } \\
\hline enhanced automaticity in SA node & diastolic depolarization & $i_{K I}, i_{f}, i_{K(A T P)}$ \\
\hline $\begin{array}{l}\text { abnormal automaticity (AV node, } \\
\text { Purkinje, atrial or ventricular cells ) }\end{array}$ & decrease of maximum & $i_{K l}, i_{f}, i_{c l}$ \\
\hline \multicolumn{3}{|l|}{ Triggered activity } \\
\hline early afterdepolarization (EAD) & Action potential duration & $i_{C a(L)}$ \\
\hline delayed afterdepolarization (DAD) & $\mathrm{Ca}^{2+}$ overload & 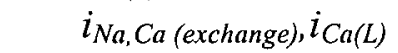 \\
\hline \multicolumn{3}{|l|}{ Reentry } \\
\hline $\begin{array}{l}\text { short excitable gap } \\
\text { long excitable gap }\end{array}$ & $\begin{array}{l}\text { Excitability and conduction } \\
\text { effective refractorv neriod }\end{array}$ & $i_{N a}, i_{C a(L)}$ \\
\hline
\end{tabular}

Modified and reproduced from Carmeliet, E. \& Mubagwa, K. (1998). Antiarrhythmic drugs and cardiac ion channels: mechanisms of action. Progress in Biophysics \& Molecular Biology 70, 172 . 
following complete repolarization of the triggering action potential, can cause secondary depolarizations, the delayed afterdepolarization (DAD) (Grant, 1992). Although some clinical arrhythmias arise from the disturbances of impulse initiation, most significant arrhythmias result from the disturbance of impulse conduction leading to reentry (Grant, 1992; Wit et al., 1974; Wit et al., 1974). Impulses from higher conduction sites are normally conducted along bifurcated pathways to activate the entire ventricular myocytes at the same time. The phenomenon called reentry can occur if slow conduction and unidirectional block exist (Mines, 1913). Consider a single Purkinje fiber with two conduction pathways to ventricular muscle. Normally, an impulse travels both limbs of the conduction pathways at the same speed. When this area is damaged by myocardial injury or a prolonged refractory period, the impulse may fail to conduct in the forward direction over one of two alternative pathways, but is still able to conduct over the other pathway, albeit slowly. This slowly conducting impulse may be able to conduct in the retrograde direction over the antegrade conduction failed area, and reenter the pathway of initial impulse origin. In principle, reentrant arrhythmias may be abolished by improving conduction in the abnormal pathway (reconverting a unidirectional block to normal forward conduction) or slowing conduction further (converting a unidirectional block into a bidirectional block) (Grant, 1992).

According to their predominant effect on the action potential, antiarrhythmic drugs are classified by Vaughan Williams into four classes(Table 1.2, shown below) (Vaughan Williams, 1970; Grant, 1992; Braunwald, 1997), which has proven remarkably durable and widely used over the last thirty years. Although this classification is convenient, it is not clear-cut, because many drugs have more than one class action or have active metabolites with a different class of action. Class I antiarrhythmic drugs, local anesthetics, which block $\mathrm{Na}^{+}$channel channels and slow the rising rate of the action potential, are used to treat the reentry form of arrhythmia by slowing conduction and converting unidirectional block to bi-directional block. Class II agents, 
Table 1.2. Vaughan Williams' classification of antiarrhythmic agents

\begin{tabular}{cll}
\hline Class & \multicolumn{1}{c}{ Effect } & \multicolumn{1}{c}{ Prototype } \\
\hline I & Local anesthetic $\left(\mathrm{Na}^{+}\right.$channel blockade) & Quinidine \\
II & BAdrenergic blockade & Propanolol \\
III & Prolongation of action potential & Amiodarone \\
IV & $\mathrm{Ca}^{2+}$ channel blockade & Verapamil \\
\hline
\end{tabular}

Modified and reproduced from Vaughan Williams, E.M. (1970). Classification of antiarrythmic drugs. In Symposium on cardiac arrythmias, eds. SONDOE E, FLENSTED-JENSEN E \& OLSEN EH, pp. 449-501. The Netherlands: Elsevier. 
which include the $\beta$-adrenergic antagonists, are used to treat tachyarrhythmias arising in the sinus node by abolishing the enhanced sympathetic activity. Class III agents, which block $\mathrm{K}^{+}$ channels and thus prolong the effective refractory period, are effective in treating arrhythmias arising from slow $\mathrm{Na}^{+}-$and $\mathrm{Ca}^{2+}$-dependent conduction. $\mathrm{Ca}^{2+}$ channel blockers, which belong to class IV antiarrhythmic agents, decrease the inward $\mathrm{Ca}^{2+}$ current and the rate of phase 4 spontaneous depolarization. These drugs are effective in treating some reentrant arrhythmias where conduction is primarily sustained by increases in permeability to $\mathrm{Ca}^{2+}$ ions (Grant, 1992; Braunwald, 1997).

\subsection{Cloned voltage-gated $\mathrm{K}^{+}$channels from myocytes and corresponding currents}

Cardiac $\mathrm{K}^{+}$-selective currents carry outward currents in the physiological range of potentials. Therefore, they act either to set the resting potential near the $\mathrm{K}^{+}$equilibrium potential or to repolarize the action potential. Five well-recognized $\mathrm{K}^{+}$currents have been described in cardiomyocytes (Fig. 1.1): $\mathrm{I}_{\mathrm{TO}}, \mathrm{I}_{\mathrm{Kur}}, \mathrm{I}_{\mathrm{Kr}}, \mathrm{I}_{\mathrm{Ks}}$ and $\mathrm{I}_{\mathrm{K} 1}$, although there are other $\mathrm{I}_{\mathrm{K}}$-like currents that have overlapping properties and are species-dependent. Voltage-gated $\mathrm{K}^{+}$channels are denoted by the prefix $\mathrm{Kv}$, and the structural class by the following number. Mammalian voltage-gated $\mathrm{K}^{+}$ channel cDNAs fall into at least nine subclasses, Kv1-Kv9 (Jan \& Jan, 1992; Hugnot et al., 1996). Genes from the first four subfamilies encode the pore-forming or $\alpha$-subunits of cardiac $\mathrm{K}^{+}$channels (Pongs, 1992; Bennett et al., 1993; Kass \& Freeman, 1993; Roberds et al., 1993; Barry \& Nerbonne, 1996). The additional subfamilies do not form functional $\mathrm{K}^{+}$channels alone but alter the properties of Kv2.x currents (Salinas et al., 1997). Eight different voltage-gated $\mathrm{K}^{+}$channel genes have been cloned from cardiac tissue: Kv1.1, Kv1.2, Kv1.4 (Tamkun et al., 1991), Kv1.5 (Tamkun et al., 1991; Philipson et al., 1991; Fedida et al., 1993), Kv4.2 (Roberds \& Tamkun, 1991; Barry et al., 1995) and Kv4.3 (Dixon et al., 1996). Kv2.1, originally cloned from rat brain was also shown by Northern blotting to be expressed at high levels in rat heart (Drewe et al., 1992), but at low levels 
in canine heart (Zou et al., 1997). Kv3 channels are not expressed or only at very low levels. These results have been confirmed using RNAse protection analysis (Barry \& Nerbonne, 1996; Xu et al., 1996), except that Kv1.1 is not transcribed at significant levels (Dixon \& McKinnon, 1994), and Kv1.4 protein is not present (Barry et al., 1995) in rat atrium or ventricle. Diversity of $\mathrm{K}^{+}$channels is increased by co-assembly as heterotetramers (Isacoff et al., 1990; Po et al., 1992; Sheng et al., 1993; Wang et al., 1993).

Human isoforms of Kv1.5 (Kv1.5) have been cloned (Tamkun et al., 1991; Philipson et al., 1991; Fedida et al., 1993), and correlated with a rapidly activating and slowly inactivating $\mathrm{K}^{+}$ current, $\mathrm{I}_{\mathrm{Kur}}$, in adult human heart (Wang et al., 1993a; Fedida et al., 1993; Wang et al., 1993b). Three of the voltage-gated $\mathrm{K}^{+}$channel $\alpha$-subunits cloned from heart have been proposed to underlie the transient outward current, almost ubiquitous in cardiac tissues (Boyett, 1981; Fedida \& Giles, 1991; Tseng \& Hoffman, 1989; Shibata et al., 1989). These are Kv1.4 (Roberds \& Tamkun, 1991), Kv4.2 (Roberds \& Tamkun, 1991; Baldwin et al., 1991) and Kv4.3 (Dixon et al., 1996). Dixon \& McKinnon (Dixon \& McKinnon, 1994) suggested Kv4.2 in rat and Kv4.3 (Dixon et al., 1996) as candidates for $\mathrm{I}_{\mathrm{TO}}$ in dog and man. This has been confirmed by antisense and dominant negative subunit expression experiments (Fiset et al., 1997; Johns et al., 1997). In other species, the properties of $\mathrm{I}_{\mathrm{TO}}$ can be different, so that the slow recovery from inactivation of $\mathrm{I}_{\mathrm{TO}}$ in rabbit is more in keeping with the properties of Kv1.4. In ferret, regional differences in Kv1.4 and Kv4.2/4.3 may underlie $\mathrm{I}_{\mathrm{TO}}$ in epi- and endocardial myocytes (Dixon \& McKinnon, 1994). HERG (the huma eagrelated gene), another family of voltage-gated $\mathrm{K}^{+}$channel $\alpha$-subunit genes, has been shown to produce currents that closely resemble $\mathrm{I}_{\mathrm{Kr}}$ (Sanguinetti et al., 1995; Trudeau et al., 1995). $\mathrm{I}_{\mathrm{Ks}}$ is now thought to arise from the co-assembly of KvLQT1 (another family of Voltage-gated $\mathrm{K}^{+}$channel $\alpha$ subunit genes) and minK (Barhanin et al., 1996; Sanguinetti et al., 1996).

\subsection{Structure of Shaker-like $\mathrm{K}^{+}$channels}


The first voltage-gated $\mathrm{K}^{+}$channels cloned were skeletal muscle ion channels from the hyperexcitable phenotype of Drosophila melanogaster known as Shaker (Tempel et al., 1987; Pongs et al., 1988; Kamb et al., 1988; Bennett et al., 1993). Four subfamilies of alternatively spliced variants have been cloned at the present time, which were defined as Shaker, Shab, Shaw and Shal according to their different gene loci and distinct amino acid sequences (Butler et al., 1989; Wei et al., 1990). Mammalian homologues for all four Drosophila $\mathrm{K}^{+}$channel gene families have been described (Stuhmer et al., 1989; Pak et al., 1991; Tamkun et al., 1991; Baldwin et al., 1991) and named as Kv1 for Shaker, Kv2 for Shab, Kv3 for Shaw and Kv4 for Shal, according to the present nomenclature (Chandy, 1991).

\section{3a. General structure of Shaker-like $\mathrm{K}^{+}$channels}

Mammalian homologues of Shaker $\mathrm{K}^{+}$channels are composed of four subunits which may be identical (homomultimers) or may involve mixtures with other $\mathrm{Kv}$ subfamily members (heteromultimers) (Isacoff et al., 1990; Jan \& Jan, 1990; Sheng et al., 1993). The cDNA of each subunit (Fig. 1.2A) encodes a protein with a molecular weight of about $70 \mathrm{kD}$. The protein has six transmembrane-spanning $\alpha$-helical segments (S1-S6), with the $\mathrm{N}$ - and $\mathrm{C}$ - termini located on the cytoplasmic side. The fourth transmembrane segment (S4) contains 5 to 7 positively charged amino acids, such as arginine and lysine at every third position. These are involved in the voltage-sensing function of voltage-gated $\mathrm{K}^{+}$channels (Jan \& Jan, 1992), although negative charges in $\mathrm{S} 2$ and $\mathrm{S} 3$ also contribute. The linker ( $\mathrm{P}$ region) between $\mathrm{S} 5$ and $\mathrm{S} 6$, which reaches into the membrane but does not pass through, forms the central part of the permeation pathway. The exposed part of the P-loop and adjacent residues in S5 and S6 form the extracellular mouth of the pore where many toxins can bind (Snyders, 1999). The wider internal mouth of the channel is lined by the intracellular sections of S5 and S6 and acts as an entrance for the

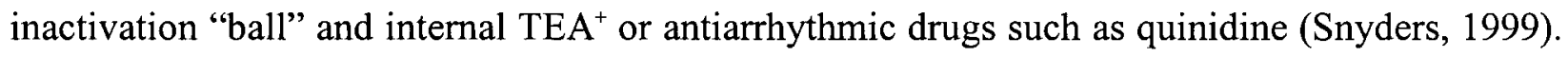
The N-terminus of the subunit blocks the channel pore from inside in a "ball and chain" manner, 
Figure 1.2. $\mathrm{K}^{+}$channel structure, $\mathrm{N}$-type and C-type inactivation mechanism (Rasmusson ét al., 1998). A) The topological relationship between voltage-gated ion channel polypeptide chains. A functional voltage-gated potassium $(\mathrm{Kv})$ channel is formed by four subunits surrounding the central pore. Each subunit consists of six transmembrane helices (S1-S6), a P region between S5 and S6, and the amino- and the carboxyl-terminal regions ( $\mathrm{N}$ and $\mathrm{C}$, respectively) on the cytoplasmic side. The S4 segment contains 4-7 positive charged amino acids, which forms the voltage sensor of the channel. In panel $\mathrm{B}$ and $\mathrm{C}$, channel activation is voltage dependent and involves S4 charge movements, which is related with gating current. B) N-type inactivation generally involves a cytoplasmic gate (ball) on the amino terminus of the channel subunit. Following activation, this ball interacts with a receptor likely residing in the S4-S5 linker, occupies the internal vestibule of the pore, and causes fast inactivation of the channel. C) Channels can also enter a C-type inactivated state from the open state. This is due to the constriction of the external mouth of the channel during a long depolarization process. Recovery from both types of inactivation is voltage dependent, which derived from a putative backward movement of S4 segment as depicted in the picture. 
瓷

$1 / 2$
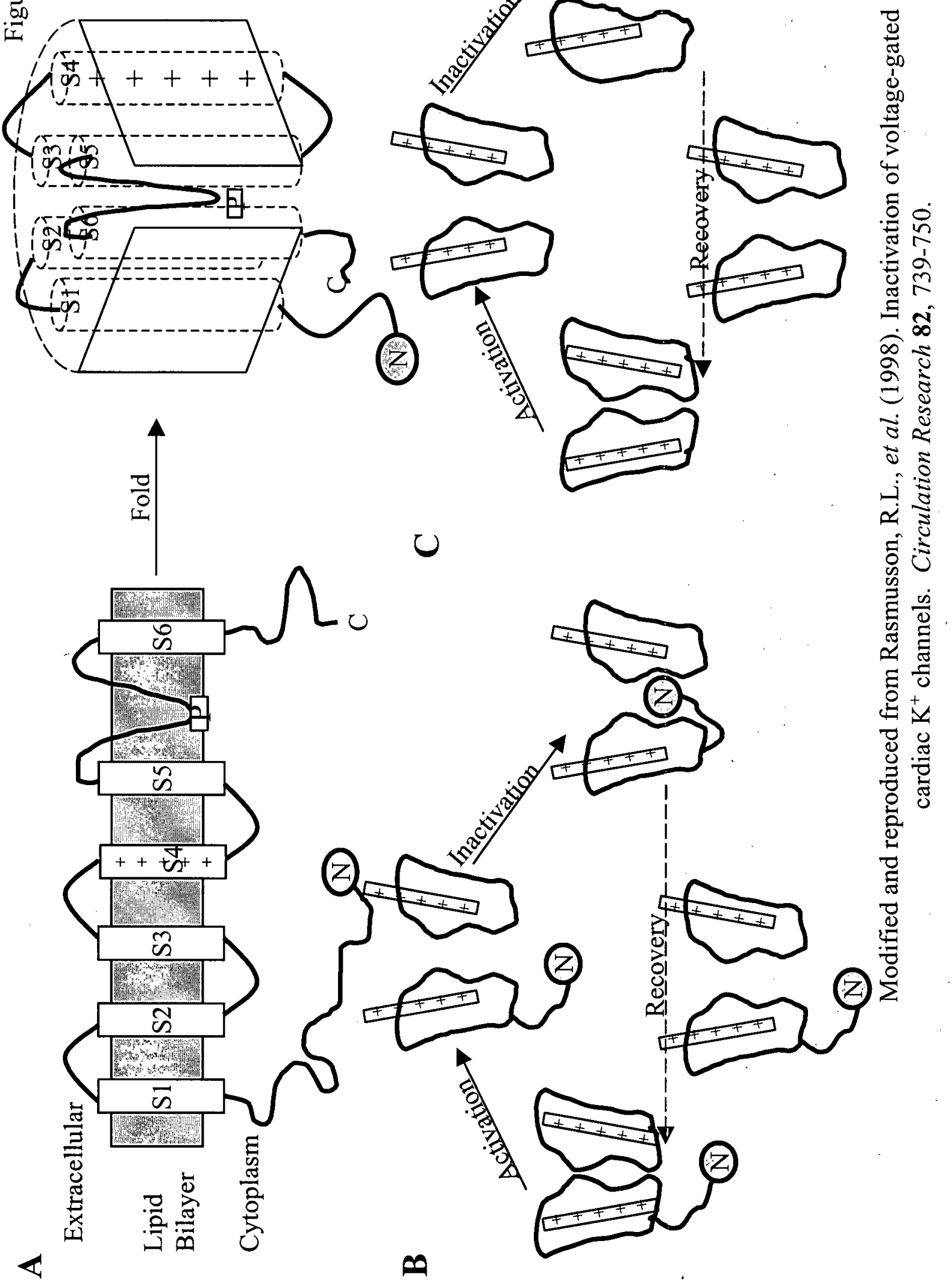
once the channel opens. This rapid inactivation is called $\mathrm{N}$-type inactivation and occurs in some types of $\mathrm{K}^{+}$channels (Zagotta et al., 1990; Hoshi et al., 1990; Miller, 1991; Jan \& Jan, 1992; Pongs, 1992). This is depicted in Fig. 1.2B as the ball that occludes the internal mouth of the pore. The external mouth of the pore constricts after the prolonged depolarization, resulting in slow inactivation (C-type inactivation) (Fig. 1.2C), which exists in almost all $\mathrm{K}^{+}$channels (Hoshi et al., 1991; Lopez-Barneo et al., 1993; Ogielska et al., 1995; Panyi et al., 1995).

\section{3b. Structural properties of the Kv1.5 channel}

The Kv1.5 channel cloned from human atrial myocytes (Fedida et al., 1993) is a human homologue of Shaker $\mathrm{K}^{+}$channels and has the typical structure of Shaker-like $\mathrm{K}^{+}$channels as described above. As shown in Fig. 1.3, Kv1.5 is also composed of four subunits, each contains six transmembrane domains with a pore region ( $\mathrm{P}$ region) and $\mathrm{S} 4$ segment rich in positively charged amino acids. A complete amino acid sequence of Kv1.5 is given in Fig. 1.3, indicating hydrophobic, hydrophilic, basic, or acidic amino acids, respectively. A comparison of amino acid alignment between Kv1.5 and Drosophila Shaker reveals that they share $\sim 50 \%$ similarity in amino acid sequence segments. In the Kv1.5 channel subunit, the pore loop consists of 22 amino acids, of which only 2 amino acids are different between Shaker and Kv1.5, and more strikingly, a 19 amino acid sequence is continuously the same in this pore loop.

Although high homology exists between Kv1.5 and Shaker channels, differences in the amino acid sequence are still clear. The most obvious difference between Kv1.5 and Shaker channels is that $\mathrm{Kv} 1.5$ doesn't possess the $\mathrm{N}$-terminal ball peptide sequence that is responsible for the rapid N-type inactivation observed in Shaker channels (Fedida et al., 1993; Deal et al., 1996). Some amino acids, which play important roles in Shaker channels, are different in Kv1.5 channel, such as T449 and V463 in ShB correspondingly to R487 (in the pore region) and A501 (in the S6 segment) in Kv1.5. Both amino acids, threonine at position 449 and valine at position 463 in $S h \mathrm{~B}$ play important roles in determining the rates of C-type inactivation (Lopez-Barneo et al., 1993; 
Figure 1.3. Proposed topology of the delayed rectifier human heart $\mathrm{K}^{+}$channel (Kv1.5). Every 10th residue is numbered. The empty oval stands for hydrophobic amino acids; the filled for hydrophilic; red for basic; and blue for acidic amino acid. $\mathrm{N}$ and $\mathrm{C}$ stand for the amino and carboxyl termini. 


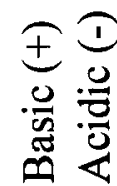

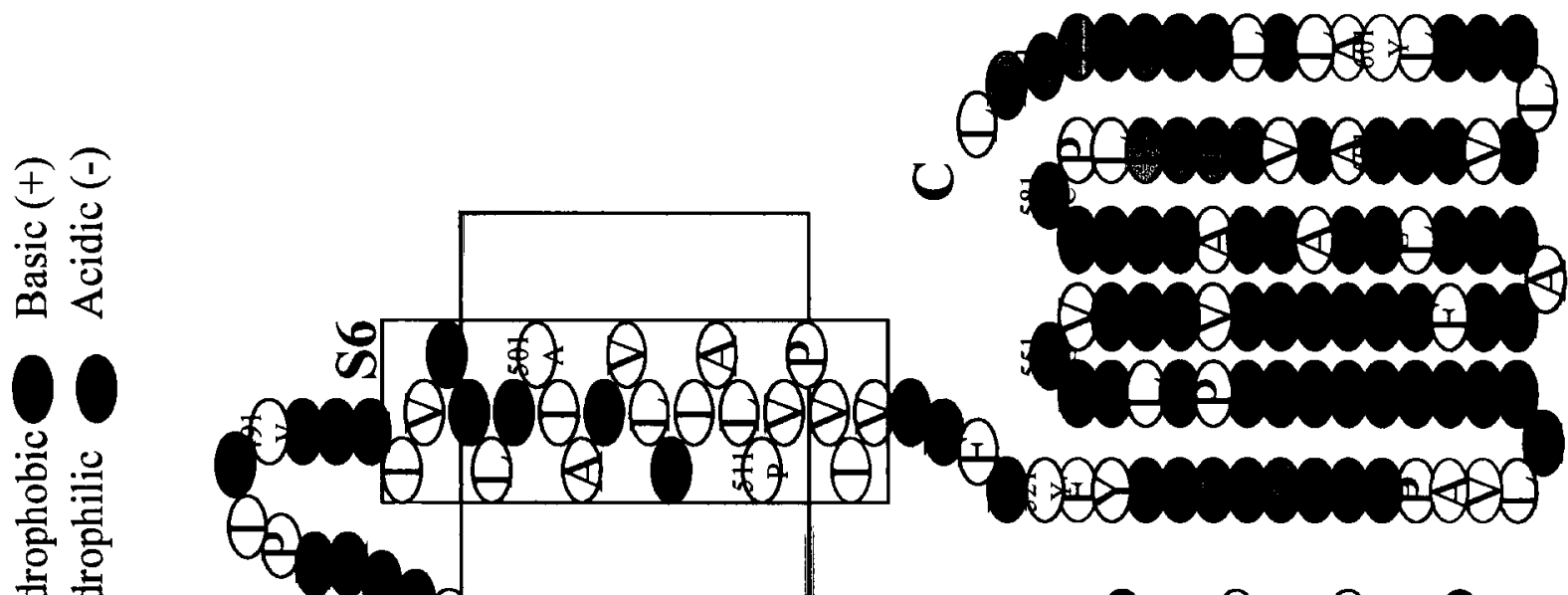

0

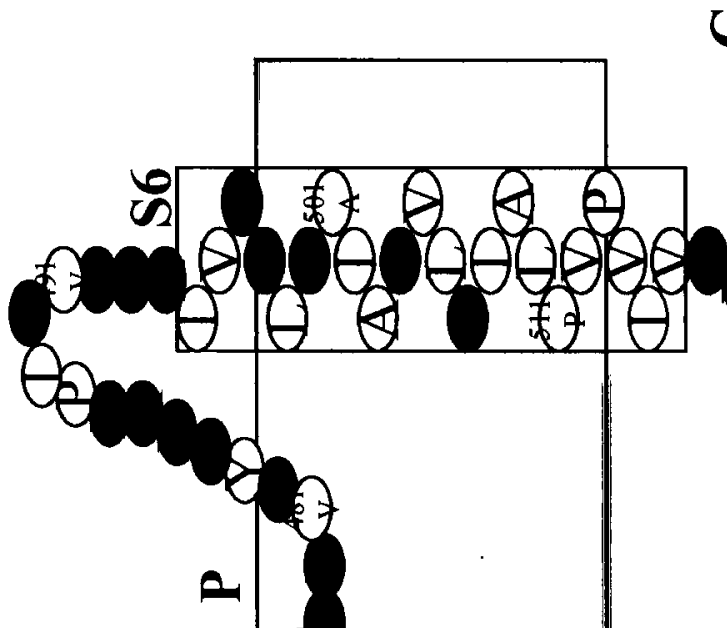

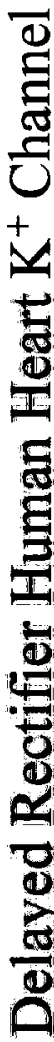

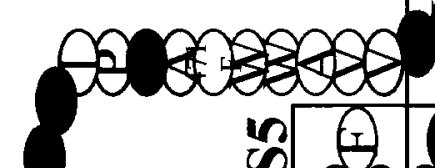

ฮูป

(I)

क $\theta$ A $\theta \theta$

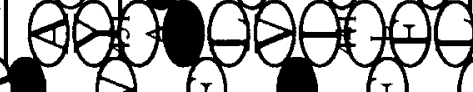

을 올

$\theta y$

(I)

भिकी भि

घद 428

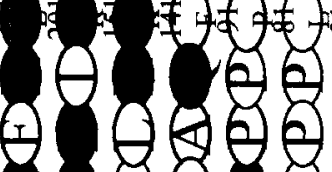

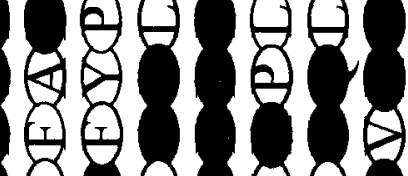

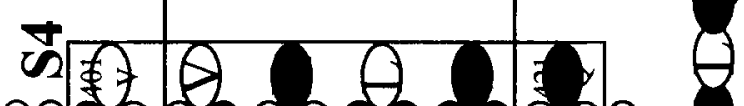
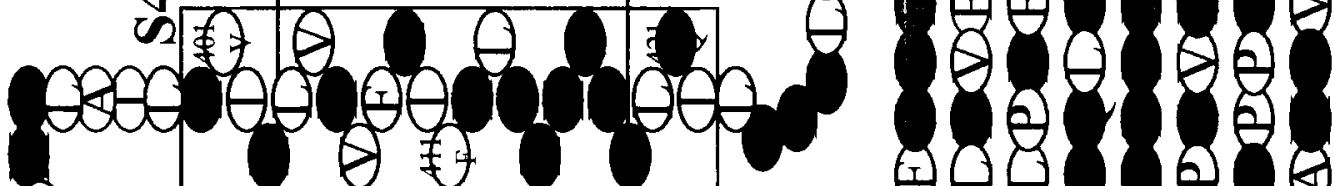

요

$\theta \rightarrow \theta$

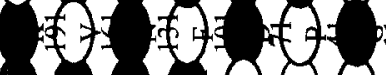

हि

G

요 $\theta \Leftrightarrow$

$\sum_{\frac{\pi}{0}}^{\infty}$

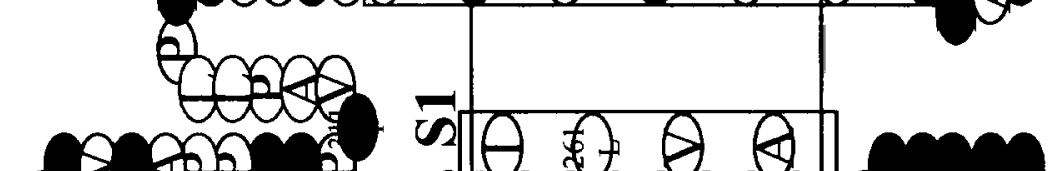

cosens int

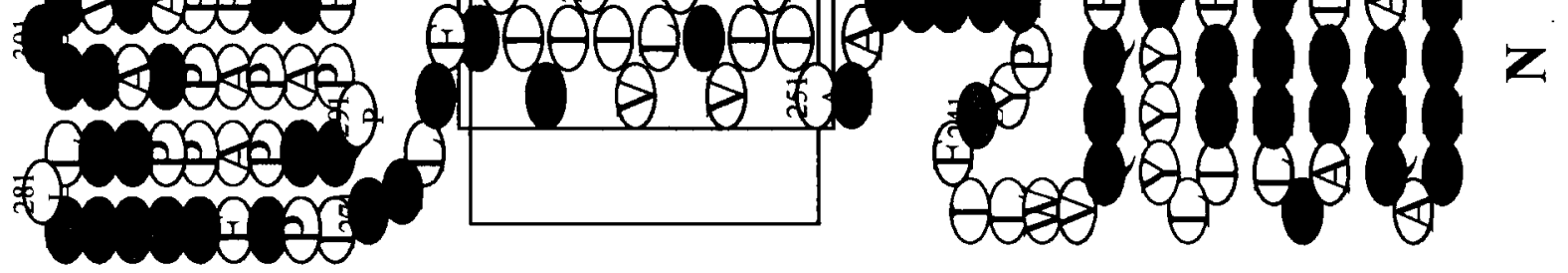


Panyi et al., 1995). These differences in the amino acid composition between Kv1.5 and Shaker channels are the structural basis that determines unique electrophysiological properties of the Kv1.5 channel.

\subsection{Structural Properties of the Ion-Conducting Pore}

Despite the different gating kinetics and pharmacological properties that exist in various $\mathrm{K}^{+}$ channel types, ion conduction is similar in different $\mathrm{K}^{+}$channels (Hille, 1992; Demo \& Yellen, 1992). This is manifested by similar conductance selectivity among permeant ions based on the high similarity existing in the pore region between S5 and S6. The ion conduction pathway consists of a sequence of approximately 20 amino acids (P region) between S5 and S6. The narrow P-region dictates the $\mathrm{K}^{+}$selectivity: an eight amino acid sequence TxTxxGYG, called the $\mathrm{K}^{+}$selectivity signature motif, is shared by all Shaker voltage-activated $\mathrm{K}^{+}$channels and many channels from other subfamilies. These include Kv1.1 (Baumann et al., 1988), Kv2.1 (Frech et al., 1989), Kv3.1 (Yokoyama et al., 1989) and Kv4.1 (Pak et al., 1991), which are the four mammalian homologues corresponding to four independent gene families from Drosophila Shaker, Shab, Shaw and Shal, respectively. A complete comparison (Table 1.3, shown below) between Shaker, Kv1.5 (Fedida et al., 1993), Kv4.2 (Baldwin et al., 1991), and these four channels supports the high degree of conservation of the eight amino acid sequence in the pore region of these channels (Heginbotham $e t$ al., 1994).

It has been proposed that highly conserved amino acids in the pore of $\mathrm{K}^{+}$channels may form a selectivity filter, for example, the GYG sequence in the P region between S5 and S6. In support of this, mutations of these amino acids resulted in a loss of $\mathrm{K}^{+}$selectivity (Heginbotham et al., 1994). The $\mathrm{K}^{+}$channel is thought of as a multi-ion pore that shows single-file conduction, with transfer rates determined by the electrostatic repulsion between ions and attraction to residues in the narrowest region of the pore (Hille, 1992; Pérez-Cornejo \& Begenisich, 1994). Doyle et al. (Doyle 
Table 1.3. The comparison of pore regions of different kind of channels

\begin{tabular}{|c|c|c|c|c|c|c|c|c|}
\hline & \multicolumn{8}{|c|}{ Pore Region } \\
\hline & 1 & 2 & 3 & 4 & 5 & 6 & 7 & 8 \\
\hline Shaker & $\mathrm{T}$ & $\mathrm{M}$ & $\mathrm{T}$ & $\mathrm{T}$ & $\mathrm{V}$ & $\mathrm{G}$ & $\bar{Y}$ & $\bar{G}$ \\
\hline HKv1.5 (Shaker) & $\mathrm{T}$ & M & $\mathrm{T}$ & $\mathrm{T}$ & $\mathrm{V}$ & $\mathrm{G}$ & $Y$ & G \\
\hline Kv1.1 (Shaker) & $\mathrm{T}$ & M & $\mathrm{T}$ & $\mathrm{T}$ & V & $\mathrm{G}$ & $Y$ & G \\
\hline Kv2.1 (Shab) & $\mathrm{T}$ & $M$ & $\mathrm{~T}$ & $\mathrm{~T}$ & $\mathrm{~V}$ & $\mathrm{G}$ & $\mathrm{Y}$ & G \\
\hline Kv3.1 (Shaw) & $\mathrm{T}$ & M & $\mathrm{T}$ & $\mathrm{T}$ & $\mathrm{L}$ & $\mathrm{G}$ & $Y$ & G \\
\hline Kv4.1 (Shal) & $\mathrm{T}$ & M & $\mathrm{T}$ & $\mathrm{T}$ & $\mathrm{L}$ & $\mathrm{G}$ & $\mathrm{Y}$ & G \\
\hline Kv4.2(Shal) & $\mathrm{T}$ & $\mathrm{M}$ & $\mathrm{T}$ & $\mathrm{T}$ & $\mathrm{L}$ & $\mathrm{G}$ & $\mathrm{Y}$ & $\mathrm{G}$ \\
\hline
\end{tabular}


et al., 1998) proposed the three-dimensional structure of the $\mathrm{K}^{+}$channel pore from Streptomyces lividans with sequence similarity to all known $\mathrm{K}^{+}$channels (Fig. 1.4). They suggested that the overall length of the pore is $45 \AA$ with various diameters along its distance. There are three different shapes of the structure along the pore from intracellular side (bottom) to the extracellular side (top) of the channel: a $18 \AA$ long tunnel (the internal pore), a wide cavity ( 10 $\AA$ across) near the middle of the membrane, and a $12 \AA$ long, narrow selectivity filter. The selectivity filter is lined by carbonyl oxygens from the $\mathrm{K}^{+}$channel signature sequence, whereas the remainder of the pore is lined with hydrophobic amino acids. When a $\mathrm{K}^{+}$ion passes from the internal pore to the cavity, it still remains mostly hydrated. The electrostatic stabilization of the $\mathrm{K}^{+}$ion is supported by filled water in the cavity and helix dipoles positioned to the center of the cavity. The selectivity filter, which is held open by structural constraints to coordinate dehydrated $\mathrm{K}^{+}$but not smaller $\mathrm{Na}^{+}$ions, contains two $\mathrm{K}^{+}$ions about $7.5 \AA$ apart. By exploiting electrostatic repulsive forces between these two ions, the $\mathrm{K}^{+}$channel overcomes attractive forces between $\mathrm{K}^{+}$ions and the carbonyl oxygen from the selectivity filter, and promotes ion conduction (Doyle et al., 1998; Rees et al., 2000).

\subsection{Gating properties of voltage-dependent $\mathrm{K}^{+}$channels}

The classical Hodgkin-Huxley (Hodgkin \& Huxley, 1952) model for the delayed rectifier $\mathrm{K}^{+}$channel in squid axon described two states of $\mathrm{K}^{+}$channels, which reflected ion conduction of the pore during an applied transmembrane voltage (Hodgkin \& Huxley, 1952). One is the permissive state that can pass $\mathrm{K}^{+}$ions after the activation of the $\mathrm{K}^{+}$channel upon a depolarization; the other is the non-permissive state corresponding to the nonconducting/closed state of a channel, before the activation of a channel. When $\mathrm{K}^{+}$currents were found in other tissues that decayed during maintained depolarization, it was proposed that channels could occupy three states like the squid axon $\mathrm{Na}^{+}$current. The three states can be expressed as a simple sequential scheme:

$$
\text { Closed } \leftrightarrow \text { Open } \leftrightarrow \text { Inactivated } \quad \text { or } \quad \mathrm{C} \leftrightarrow \mathrm{O} \leftrightarrow \mathrm{I}
$$


Figure 1.4. The pore structure of the $\mathrm{K}^{+}$channel. A) Four subunits surround and form the pore (Top view). When the channel activates, $\mathrm{K}^{+}$ion can pass through the pore. B) The proposed three-dimensional structure of the $\mathrm{K}^{+}$channel pore from Streptomyces lividans (Doyle et al., 1998). The total length of the pore is about $45 \AA$, with an $18 \AA$ tunnel, $10 \AA$ across cavity and 12 $\AA$ selectivity filter. There are three $\mathrm{K}^{+}$ions, one is mostly hydrated in the cavity and two dehydrated $\mathrm{K}^{+}$ions about $7.5 \AA$ apart in the narrow selectivity filter. Rectangle in the picture represents helix dipoles, which are positioned to the center of the bilayer and stabilize the $\mathrm{K}^{+}$in the cavity. GYG from the $\mathrm{K}^{+}$channel signature sequence forms part of the selectivity filter, and coordinate dehydrated $\mathrm{K}^{+}$but not smaller $\mathrm{Na}^{+}$ions. 


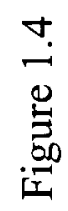
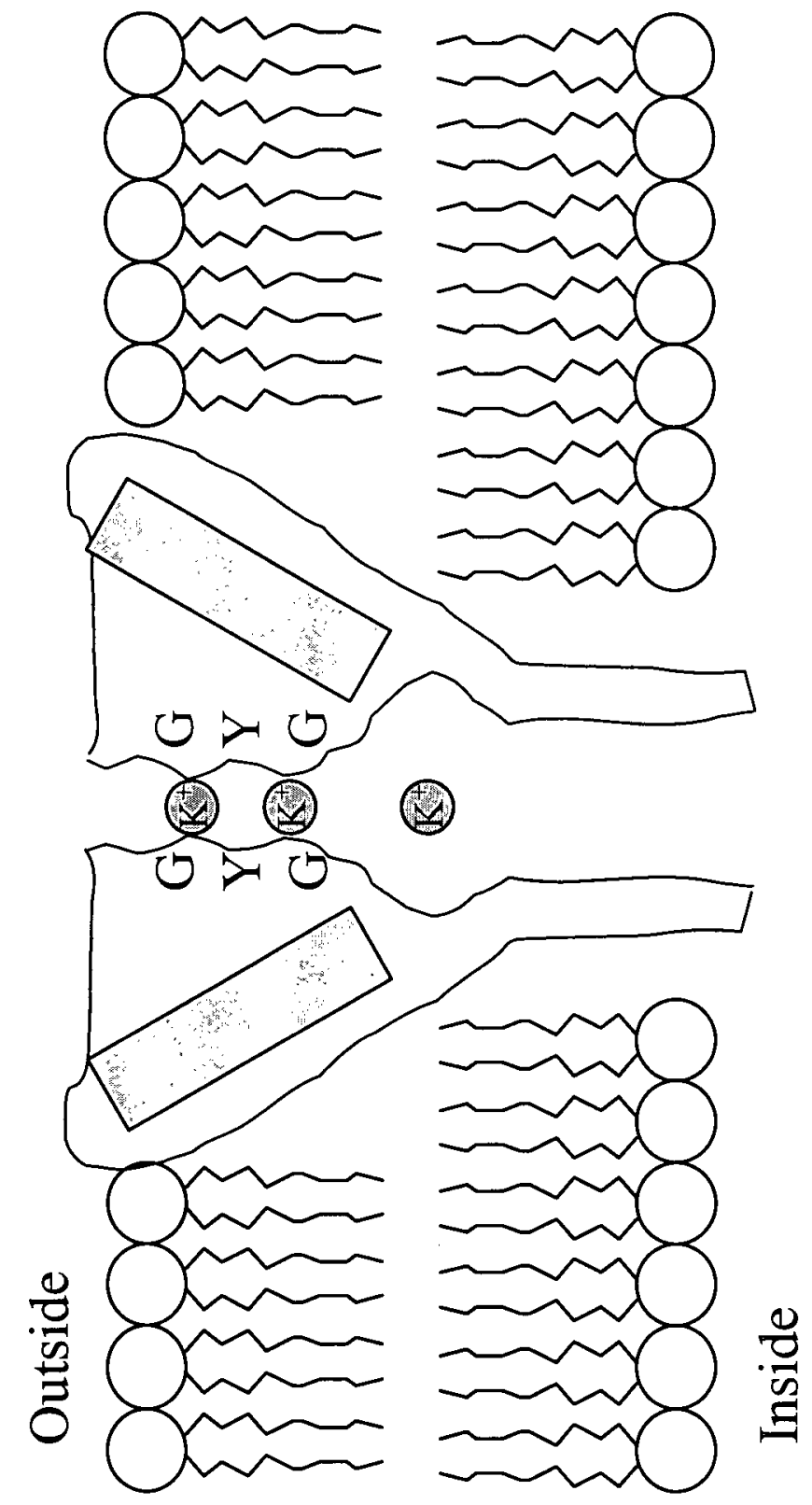

คิ

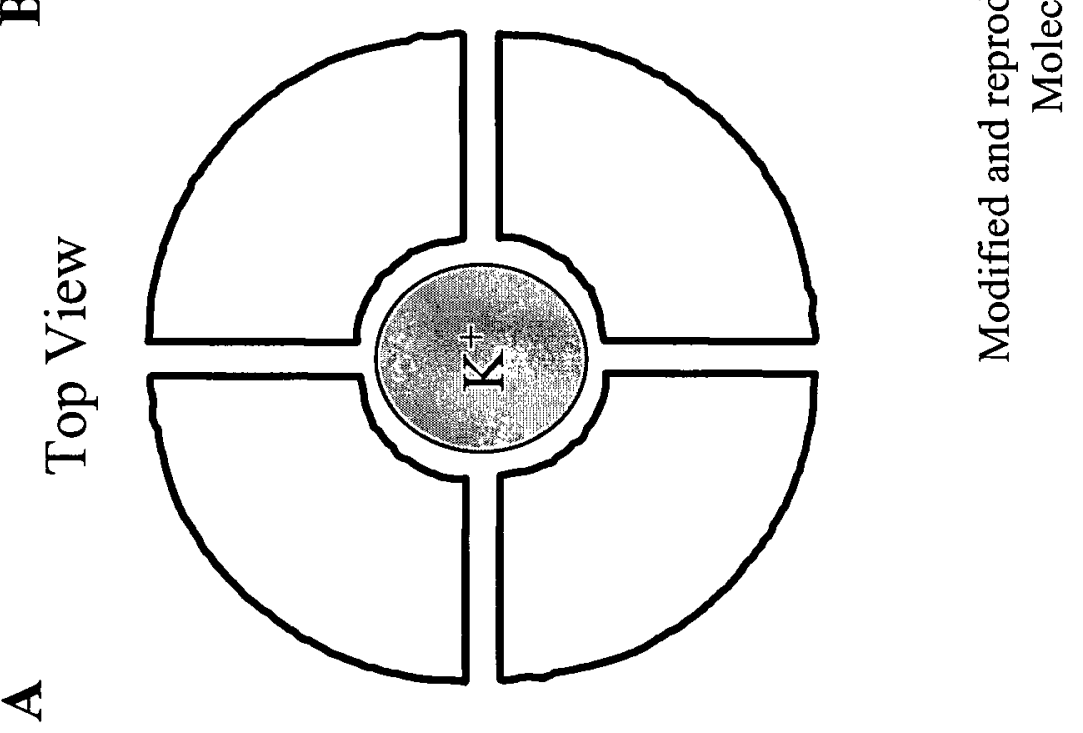


This simplistic model indicates that there is an open state through which $\mathrm{K}^{+}$ions flow and two nonconducting, but distinct states, $\mathrm{C}$ and $\mathrm{I}$, in which states ions cannot permeate the channel. Membrane potential can strongly influence transitions among three states.

\section{5a. Activation gating mechanism}

Voltage-gated $\mathrm{K}^{+}$channels are exquisitely sensitive to small changes in membrane potential. Hodgkin and Huxley (Hodgkin \& Huxley, 1952) realized that $\mathrm{K}^{+}$channel opening must result from movement of charges within the membrane. Since the $\mathrm{K}^{+}$channel has been cloned, it is widely believed that this voltage-sensing function is primarily performed by the S4 segment, which functions as a voltage sensor. As described above, the amino acid sequence in the S4 segment is punctuated by basic amino acids (positively charged), such as arginine or lysine at every third or fourth residue. Mutant channels with neutral residues replacing some of the positive charges in S4 give different voltage-dependent activation gating and kinetics (Papazian et al., 1991; Perozo et al., 1992; Kukuljan et al., 1995). In response to depolarizing voltage, these positively charged amino acids are drawn toward the external side (Mannuzzu et al., 1996). Aldrich and colleagues concluded that the S4 segments of the individual domains moved independently at first, followed by a "concerted" step involving all four domains (Zagotta et al., 1994). Gating current measurements from $\mathrm{K}^{+}$channels also strongly support the concept of a late, slow voltage-dependent step during activation (Stefani et al., 1994). Movement of the S4 segment provides the impetus for conformational change leading to channel opening. A reasonable candidate of the physical gate would be the internal S4-S5 linker (Armstrong \& Hille, 1998), although at present we do not have a detailed understanding of the conformational changes resulting in the gate opening.

\section{5b. Inactivation gating mechanism}

Although the activation process is strongly voltage-dependent, the inactivation process of voltage-dependent $\mathrm{K}^{+}$channels shows little voltage-dependence (DeCoursey, 1990). Once the channel has opened, the time course required for the channel to reach steady-state inactivation 
varies from several milliseconds to tens of seconds, depending on the molecular structure of the

different channel types. In Shaker $\mathrm{K}^{+}$channels, according to the relative location of the primary structure involved in the inactivation, two types of inactivation are recognized: rapid N-type inactivation and slow C-type inactivation (Hoshi et al., 1991).

\section{5b.i. Basic properties of $N$-type inactivation}

$\mathrm{N}$-type inactivation (Fig. 1.2B), which occurs on the order of milliseconds to tens of milliseconds, was suggested to be mediated in a "ball and chain" manner (Rasmusson et al., 1998). The evidence came from the mutagenesis studies of the $\mathrm{N}$ terminus of Shaker $\mathrm{K}^{+}$(Hoshi et al., 1990). The deletion of first 20 amino acids in the N-terminus of the channel protein completely remove fast inactivation, while deletions in the next 63 amino acids (number 21-83) have the remarkable effect of speeding inactivation. Once the channel has opened, any one of the four inactivation particles (the first 20 amino acids) can inactivate a channel. It was suggested that a simple chance decides which one gets there first (Gomez-Lagunas \& Armstrong, 1995). The inactivation ball binds to a receptor in the mouth of the open $\mathrm{K}^{+}$channel, which is located in the 13 residue chain linking S4 and S5 (Isacoff et al., 1991). A point mutation from threonine to serine in this area almost completely removed inactivation, but did not affect the function of the activation gate. Kv4.2 does possess this kind of ball and displays rapid inactivation, and the fastest component can be slowed by the deletion of 3 basic residues in the amino-terminal region (Baldwin et al., 1991). Kv1.5 does not possess such an inactivating ball (Fedida et al., 1993).

\section{5b.ii. Basic properties of C-type inactivation}

After the deletion of the N-terminal in Shaker $\mathrm{K}^{+}$channels, a slow inactivation (C-type) still exists (Fig. 1.2C) (Hoshi et al., 1990). The kinetics of C-type inactivation vary from tens of milliseconds to more than ten seconds in different $\mathrm{K}^{+}$channels (Hoshi et al., 1991; Lopez-Barneo et $a l ., 1993)$. It was found that the extracellular side of S6 plays a critical role in C-type inactivation, rather than the cytoplasmic portion of the C-terminus (Hoshi et al., 1990). Liu et al. (1996) 
illustrated that C-type inactivation promotes a local rearrangement and constriction of the channel at the outer mouth of the pore (Fig. 1.3C). A number of amino acid residues in the $\mathrm{S} 6$ or outer pore mouth have been shown to be important in the control of C-type inactivation: the first is A463 in the Shaker B (ShB) channel (Hoshi et al., 1991), or A413 in Kv1.3 (Panyi et al., 1995); the second is T449 in ShB, nearer the pore region (Lopez-Barneo et al., 1993; Ogielska et al., 1995; Schlief et al., 1996). H402 is significant for inactivation in Kv1.3 (Busch et al., 1991; Pardo et al., 1992). Functional data also indicated that C-type inactivation was slowed by increasing concentrations of the external ion (i.e., $\mathrm{K}^{+}$) (Lopez-Barneo et al., 1993) and by the application of extracellular, but not intracellular, TEA ${ }^{+}$(Choi et al., 1991). These experiments all indicate that during the onset of Ctype inactivation, occupancy of a site in the mouth of the $\mathrm{K}^{+}$channel pore by ions can slow channel closing in a "foot-in-the-door" manner (Marchais \& Marty, 1979; Swenson \& Armstrong, 1981; Lopez-Barneo et al., 1993). This is not a universal phenomenon. Fedida (Fedida et al., 1999) suggested that the slow inactivation of Kv1.5 is different from the "classical" C-type inactivation. Changes in the extracellular cation species or concentration had relatively minor effects on the inactivation rate, and on the recovery from inactivation. Mutation of residues at a putative regulatory site at R487 (correspond to T449 in ShB) in the outer mouth of the pore did not affect slow inactivation or recovery. Intracellular ion modulatory actions were more potent than extracellular actions.

\subsection{Investigation of Drug-Channel Interaction}

Different drugs have been widely used to provide information about the structural properties of various ion channels. For example, $\mathrm{TEA}^{+}$is the drug classically used to probe the drug binding sites and mechanisms of inactivation in $\mathrm{K}^{+}$channels. When applied internally, $\mathrm{TEA}^{+}$blocks the channel like an inactivation particle to simulate N-type inactivation (in a "ball-and-chain" manner). 
When applied externally, $\mathrm{TEA}^{+}$occupies the external mouth of pore to slow the rate of the C-type inactivation (in a "foot-in-the-door" mechanism) (Grissmer \& Cahalan, 1989; Choi et al., 1991).

\section{6a. $\mathrm{Ca}^{2+}$ channel antagonist-dihydropyridine}

$\mathrm{Ca}^{2+}$ channel blockers currently used in cardiovascular therapeutics fall into one of the three major chemical classes: Phenylalkylamines, exemplified by verapamil: dihydropyridines (DHP), such as nifedipine and nicardipine; and the benzothiazepines, such as diltiazem. Radioligand binding studies suggest that each of the three classes bind to a distinct receptor on the $\mathrm{Ca}^{2+}$ channel protein (Fig. 1.5) (Grant, 1992). Dihydropyridines contain a dihydropyridine ring and a phenyl ring. Some dihydropyridine compounds can be agonists (BayK 8644), or both agonists and antagonists of L-type $\mathrm{Ca}^{2+}$-channels (nimodipine) (Tsien et al., 1987). Chimeric studies suggested that within the L-type channel, IIIS5, IIIS6 and IVS6 are critical for DHP interaction (Fig. 1.6.A) (grabner et al., 1996; Striessnig et al., 1998).

Fig. 1.6 shows residues found to participate in DHP binding in the putative IIIS5, IIIS6, and IVS6 $\alpha$-helices. Although there are nine different amino acid residues in IIIS5 between L and nonL type $\mathrm{Ca}^{2+}$ channels, systematic analysis in an Al12-like chimera suggest that only two of the residues, L-channel Thr1039 and Gln1043 (numbering according to anc-II, Genebank accession number M67515), are required for DHP binding (Mitterdorfer et al., 1996). It was further supported by the point mutations in the L- channel $\alpha 1_{C}$ subunit to the corresponding residues in $\alpha 1_{A}$ sequence (Adams \& Tanabe, 1997). Alanine scanning mutagenesis study (Cunningham \& Wells, 1989), which systematically replaced individual residues by alanine, provides the most detailed information about the individual residues involving the DHP binding for the IIIS6 and IVS6 helices. Point residue substitution in the cardiac or skeletal L-channel $\alpha 1$-subunit by the respective non-L residues $\left(\alpha 1_{\mathrm{S}}\right)$ is also effective for selecting the DHP binding residues (Striessnig et al., 1998; Peterson et al., 1996; Schuster et al., 1996; Peterson et al., 1997; Hockerman et al., 1997). It was 
Figure 1.5. Chemical structures of nifedipine, verapamil and diltiazem, the three prototypical $\mathrm{Ca}^{2+}$ antagonists. 
Figure 1.5

Nifedipine

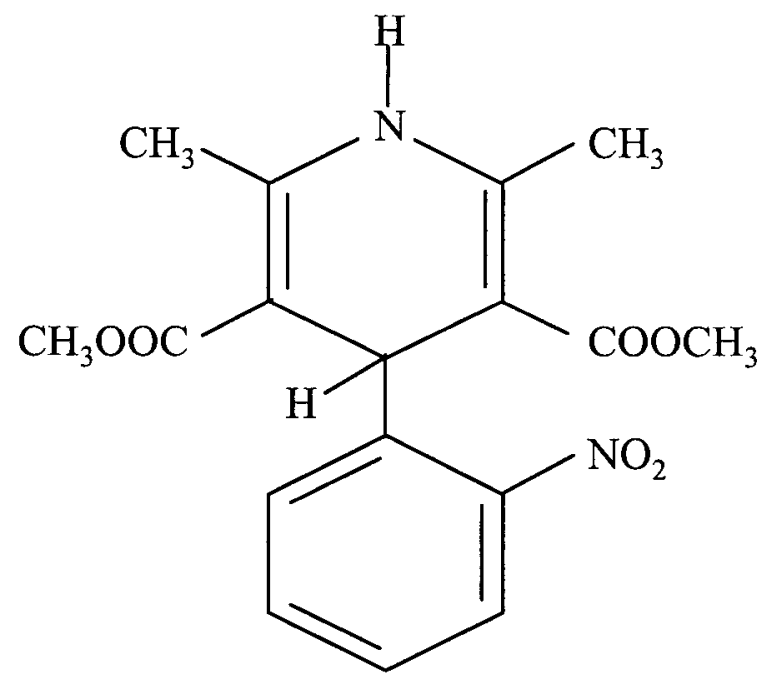

Verapamil

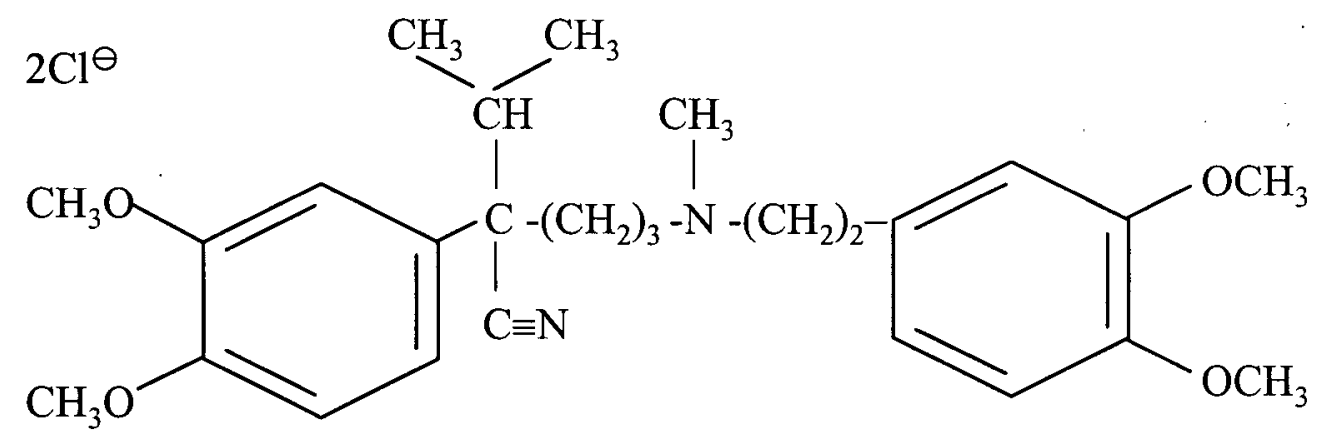

Diltiazem

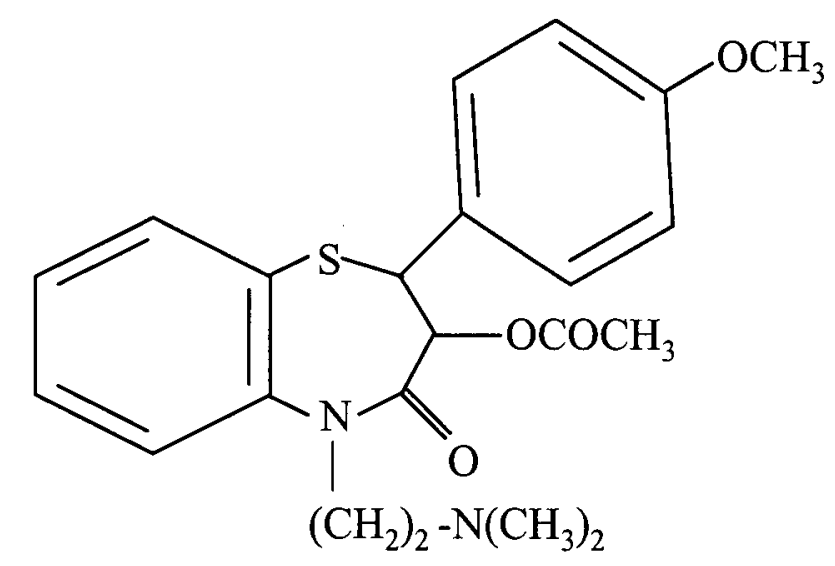


Figure 1.6. Dihydropyridine binding sites in sensitive $\mathrm{Ca}^{2+}$ channels (Striessnig et al.,1998). A) A schematic indication of possible interaction of transmembrane helices (IIIS5, IIIS6, and IVS6) and dihydropyridine (DHP), which is presented by a triangle. B) The L-channel $\alpha 1 \mathrm{c}$ sequence is shown in single amino acid letter code. The shaded individual amino acids in transmembrane helices IIIS5, IIIS6 and IVS6 involved in DHP binding are suggested by mutagenesis studies. Strong (dark shading; affinity decreased more than fivefold when mutated) and weak (light shading; less than five-fold) effects on DHP binding are indicated. Two glutamates (from III and IV S6 domains) of the $\mathrm{Ca}^{2+}$ selectivity filter and the bound $\mathrm{Ca}^{2+}$ are shown in the pore area. 


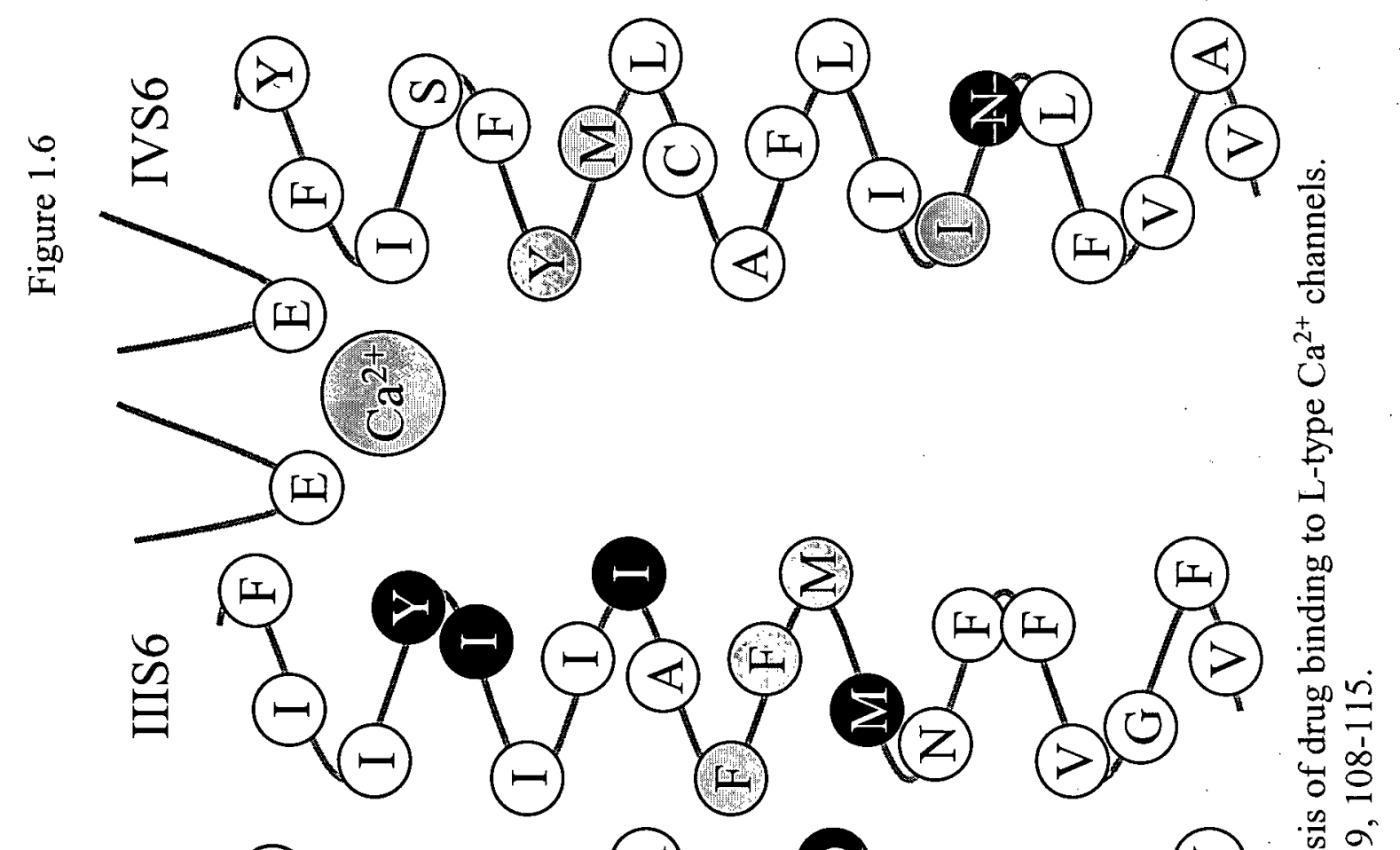

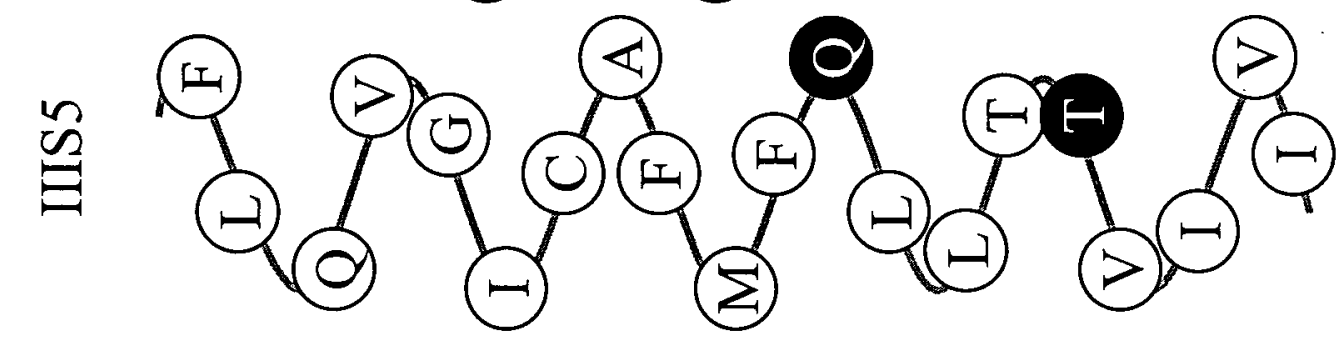

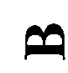

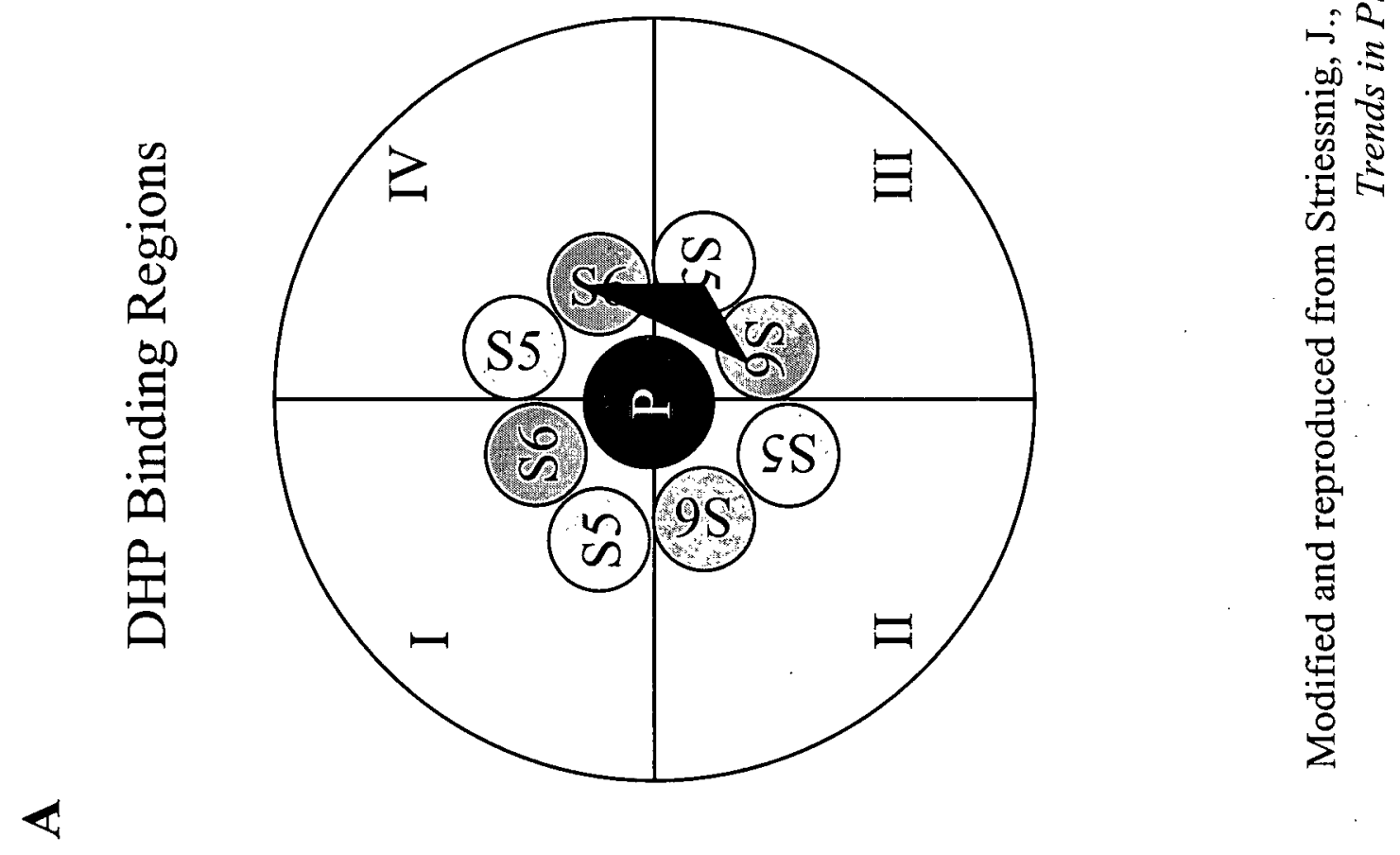


found that the most important five residues, four in IIIS6 (Tyr1152, Ile1153, Ile1156, and Met1161) and one in IVS6 (Asn1472), decreased apparent DHP antagonist affinity in binding or functional experiments by more than five-fold. There are also at least six additional IIIS6 and IVS6 residues (Phe1158, Phe1159, Met1160, Tyr1463, Met1464, Ile1471) in $\alpha 1_{C}$, which caused smaller (about two- to fivefold) decreases in DHP affinity when mutated (Striessnig et al., 1998). Although a portion of the above amino acids (comprising residues Tyr1152, Phe1158, Phe1159, and Asn1472) is conserved in non- $\mathrm{L}$ channels, it was proposed that these amino acids not present in the non- $\mathrm{L}$ channels play a more important role to confer high affinity DHP interaction in L channels.

\section{6b. Nifedipine and $K^{+}$channels}

It is known that the three representative $\mathrm{Ca}^{2+}$ channel antagonists, verapamil, diltiazem and nifedipine, all blocked cloned (Rampe et al., 1993; Grissmer et al., 1994; Rauer \& Grissmer, 1996) or native $\mathrm{K}^{+}$channels in different tissues, including atrial and ventricular myocytes (Jahnel et al., 1994) and alveolar epithelial tissues (Jacobs \& DeCoursey, 1990; DeCoursey, 1995). To understand the mechanisms of action of $\mathrm{Ca}^{2+}$ antagonists in blocking $\mathrm{K}^{+}$channels can also provide valuable information about common binding sites of $\mathrm{Ca}^{2+}$ channel antagonists in $\mathrm{K}^{+}$and $\mathrm{Ca}^{2+}$ channels, and can further illustrate the drug-channel interaction in both types of channels. Nifedipine is a classical 1,4 dihydropyridine $\mathrm{Ca}^{2+}$ channel antagonist. It is characterized by lightsensitivity, lipid-solubility, higher affinity to the inactivated $\mathrm{Ca}^{2+}$ channel and a pKa $<1.0$ at physiological $\mathrm{pH}$ range of 7.35 to 7.45 (Hume, 1985). A pKa $<1.0$ indicates that nifedipine is a neutral drug at physiological $\mathrm{pH}$ (Hume, 1985). It is widely used in clinics as a vasodilator in the treatment of various smooth muscle disorders, such as hypertension, and Reynaud's disease (hypersensitivity to cold), and has uses in the heart as an antiarrhythmic agent and in the treatment of angina. Avdonin (Avdonin et al., 1997) investigated the effects of nifedipine on the Shaker $\mathrm{K}^{+}$ channel expressed in Xenopus oocytes. The results indicated that intracellular nifedipine interacts with the open state of the Shaker channel inducing apparent inactivation. The results also showed 
that the overall efficacy could be modulated by a single amino acid mutation in the S6 segment. Data from our laboratory (Zhang et al., 1997) examining the effect of nifedipine on Kv1.5 channels expressed in HEK cells, also suggested that nifedipine was an open channel blocker, but that binding site was preferentially located on the extracellular side of the channel.

\section{6c. Ions and the drug binding domain}

It was suggested that the channel-bound $\mathrm{Ca}^{2+}$ ion is also required for the affinity of $\mathrm{Ca}^{2+}$ antagonists for the $\mathrm{Ca}^{2+}$ channel, and an allosteric model was proposed (Glossmann \& Striessnig, 1990; Glossmann et al., 1985). Removal of $\mathrm{Ca}^{2+}$ from the external medium decreased the affinity of $\mathrm{Ca}^{2+}$ antagonists for the $\mathrm{Ca}^{2+}$ channel, but when free $\mathrm{Ca}^{2+}$ was added, it restored high-affinity DHP binding with apparent $\mathrm{EC}_{50}$ values in the micromolar ranges (Glossmann \& Striessnig, 1990; Glossmann et al., 1985; Mitterdorfer et al., 1995; Peterson \& Catterall, 1995). Further evidence indicates that the high-affinity $\mathrm{Ca}^{2+}$ binding and the channel's $\mathrm{Ca}^{2+}$ selectivity filter are one and the same, which can bind one $\mathrm{Ca}^{2+}$ ion with submicromolar affinity (non-permeating state) or two with low (millimolar) affinity (allowing $\mathrm{Ca}^{2+}$ permeation) (Yang et al., 1993). This site is formed by four glutamate residues arranged in an asymmetric ring in the center of the pore. At present, the relation of $\mathrm{Ca}^{2+}$ ion and DHP is not clear. Although ion-induced conformational changes in an allosteric model were proposed, a direct (steric) interaction of bound drugs with bound $\mathrm{Ca}^{2+}$ caused by the close position of DHP and $\mathrm{Ca}^{2+}$ binding sites was not rejected (Striessnig et al., 1998).

Similarly, the $\mathrm{TEA}^{+}$block of the cloned $\mathrm{K}^{+}$channel, Kv2.1, is cation-dependent (Ikeda \& Korn, 1995; Immke et al., 1999). Normally, external application of $30 \mathrm{mM} \mathrm{TEA}^{+}$can block $\mathrm{K}^{+}$ currents by $87 \%$, while the same external concentration of $\mathrm{TEA}^{+}$has no effects on $\mathrm{Na}^{+}$currents through the same channel (Ikeda \& Korn, 1995). TEA ${ }^{+}$sensitivity was reinstated as $\left[\mathrm{K}^{+}\right]$was added into the solution as low as $30-100 \mu \mathrm{M}$. The $\left[\mathrm{K}^{+}\right]$range to induce $\mathrm{TEA}^{+}$sensitivity of the channel is the same as that required to block $\mathrm{Na}^{+}$current through the channel. This lead Immke et al. to suggest that a high affinity binding site by $\mathrm{K}^{+}$near selectivity filter was involved in modulation of 
$\mathrm{TEA}^{+}$sensitivity (Immke et al., 1999). This hypothesis was further supported by the experiment that demonstrated that the cation binding site associated with modulation of $\mathrm{TEA}^{+}$sensitivity was located between the internal and external $\mathrm{TEA}^{+}$binding sites (Immke et al., 1999), and the selectivity filter was specifically suggested. An allosteric model, a conformational change in the outer mouth of the pore in the Kv2.1 channel resulted from the removal of $\mathrm{K}^{+}$, was proposed to explain $\mathrm{TEA}^{+}$sensitivity abolishment in the absence of the $\mathrm{K}^{+}$(Immke et al., 1999). The hypothesis was confirmed by two point mutations in the outer mouth of the pore. Mutation from lysine 356 to glycine and lysine 382 to valine increased $\mathrm{TEA}^{+}$potency for block of $\mathrm{K}^{+}$currents by half a log unit, respectively. These data suggested that the cation-induced pore conformational change could extend to the outer mouth, result in the movement of residues in conduction pathway and affect the access of $\mathrm{TEA}^{+}$to its binding site. 
CHAPTER II

INLUENCE OF PERMEATING IONS ON KV1.5 CHANNEL

BLOCK BY NIFEDIPINE 


\subsection{ABSTRACT}

Our lab has previously reported that nifedipine can block $\mathrm{K}^{+}$currents through $\mathrm{Kv} 1.5$ channels expressed in HEK cells in an open-channel manner (Zhang et al., 1997). Replacement of internal and external $\mathrm{K}^{+}$with equimolar $\mathrm{Rb}^{+}$or $\mathrm{Cs}^{+}$reduced nifedipine block of $\mathrm{Kv} 1.5$ with $\mathrm{K}_{d}$ 's of $7.3\left(\mathrm{~K}^{+}\right), 16.0\left(\mathrm{Rb}^{+}\right)$, and $26.9 \mu \mathrm{M}\left(\mathrm{Cs}^{+}\right)$, respectively. The voltage-dependence of block was unaffected and all three ions conformed to a single binding site block model. This further suggested that nifedipine block of Kv1.5 channels was related to ion-conduction within the pore. Varying ion species at the intracellular and extracellular mouth of the channel demonstrated that block was conditioned by the ion permeating the pore, and to a lesser extent by the extracellular ion species alone. In Kv1.5 the outer pore mutation R487V reduced nifedipine potency close to that of $\mathrm{Kv} 4.2$, and other Kv channels with an equivalent valine. Although the potency of nifedipine block of this mutant was changed, the modulation by different ion species remained, but to a lesser degree. 


\subsection{INTRODUCTION}

Nifedipine has been widely used for almost two decades to control cardiac chest pain and hypertension, but has been associated in a dose-dependent manner (Furberg et al., 1995) with unfavourable side effects like negative inotropy and hypotension, proarrhythmia, and in some studies, increased mortality (Yusuf, 1995; Furberg et al., 1995). This may occur especially with the administration of short-acting forms of nifedipine in patients who are already hemodynamically compromised (Grossman et al., 1996; Marwick, 1996). Part of the mechanism for proarrhythmia caused by nifedipine may be the block of myocardial $\mathrm{K}^{+}$channels, which has been described both in mammalian ventricular myocytes with $\mathrm{K}_{\mathrm{d}}$ s $\mathrm{s}$ of $0.5-1 \mu \mathrm{M}$, and in cloned channels (Grissmer et al., 1994; Zhang et al., 1997). The plateau phase of the cardiac action potential is normally terminated by repolarizing outward potassium fluxes. Therefore, nifedipine block can prolong the action potential, cause a dispersion of refractoriness as these channels differ in their regional distribution across the myocardial wall (Liu et al., 1993), and lead to instability of the resting potential of the ventricular muscle.

Despite the potential importance of these $\mathrm{K}^{+}$channel actions of nifedipine, the mechanisms by which it exerts its actions on $\mathrm{K}^{+}$channels are not fully defined. Many compounds block $\mathrm{K}^{+}$channel currents by binding at, or near the internal or external mouth of the ion-conducting pore, where they may act as direct open channel blockers by physically occluding the ion-conducting pore to prevent ion passage. Examples of this kind of blocker are quinidine and the quaternary ammonium compounds, like $\mathrm{TEA}^{+}$, as well as the $\mathrm{N}$-terminal inactivation particle in Shaker channels (Demo \& Yellen, 1992). It is known that nifedipine acts as an open-channel blocker of single Shaker mutant channels (Avdonin et al., 1997), and of the mammalian homologue Kv1.5 channels with a $\mathrm{K}_{d}$ of $6.3 \mu \mathrm{M}$ (Zhang et al., 1997). Whether nifedipine acts at the internal or external mouth of the $\mathrm{K}^{+}$channel pore, though, is presently uncertain. 
It has been reported that permeating ions can affect the efficacy of channel block by charged drugs like TEA ${ }^{+}$(Block \& Jones, 1997; Ikeda \& Korn, 1995). In cloned Kv2.1 channels, external application of $30 \mathrm{mM} \mathrm{TEA}^{+}$can block $\mathrm{K}^{+}$currents by $87 \%$, while the same external concentration of TEA ${ }^{+}$has no effects on $\mathrm{Na}^{+}$currents through the same channel (Ikeda \& Korn, 1995). The details of the action of permeant ions on nifedipine block are poorly understood.

$\mathrm{Kv} 1.5$ is a prominent cardiac $\mathrm{K}^{+}$channel $\alpha$ subunit as it is expressed in human heart particularly in human and possibly in other regions of the human cardiovascular system (Tamkun et al., 1991; Fedida et al., 1993). Here we present evidence that the nature of the permeant ion does affect the dose-dependence and kinetics of nifedipine block of Kv1.5 channels. This suggests that nifedipine block involves coupling between permeation and the blocking sites and locates the binding of nifedipine within the permeation pathway of $\mathrm{K}^{+}$channels. Outer pore mutations of $\mathrm{R} 487$ reduce the nifedipine affinity for Kv1.5 channel in a manner consistent with other channels that have a valine at equivalent sites. The modulation effect of ions on nifedipine block of Kv1.5 is still exists, although the difference is less than that in the wild type channel. 


\subsection{MATERIALS AND METHODS}

\section{3a. Cell culture:}

Kv1.5 was cloned from a human fetal heart library, and subcloned into the mammalian expression vector pRc/CMV (pcDNA-3) (Fedida et al., 1993). The methods used to establish stable human embryonic kidney (HEK 293) cell lines expressing the $\mathrm{Kv} 1.5 \mathrm{~K}^{+}$channel and those used for electrophysiological measurement of Kv1.5 have been described in detail previously (Fedida et al., 1993). Alternatively, Kv4.2 was transfected into HEK cells using the mammalian expression vector pcDNA-3. HEK 293 cells were stably transfected with pcDNAs containing channel genes using LipofectACE reagent (Canadian Life Technologies, Bramalea, ON) in a 1:10 (w:v) ratio. We have generated a number of stable cell lines through antibiotic selection expressing these channels in HEK cells (including Kv1.5, Kv4.2, R487V (Y) mutant of Kv1.5, and $\mathrm{NCM}_{2}$, a non-conducting W472F mutant of Kv1.5). Cells are grown in Modified Eagle's Medium supplemented with $10 \%$ fetal bovine serum and $1 \%$ antimycotic. These cells have been continuously passaged on a weekly basis for 3-10 months with no apparent loss of channel activity. Cells used for electrophysiological experiments are seeded on glass coverslips 12-36 hours before use. Human Kv1.5 channels stably expressed in HEK 293 cell lines were used in all experiments. Kv1.5 in the plasmid expression vector, pcDNA-3 was mutagenized using the Quickchange Kit (Stratagene, La Jolla, CA) to convert arginine 487 to valine (R487V) or tyrosine (R487Y). For transient expression, cells are co-transfected with the channel construct and the vector pHook-1 (Invitrogen, San Diego, CA, USA). This plasmid encodes the production of an antibody to the hapten phOX, which, when expressed, is displayed on the cell surface, and detected by antigen-coated beads. Equal concentrations of individual channel and pHook-1 DNA are incubated with 10x concentration of lipofectAce in Modified Eagle's Medium and incubated with 
parent HEK cells plated on glass coverslips in $25 \mathrm{~mm}$ culture Petri dishes. After $3-4$ hours the solution is replaced with a standard culture medium plus $10 \%$ fetal bovine serum and $1 \%$ antimycotic. Transfected cells are maintained at $37^{\circ} \mathrm{C}$ in an air $/ 5 \% \mathrm{CO}_{2}$ incubator for $24-48$ hours to allow channel expression to occur. Twenty minutes prior to experiments, cells are treated with beads coated with phOX. After 15 minutes, excess beads are washed off with culture medium and cells which have beads stuck to them are used for electrophysiological testing. The efficiency of dual transfection was observed to be better than $80 \%$, so the beads provided a good means of identifying those cells that expressed Kv1.5 mutant channels. The human embryonic kidney cell line 293 (HEK 293) was used as a transient or stable expression system due to the ease of transfection of cells, the ability to express channels at high levels (Zhang et al., 1997), and the lack of endogenous $\beta$-subunits in these cells (Wible \& Fedida, 1994; Uebele et al., 1996).

\section{3b. Electrophysiological Solutions:}

Briefly, for whole-cell recording of ionic current, the solutions superfusing cells contain (in $\mathrm{mM}$ ): $\mathrm{NaCl}, 135 ; \mathrm{KCl}, 5$; sodium acetate, $2.8 ; \mathrm{MgCl}_{2}, 1 ; \mathrm{HEPES}, 10 ; \mathrm{CaCl}_{2}, 1$; adjusted to $\mathrm{pH} 7.4$ with $\mathrm{NaOH}$. The pipette filling solutions contain (in $\mathrm{mM}$ ): $\mathrm{KCl}, 130 ; \mathrm{Na}_{2}-\mathrm{ATP}, 4$; GTP, 0.1 ; HEPES, 10; $\mathrm{MgCl}_{2}$, 1; EGTA, 5; adjusted to $\mathrm{pH} 7.2$ with $\mathrm{KOH}$. When $\mathrm{KCl}$ was substituted with $\mathrm{CsCl}, \mathrm{RbCl}$, or N-Methyl-D-Glucamine $\left(\mathrm{NMG}^{+}\right), \mathrm{pH}$ was adjusted with $\mathrm{KOH}, \mathrm{CsOH}, \mathrm{RbOH}$, or $\mathrm{HCl}$, respectively. For gating current experiments, to prevent all ionic current, cells are superfused with a solution containing (in $\mathrm{mM}$ ): $\mathrm{NMG}^{+}, 140$; HEPES, 10; dextrose, 10; $\mathrm{pH} 7.4$ with $\mathrm{HCl}$. The pipette solution used (in $\mathrm{mM}$ ): $\mathrm{NMG}^{+}, 140$; HEPES, 10; EGTA, 10; pH 7.2 with HCl. For recordings in the presence of different $\mathrm{Cs}^{+}, \mathrm{Rb}^{+}$, or $\mathrm{K}^{+}$concentrations, the $\mathrm{NMG}^{+}$base solution was used and $\mathrm{NMG}^{+}$was substituted by the appropriate ions. Nifedipine was dissolved in ethanol at a stock concentration of $20 \mathrm{mM}$ and was protected from exposure to light at $<4^{\circ} \mathrm{C}$. The vehicle has no effect alone. The drug solutions are prepared fresh from these stock solutions and 
vortexed immediately before each use. Drugs are used 'at concentrations between 0.1 and $500 \mu \mathrm{M}$ and are protected from the light during all experiments. The perfusion system is periodically cleaned with ethanol to prevent the influence of nifedipine accumulation. Other solutions are made according to experimental needs. Throughout the text the subscripts ${ }_{i}$ or $_{o}$ denote intra- or extracellular ion concentrations, respectively. All chemicals were from Sigma Aldrich Chemical Co. (Mississauga, Ont.). The purity of N-Methyl D-Glucamine was $99-100.5 \%$ (by $\mathrm{HCl}$ titration, Sigma M2004).

\section{3c. Electrophysiological procedures:}

Coverslips containing cells were removed from the incubator before experiments and placed in a superfusion chamber (volume $250 \mu \mathrm{l}$ ) containing the control bath solution at $22-23^{\circ}$ C. The bath solution was exchanged by switching the perfusates at the inlet of the chamber, with complete bath solution changes taking 5-10 s. Whole-cell current recording and data analysis were done using an Axopatch 200A amplifier and pClamp6 software (Axon Instruments, Foster

City, CA). Patch electrodes were fabricated using thin-walled borosilicate glass (World Precision Instruments; FL, USA). Capacity compensation and $80-95 \%$ series resistance $\left(\mathrm{R}_{\mathrm{s}}\right)$ compensation were routinely used. Averaged cell membrane capacitance was $15.1 \pm 0.5 \mathrm{pF}, \mathrm{n}=$ 128, and measured series resistance was between 0.5-5.5 $\mathrm{M} \Omega$ for all recordings (averaged series resistance was $2.3 \pm 0.1 \mathrm{M} \Omega, \mathrm{n}=128$ ). When this changed during the course of an experiment, data were discarded. Junction potentials $\left(\mathrm{E}_{\mathrm{L}}\right)$ arise between the different pipette and bath solutions and can be balanced by an offset potential. After the formation of a whole-cell configuration and the complete solution exchange between the pipette and cell, the membrane potential (Vm) will be related to patch command potential $\left(V_{P}\right)$ and $E_{L}$ by: $V m=V_{P}-E_{L}$. The junction potentials for different solutions can be estimated by JPCalc software (University of New South Wales, Sydney, Australia). In the presence of $\mathrm{K}^{+}, \mathrm{Rb}^{+}$, and $\mathrm{Cs}^{+}$, the junction potentials in recording ionic currents 
are $4.7,5.3$, and $5.2 \mathrm{mV}$, respectively. In recording gating currents, the junction potentials are 5.6, 6.3 and $6.2 \mathrm{mV}$ for external $\mathrm{K}^{+}, \mathrm{Rb}^{+}$, and $\mathrm{Cs}^{+}$, respectively, in the presence of internal $\mathrm{NMG}^{+}$. When small cation exchanges with $\mathrm{NMG}^{+}$, the junction potential is the same but the sign is changed. Membrane potentials have not been corrected for any junction potentials because of their relatively small amplitudes. Ionic currents are filtered at $5 \mathrm{kHz}$, sampled at $10-20 \mathrm{kHz}$ and stored on a microcomputer for later analysis using pClamp6 software. In experiments where gating currents (Ig) are recorded, the sample rate is $100-200 \mathrm{kHz}$ (unless otherwise stated) and records filtered at 10-50 kHz. Currents can be leak-subtracted using a P/6 protocol (Stühmer et al., 1991; McCormack et al., 1994). The data for analysis and presentation were off-line leak subtracted if required, and data were discarded if the leakage conductance was $>\ln S$. Throughout the text data are shown as mean \pm S.E.

\section{3d. Data Analysis:}

The concentration response curves for permeating $\mathrm{K}^{+}, \mathrm{Rb}^{+}$and $\mathrm{Cs}^{+}$ions in peak and steady-state current were computer-fitted to the Hill equation:

$$
\mathrm{f}=1 /\left[1+\left(\mathrm{IC}_{50} /[\mathrm{D}]^{\mathrm{nH}}\right)\right]
$$

where $\mathrm{f}$ is the fractional current $\left(\mathrm{I}_{\mathrm{drug}} / \mathrm{I}_{\text {control }}\right)$ at drug concentration [D]; $\mathrm{IC}_{50}$ is the concentration producing half maximal inhibition and $n_{H}$ is the Hill coefficient. The rapid component of current decay was much faster than that observed in the absence of drug. Therefore we used this drug-induced time-constant $\left(\tau_{2}\right)$ as an approximation of the drug channel interaction kinetics, as described previously (Castle et al., 1994; Zhang et al., 1997), according to the equation:

$$
1 / \tau_{2}=\mathrm{k}_{+1}[\mathrm{D}]+\mathrm{k}_{-1}
$$


and

$$
\mathrm{K}_{\mathrm{d}}=\mathrm{k}_{-1} / \mathrm{k}_{+1}
$$

in which $\tau_{2}$ is the current decay time constant caused by the drug; [D] is the concentration of drug; $\mathrm{k}_{+1}$ and $\mathrm{k}_{-1}$ are the apparent rate constants of binding and unbinding for the drug, respectively, and $K_{d}$ represents the affinity of the drug for its binding site.

The data for current decay in Kv1.5 without nifedipine was fit using a single exponential equation:

$$
y=A * \exp (-t / \tau)+C
$$

where $\mathrm{A}$ is the amplitude, $\mathrm{t}$ is the time, $\tau$ is the time constant for the decay phase of the current and $\mathrm{C}$ is the offset constant. Current decays in Kv4.2 without nifedipine block and in Kv4.2 and Kv1.5 with nifedipine were fit using a double exponential equation:

$$
y=A_{2} * \exp \left(-t / \tau_{2}\right)+A_{1} * \exp \left(-t / \tau_{1}\right)+C
$$

in which $\tau_{2}$ and $\tau_{1}$ are the fast and slow time constants of current decay, $A_{2}$ and $A_{1}$ are the corresponding amplitudes and $\mathrm{C}$ indicates the non-inactivating or nifedipine insensitive current.

Experimental values are given as means \pm S.E.. ANOVA and multiple pairwise comparison were used to test for significant differences between groups (Fig. 2.5). An unpaired t-test was used to compare off-gating current reduction with external or internal cations of each species. A value of $\mathrm{P}<0.05$ was considered statistically significant. 


\subsection{RESULTS}

\section{4a. Nifedipine blocks $\mathrm{K}^{+}, \mathrm{Rb}^{+}$and $\mathrm{Cs}^{+}$currents through $\mathrm{Kv} 1.5$ channels}

The currents in Fig. 2.1 illustrate the actions of nifedipine on $\mathrm{K}^{+}, \mathrm{Rb}^{+}$and $\mathrm{Cs}^{+}$currents through Kv1.5 channels. Currents were recorded using a physiological ion gradient across the cell membrane $\left(135 \mathrm{mM} \mathrm{K}_{\mathrm{i}}^{+} / 5 \mathrm{mM} \mathrm{K}_{\mathrm{o}}^{+}\right.$) or a solution with external and internal $\mathrm{K}^{+}$replaced by equimolar $\mathrm{Rb}^{+}$or $\mathrm{Cs}^{+}$. Control traces in Fig. 2.1A were elicited from a holding potential of $-80 \mathrm{mV}$ to potentials between -30 and $+40 \mathrm{mV}$. For a $400 \mathrm{~ms}$ pulse from a holding potential of $-80 \mathrm{mV}$, the sigmoidal shape of current activation elicited upon depolarization did not vary among the three different ionic conditions. In the current voltage relations in the Fig. 2.2 , steady state activation results in a "bulge" in the relationships between -20 and $+20 \mathrm{mV}$. No significant difference was found in the voltage-dependence of peak I-V relations or in the thresholds for current activation (-20 $\mathrm{mV}$ in all cases). In control, the main difference between currents carried by the different ions was a decrease in current amplitude that reflected the decreased permeability of $\mathrm{Rb}^{+}$and $\mathrm{Cs}^{+}$compared with $\mathrm{K}^{+}$and a reduction in the amount of slow C-type inactivation in $\mathrm{Cs}^{+}$(Fedida et al., 1999), most visible at the more positive potentials. External application of $10 \mu \mathrm{M}$ nifedipine markedly inhibited both peak and steady-state $\mathrm{K}^{+}$currents with an apparent acceleration in the decay rates of outward currents positive to $+10 \mathrm{mV}$ (Fig. 2.1B). The characteristics of nifedipine block of $\mathrm{K}^{+}$ currents through Kv1.5 channels have been previously studied in detail (Zhang et al., 1997). It is noticeable that the acceleration of current decay only becomes apparent at more positive potentials where the channel activation rate significantly exceeds the nifedipine block rate. At more negative potentials, block reduces current amplitude without significantly altering kinetics. External application of $10 \mu \mathrm{M}$ nifedipine also blocked $\mathrm{Rb}^{+}$and $\mathrm{Cs}^{+}$currents (Fig. 2.1B), but the potency of block was significantly less. Application of $50 \mu \mathrm{M}$ nifedipine (Fig. 2.1C) produced a more marked 
Figure 2.1. Block of $\mathrm{Kv} 1.5 \mathrm{~K}^{+}, \mathrm{Rb}^{+}$, and $\mathrm{Cs}^{+}$currents in $\mathrm{HEK}$ cells by nifedipine. Whole-cell currents were elicited from a holding potential of $-80 \mathrm{mV}$ to voltages between -30 and $+40 \mathrm{mV}$ in increments of $10 \mathrm{mV}$. As indicated, $\mathrm{K}^{+}$(left column), $\mathrm{Rb}^{+}$(middle column) and $\mathrm{Cs}^{+}$(right column) currents were recorded in the control, $\mathrm{A}$, and presence of $10 \mu \mathrm{M}$ and $50 \mu \mathrm{M}$ nifedipine in $\mathrm{B}$ and $\mathrm{C}$, respectively. The scale bars in A also apply to panels $\mathrm{B}$ and $\mathrm{C}$, and data for each ion in $\mathrm{A}-\mathrm{C}$ are from the same cells. 
Figure 2.1

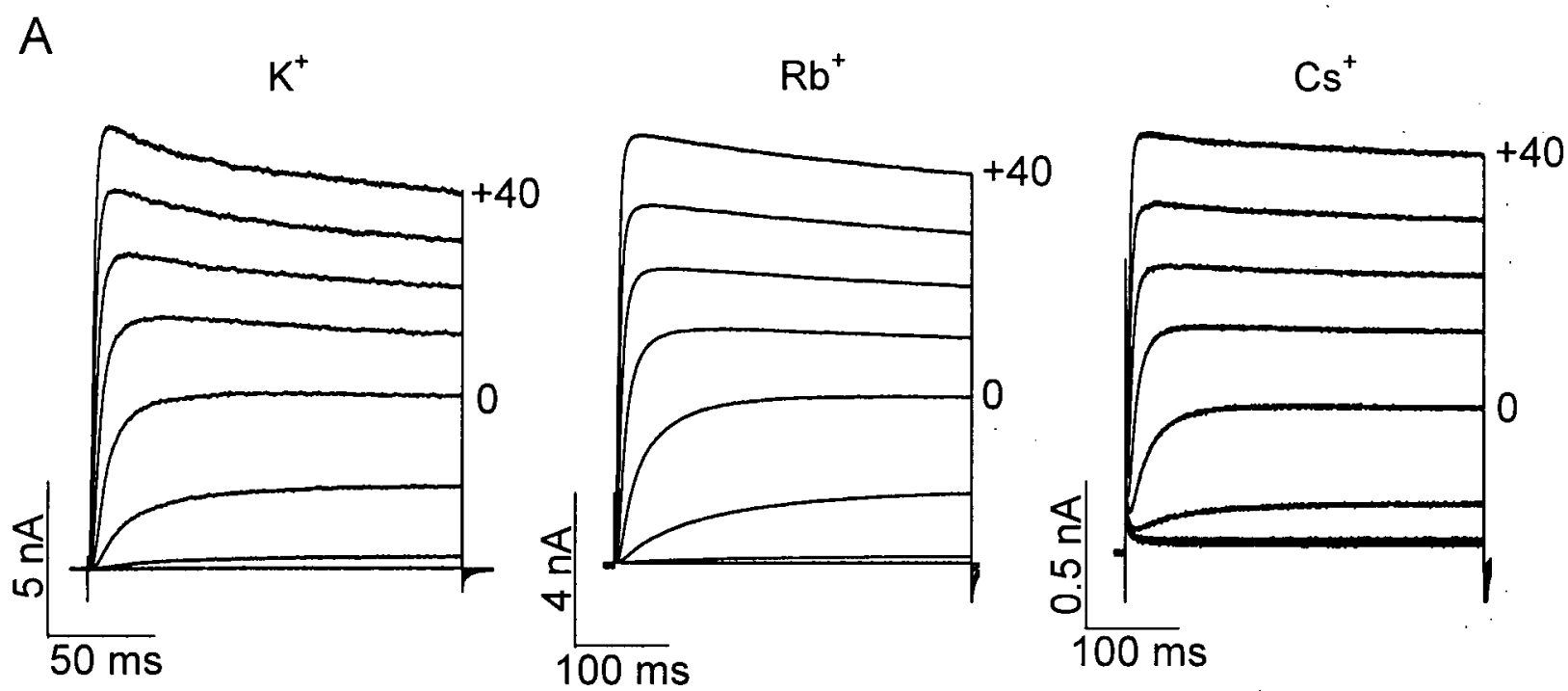

B

$10 \mu \mathrm{M}$ Nifedipine
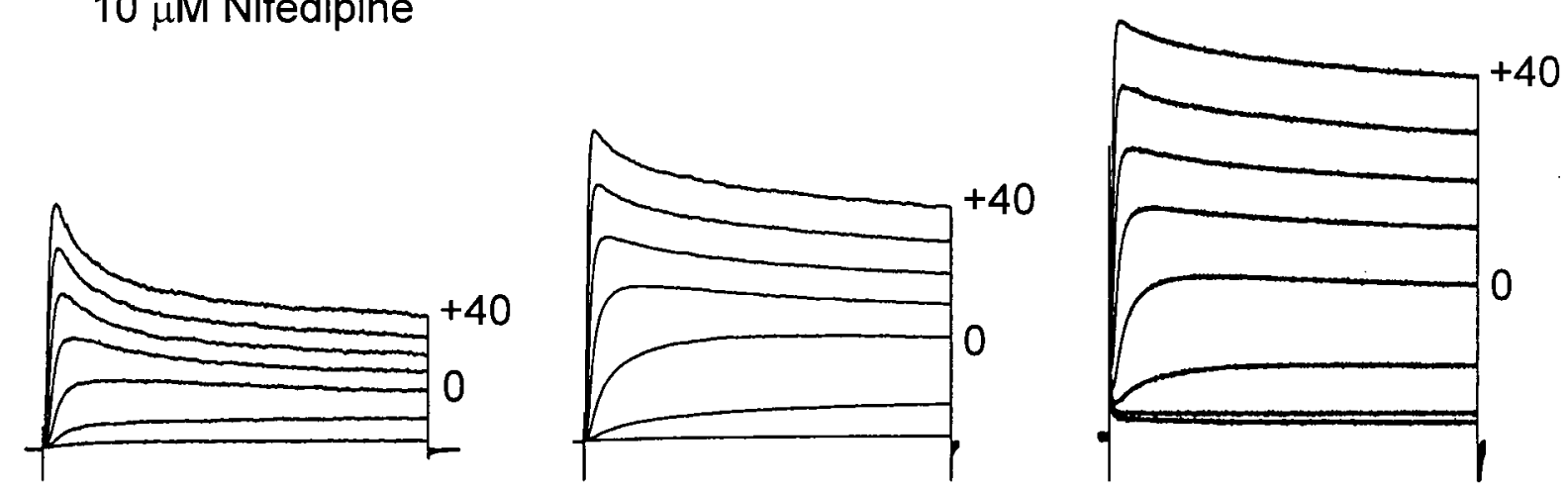

C

$50 \mu \mathrm{M}$ Nifedipine
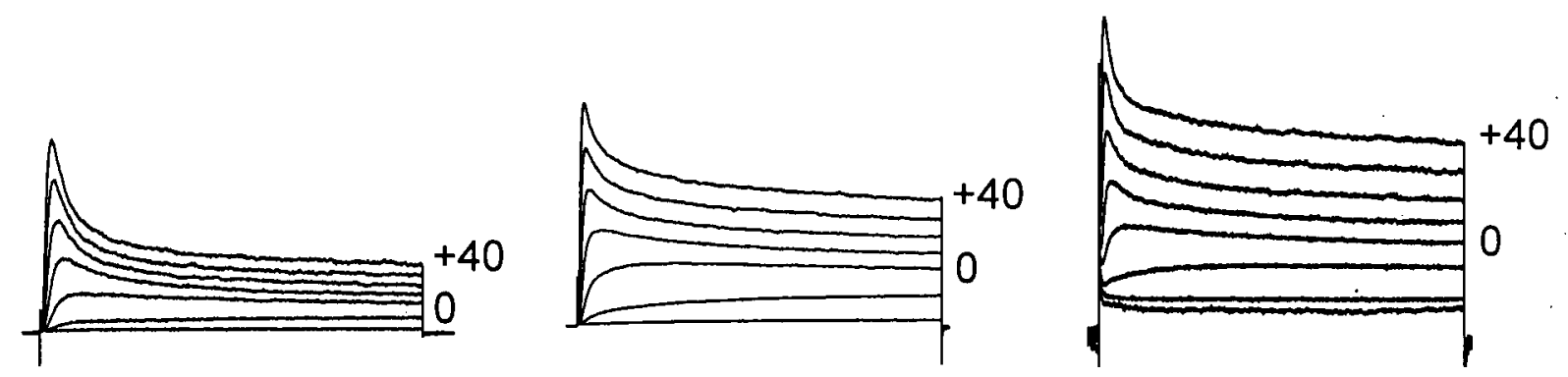
block of current carried by all three cations and a significant acceleration of current decay that reflected open-channel block caused by the drug. Steady-state current-voltage relations from these data are in Fig 2.2 for the three ions, and show the increased potency of nifedipine action when $\mathrm{K}^{+}$ was carrying current through $\mathrm{Kv} 1.5$ rather than when $\mathrm{Rb}^{+}$or $\mathrm{Cs}^{+}$were carrying current. At +40 $\mathrm{mV}$, external application of $10 \mu \mathrm{M}$ nifedipine blocked more than $60 \%$ of $\mathrm{K}^{+}$current. However, the same concentration of nifedipine only blocked $35 \%$ of $\mathrm{Rb}^{+}$current and $20 \%$ of $\mathrm{Cs}^{+}$current. External application of $50 \mu \mathrm{M}$ nifedipine blocked $86 \%$ of $\mathrm{K}^{+}$current, $70 \%$ of $\mathrm{Rb}^{+}$current and $60 \%$ of $\mathrm{Cs}^{+}$current. As we have previously noted (Zhang et al., 1997) nifedipine block was minimal until potentials around $-10 \mathrm{mV}$ when channel open probability was significant. At potentials where the $P_{o}$ was high, block was only mildly dependent on pulse potential, with a small reduction of block at more positive potentials.

The potency of nifedipine block was quantified in the dose-response curves shown in Fig. 2.3. Normalized data for the three ions are directly compared in Fig. $2.3 \mathrm{~A}$. Here, at $+40 \mathrm{mV}, 20$ $\mu \mathrm{M}$ nifedipine blocked $\mathrm{K}^{+}$current by $73 \%$ whereas the $\mathrm{Cs}^{+}$current was only blocked by $46 \%$. Nifedipine block was quantified in the dose-response curves shown in Fig. 2.3B. Using a Hill equation to fit curves obtained from measurements of steady-state $\mathrm{K}^{+}, \mathrm{Rb}^{+}$and $\mathrm{Cs}^{+} \mathrm{Kv} 1.5$ currents at different concentrations of nifedipine, the resulting $\mathrm{IC}_{50}$ values were $7.3,16.0,26.9 \mu \mathrm{M}$, with Hill coefficients of $0.93,1.06,1.20$, for $\mathrm{K}^{+}, \mathrm{Rb}^{+}$and $\mathrm{Cs}^{+}$respectively (Fig. 2.3B). Hill coefficients close to 1.0 suggested a single binding site for nifedipine block of Kv1.5 no matter which ion species was permeating the channel. These results indicated that the potency of nifedipine block of Kv1.5 was not only dependent on nifedipine concentration, but also strongly dependent on the permeating-ion species carrying Kv1.5 currents.

One of the noticeable features of the inhibition of Kv1.5 by nifedipine was the concentration-dependent increase in the apparent rate of current inactivation (Fig. 2.1). In control, the currents reached their peak at $\sim 10 \mathrm{~ms}$ and then declined slowly. During $400 \mathrm{~ms}$ voltage pulses 
Figure 2.2. Steady-state $\mathrm{I}-\mathrm{V}$ relations for $\mathrm{K}^{+}, \mathrm{Rb}^{+}$and $\mathrm{Cs}^{+}$current block by nifedipine. Original current data from Fig. 2.1. In the absence (open symbols) and presence of 10 , and $50 \mu \mathrm{M}$ nifedipine (filled symbols), the steady-state $\mathrm{K}^{+}(\mathrm{A}), \mathrm{Rb}^{+}(\mathrm{B})$ and $\mathrm{Cs}^{+}(\mathrm{C})$ currents measured at the end of current traces were plotted against test potential. 


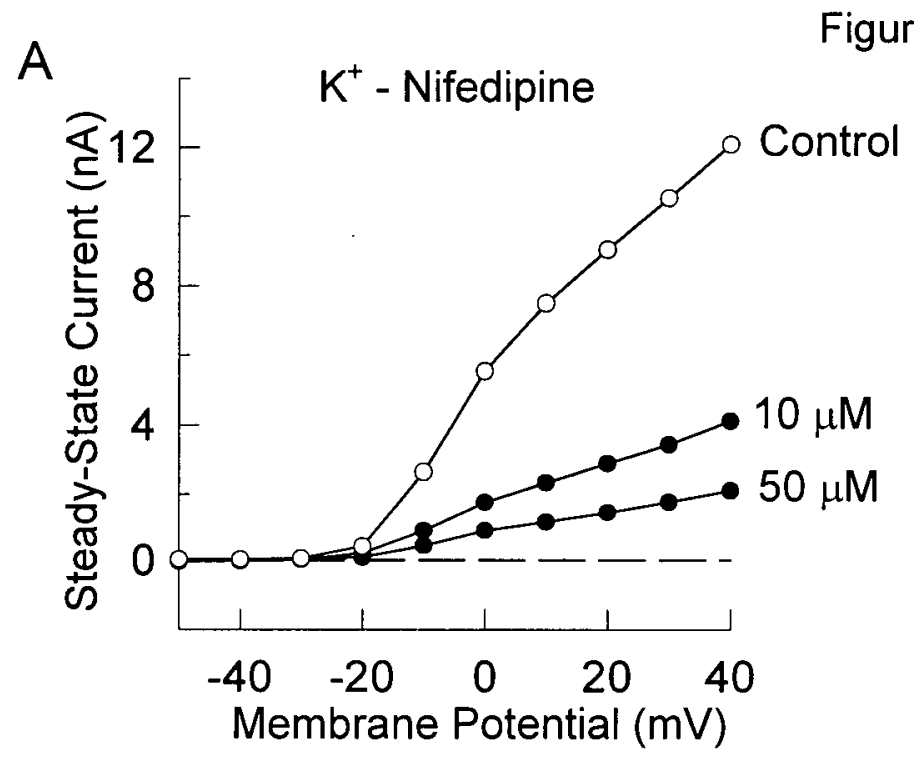

B

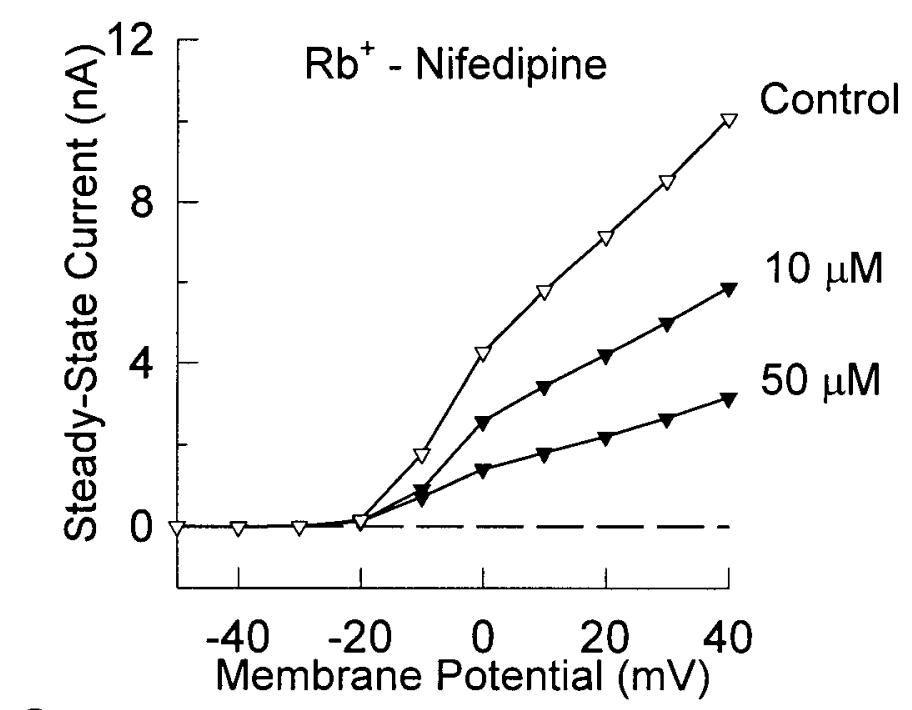

C

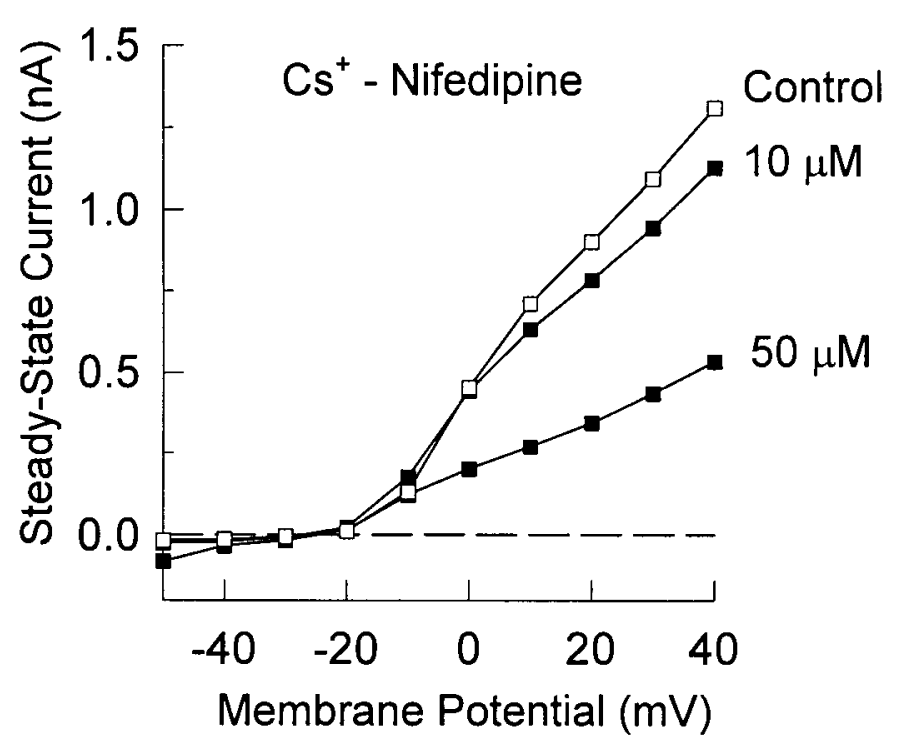


Figure 2.3. Concentration-dependence of nifedipine block of $\mathrm{Kv} 1.5 \mathrm{~K}^{+}, \mathrm{Rb}^{+}$and $\mathrm{Cs}^{+}$currents. A) $\mathrm{K}^{+}, \mathrm{Rb}^{+}$and $\mathrm{Cs}^{+}$currents during a $+40 \mathrm{mV}$ test pulse from a holding potential of $-80 \mathrm{mV}$ in the presence of $20 \mu \mathrm{m}$ nifedipine. Each tracing from a different cell normalized to peak outward current. B) Concentration-response curves for nifedipine block of steady-state $\mathrm{K}^{+}, \mathrm{Rb}^{+}$and $\mathrm{Cs}^{+}$ currents $\left(\mathrm{I}_{\text {nif }} / \mathrm{I}_{\text {control }}\right)$. Current block was measured at the end of $400 \mathrm{~ms}$ depolarizations and normalized to current level before nifedipine. Solid lines were fit to the data using the Hill equation (see Materials and Methods). The $\mathrm{IC}_{50}$ concentrations for $\mathrm{K}^{+}, \mathrm{Rb}^{+}$and $\mathrm{Cs}^{+}$currents blocked by nifedipine were $7.3 \pm 0.3,16.0 \pm 0.8$ and $26.9 \pm 1.3 \mu \mathrm{M}$ and the Hill coefficients were $0.9 \pm 0.1,1.1 \pm 0.1$ and $1.2 \pm 0.1$ respectively. Data are mean \pm S.E. $(n=6-14)$ 


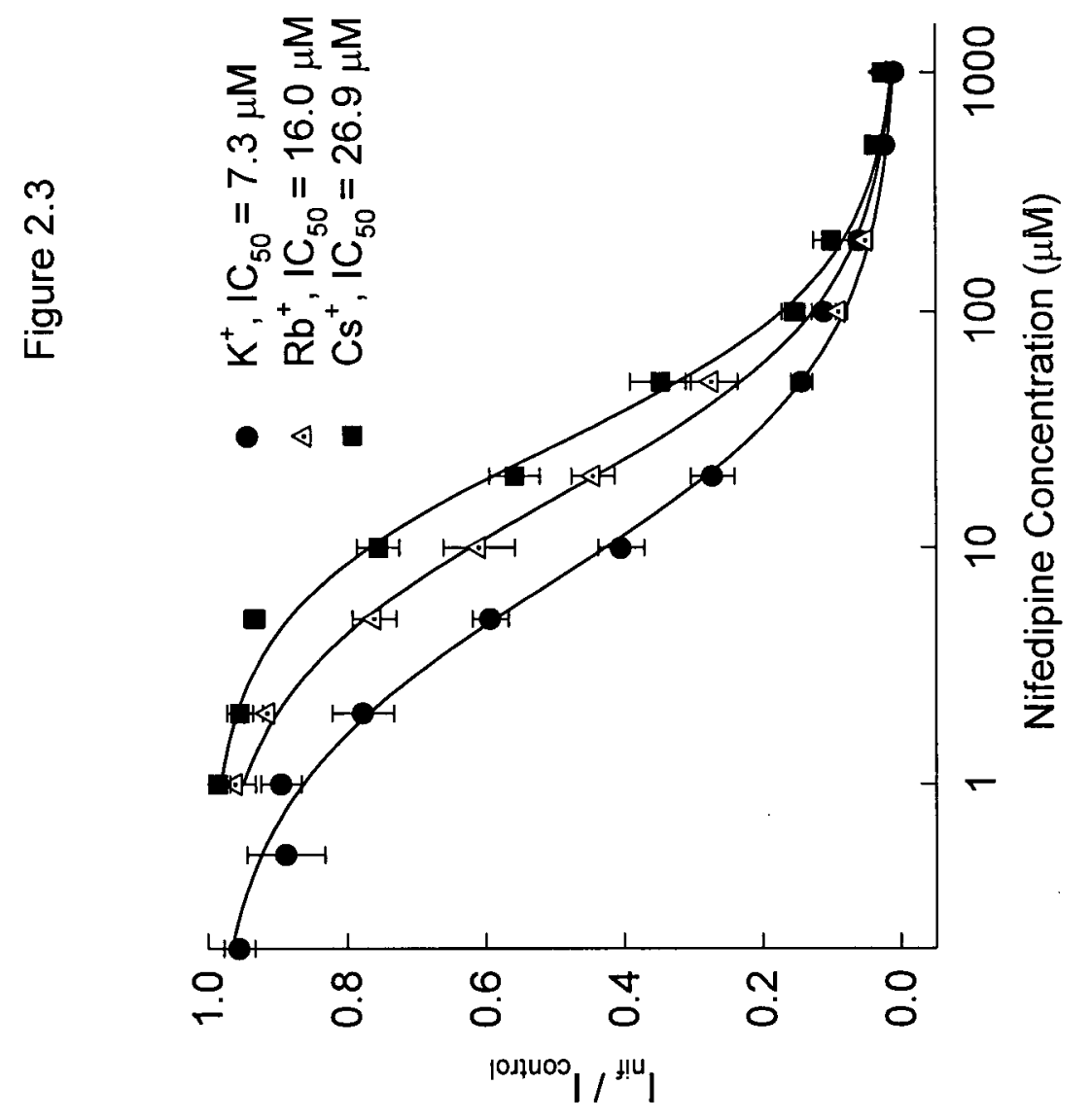

$m$

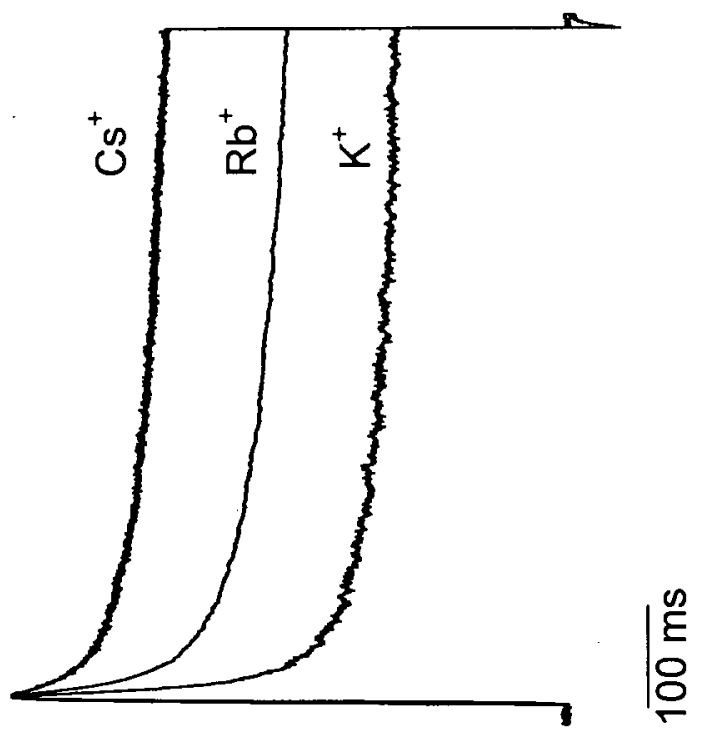

$\alpha$ 
at $+40 \mathrm{mV}$, the currents could be fitted to a single exponential function [3a] with a decay time constant of $214 \pm 17 \mathrm{~ms}(\mathrm{n}=20), 297 \pm 20 \mathrm{~ms}(\mathrm{n}=12)$ and $298 \pm 29 \mathrm{~ms}(\mathrm{n}=9)$ for $\mathrm{K}^{+}, \mathrm{Rb}^{+}$and $\mathrm{Cs}^{+}$, respectively. In the presence of nifedipine the peak current was reduced and reached at earlier times. The subsequent decay introduced an additional exponential component superimposed on the slow inactivation, so a bi-exponential function was used to fit the current decay in the presence of nifedipine [3b]. Between 5 and $50 \mu \mathrm{M}$ nifedipine, the time constants of the slow component of the current decay $\left(\tau_{1}\right)$ are not significantly different from the control values (Table 2.1 ), suggesting that the process of slow inactivation was not modified by nifedipine. The time constants of the initial fast-decaying component $\left(\tau_{2}\right)$ decrease monotonically as a function of the nifedipine concentration (Table 2.1). This extra fast component is at least 10 times faster than the slow inactivation. Therefore, the time constant $\left(\tau_{2}\right)$ for this fast-decaying component was considered to be a reasonable approximation of the drug-channel interaction kinetics and was used to calculate the $\mathrm{K}_{\mathrm{d}}$ and on- and off-rates for nifedipine binding according to a single site model (4). As shown in Fig. 2.4, we calculated $1 / \tau_{2}$ for Kv1.5 channels with the three permeant ions, $\mathrm{K}^{+}, \mathrm{Rb}^{+}$, and $\mathrm{Cs}^{+}$, and plotted it as a function of nifedipine concentration. The relationship between $1 / \tau_{2}$ and nifedipine concentration is well fit by equation [2a]. From the fit lines we extracted the apparent $K_{d}$ values of $7.8,16.5$ and $27.2 \mu \mathrm{M}$ for $\mathrm{K}^{+}, \mathrm{Rb}^{+}$, and $\mathrm{Cs}^{+}$block, respectively. These are close to the $\mathrm{IC}_{50}$ values obtained from the concentration-response relations in Fig. 2.3B, therefore, support the applicability of a single binding site model for nifedipine action on Kv1.5 with the three different permeant ions.

\section{4b. Membrane sidedness of cation modulation of nifedipine action}

One of the primary aims of the present study was to determine the site of action of nifedipine on the Kv1.5 channels. Since the potency of block varied with different cation species permeating the channel, the following experiments were designed to test whether or not Kv1.5 


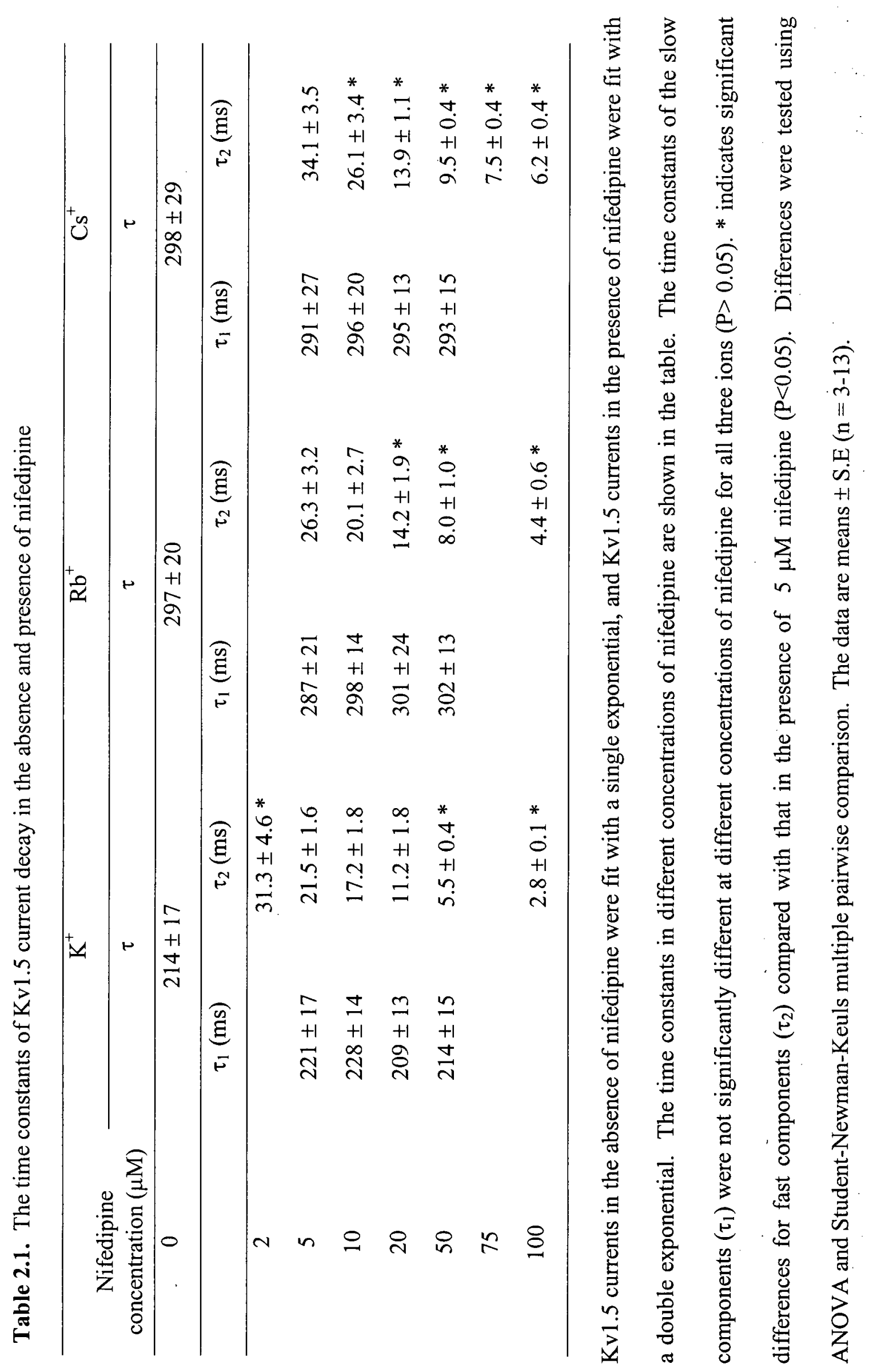


Figure 2.4. Decay time constants of $\mathrm{Kv} 1.5 \mathrm{~K}^{+}, \mathrm{Rb}^{+}$and $\mathrm{Cs}^{+}$currents in the presence of nifedipine. The reciprocal of the nifedipine-induced fast time constant of block $\left(1 / \tau_{2}\right)$ at $+40 \mathrm{mV}$ for the different ions is plotted against the concentration of nifedipine. The solid line is the best fit to the data using the equation $1 / \tau_{2}=\mathrm{k}_{+1} *[\mathrm{D}]+\mathrm{k}_{-1}$ (see Methods). The association rate constants $\left(\mathrm{k}_{+1}\right)$ were $3.26 \times 10^{6}, 2.05 \times 10^{6}$ and $1.33 \times 10^{6} \mathrm{M}^{-1} \mathrm{~s}^{-1}$ for $\mathrm{K}^{+}, \mathrm{Rb}^{+}$and $\mathrm{Cs}^{+}$currents, respectively, and the dissociation rate constants $\left(\mathrm{k}_{-1}\right)$ were $25.34,33.88$ and $36.16 \mathrm{~s}^{-1}$ for $\mathrm{K}^{+}, \mathrm{Rb}^{+}$ and $\mathrm{Cs}^{+}$currents, respectively. The $\mathrm{K}_{\mathrm{d}}{ }^{\prime} \mathrm{s}\left(\mathrm{k}_{-1} / \mathrm{k}_{+1}\right)$ for $\mathrm{K}^{+}, \mathrm{Rb}^{+}$and $\mathrm{Cs}^{+}$currents were $7.8,16.5$ and $27.2 \mu \mathrm{M}$, respectively. Data points are means \pm S.E. $(n=3-14)$. 


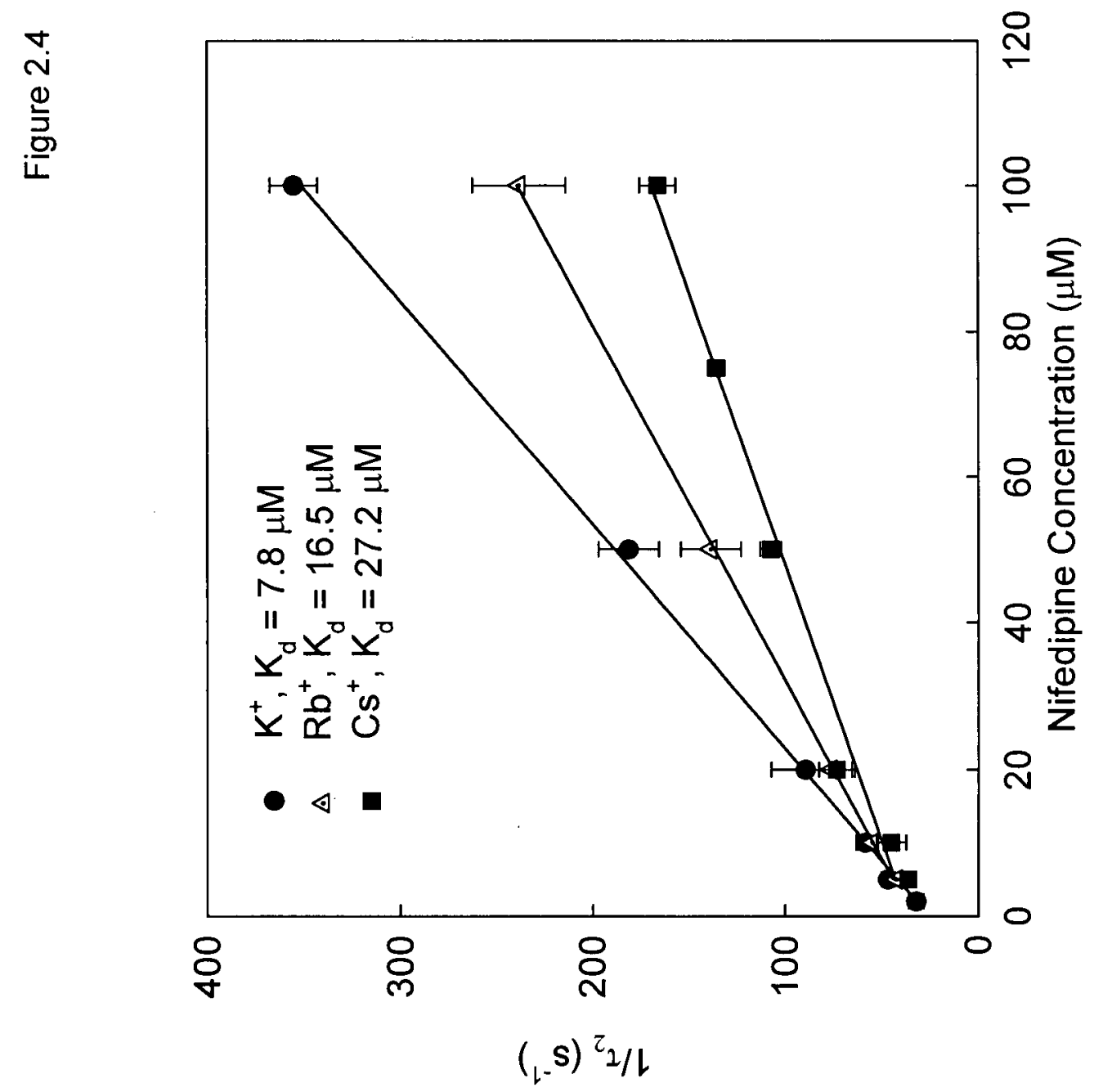


block by nifedipine was mediated within the pore region itself. The rationale was based on the preceding experiments where it appeared that the presence of larger cations within the pore, like $\mathrm{Cs}^{+}$ and $\mathrm{Rb}^{+}$, reduced the potency of nifedipine binding compared with $\mathrm{K}^{+}$. The intracellular $\mathrm{Cs}^{+}$ concentration was kept constant at $130 \mathrm{mM}$ and the external ion concentration and species was changed to alter the direction of ion flow across the pore. A two pulse protocol was used, with an initial $200 \mathrm{~ms}$ prepulse to index block of Kv1.5 outward $\mathrm{Cs}^{+}$current at $+80 \mathrm{mV}$ by $20 \mu \mathrm{M}$ nifedipine, and a test pulse to $+30 \mathrm{mV}$ to measure nifedipine block of current under different extracellular ion conditions (Fig. 2.5A-D). Mean currents measured at the end of the $200 \mathrm{~ms}$ prepulse and the $400 \mathrm{~ms}$ test pulse are shown in Fig. 2.6. At the end of the $200 \mathrm{~ms}$ prepulse with an outward $\mathrm{Cs}^{+}$current in all cases, there was no significant difference in the nifedipine block between extracellular $\mathrm{Cs}^{+}$and $\mathrm{K}^{+}$. During the test pulse at $+30 \mathrm{mV}$, in Fig. 2.5A, C, and $\mathrm{D}$ an outward $\mathrm{Cs}^{+}$current is present and there is little difference in the action of nifedipine.

The essential observation is shown in Fig. $2.5 \mathrm{~B}$ with $70 \mathrm{mM} \mathrm{K}^{+}$o where the inward $\mathrm{K}^{+}$ current at $+30 \mathrm{mV}$ is significantly blocked by $20 \mu \mathrm{M}$ nifedipine. The current is inward at this potential due to the higher permeability of the pore for $\mathrm{K}^{+}$than $\mathrm{Cs}^{+}$. The current reduction is greater than for any other ionic conditions (Fig 2.6), and is the only condition where $\mathrm{K}^{+}$is actually the permeating ion. In all other ionic conditions in these experiments, $\mathrm{Cs}^{+}$is the permeating ion. These data support those in previous figures that indicated higher nifedipine potency with $\mathrm{K}^{+}$in the bath and pipette, rather than $\mathrm{Cs}^{+}$. These data extend that idea to show that it is pore ion species that determines nifedipine potency. When $\mathrm{K}^{+}$is the permeating ion, as in Fig. 2.5B during the test pulse, the blocking action of nifedipine is enhanced compared with the prepulse when $\mathrm{Cs}^{+}$is the pore permeating ion.

\section{4c. Nifedipine action on Kv1.5 mutant channels}


Figure 2.5. Nifedipine block is modulated by the ion species occupying the pore. The same twin-pulse voltage protocol was used in all panels, in the presence of $130 \mathrm{mM} \mathrm{Cs}^{+}{ }_{i}$ (all panels) and $\mathrm{A}, 70 \mathrm{mM} \mathrm{Cs}^{+}{ }_{0} ; \mathrm{B}, 70 \mathrm{mM} \mathrm{K}^{+} ; \mathrm{C}, 5 \mathrm{mM} \mathrm{Cs}^{+}$; and $\mathrm{D}, 5 \mathrm{mM} \mathrm{K}_{0}^{+}$. Outward $\mathrm{Cs}^{+}$current was elicited at $+80 \mathrm{mV}$ from a $-80 \mathrm{mV}$ holding potential during the first $200 \mathrm{~ms}$ pulse. During the second pulse, cells were depolarized to $+30 \mathrm{mV}$ for $200 \mathrm{~ms}$. Current tracings are shown in the absence and presence of $20 \mu \mathrm{M}$ nifedipine. 


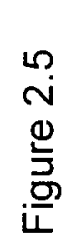

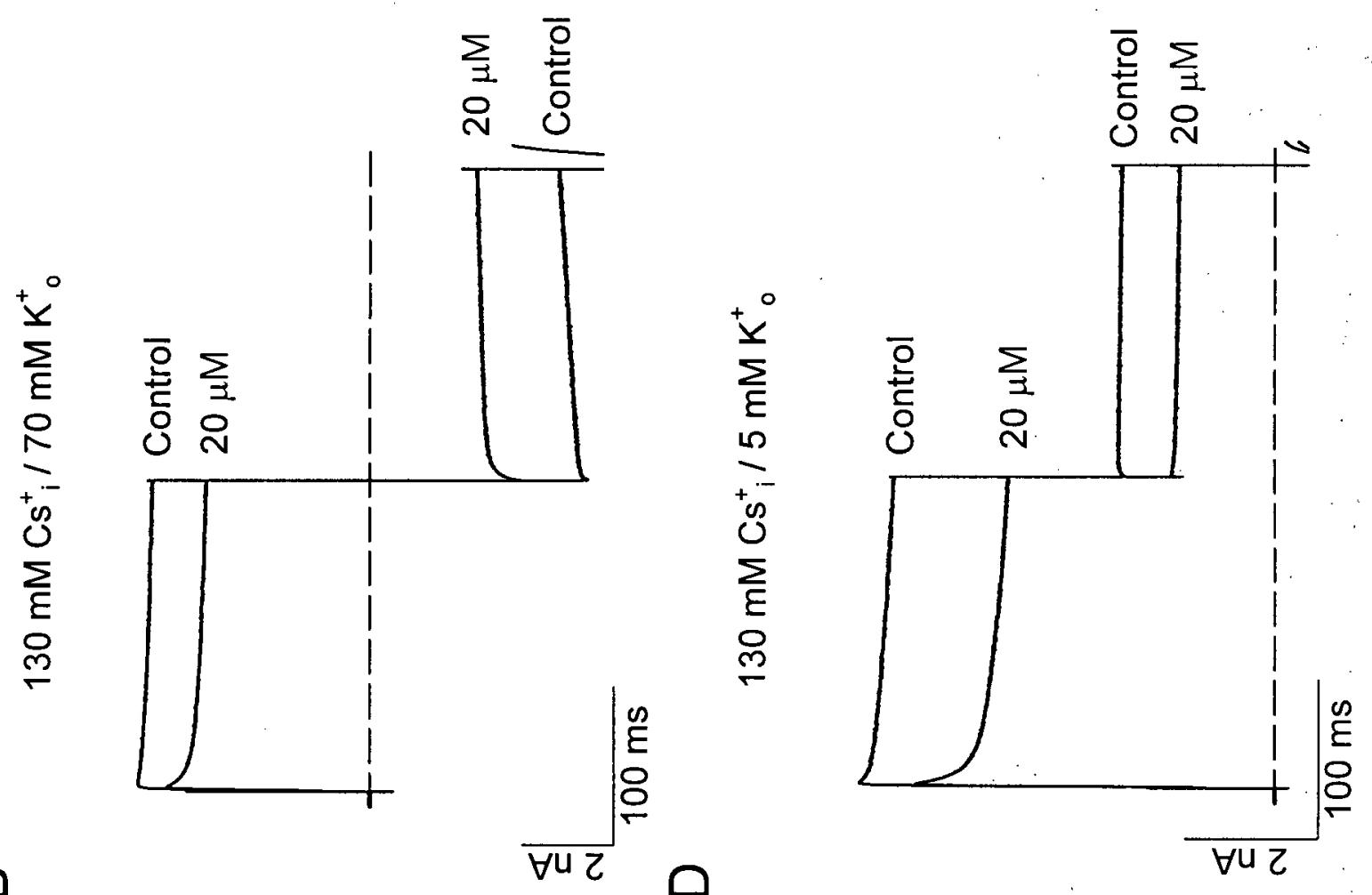

$m$

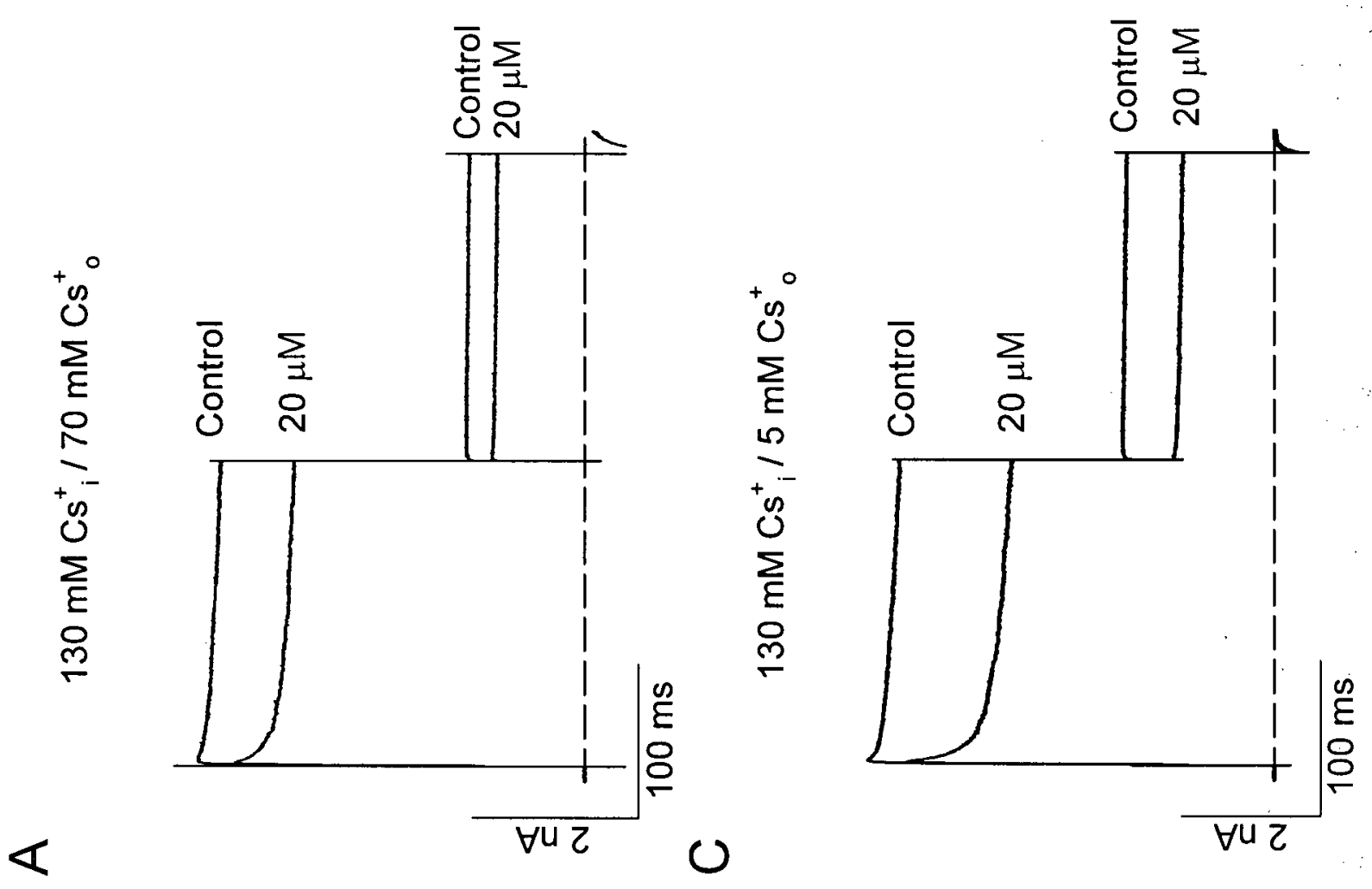


Figure 2.6. Quantification of permeating ion modulation of nifedipine block. The normalized unblocked steady-state currents $\left(\mathrm{I}_{\text {nif }} / \mathrm{I}_{\text {ctrl }}\right)$ left after the prepulse in left bars $(200 \mathrm{~ms})$ and second pulse to $+30 \mathrm{mV}$ in right bars (at $400 \mathrm{~ms})$ from data in Fig. 2.5. The data are mean \pm S.E $(\mathrm{n}=6$ 12). In all cases the internal solution was $135 \mathrm{mM} \mathrm{Cs}^{+}$. External solutions in each case are shown on the abscissa. No significant differences were noted between columns except as noted by * $(\mathrm{P}<0.05)$. 
0
ํ.
$\stackrel{ }{5}$
믄

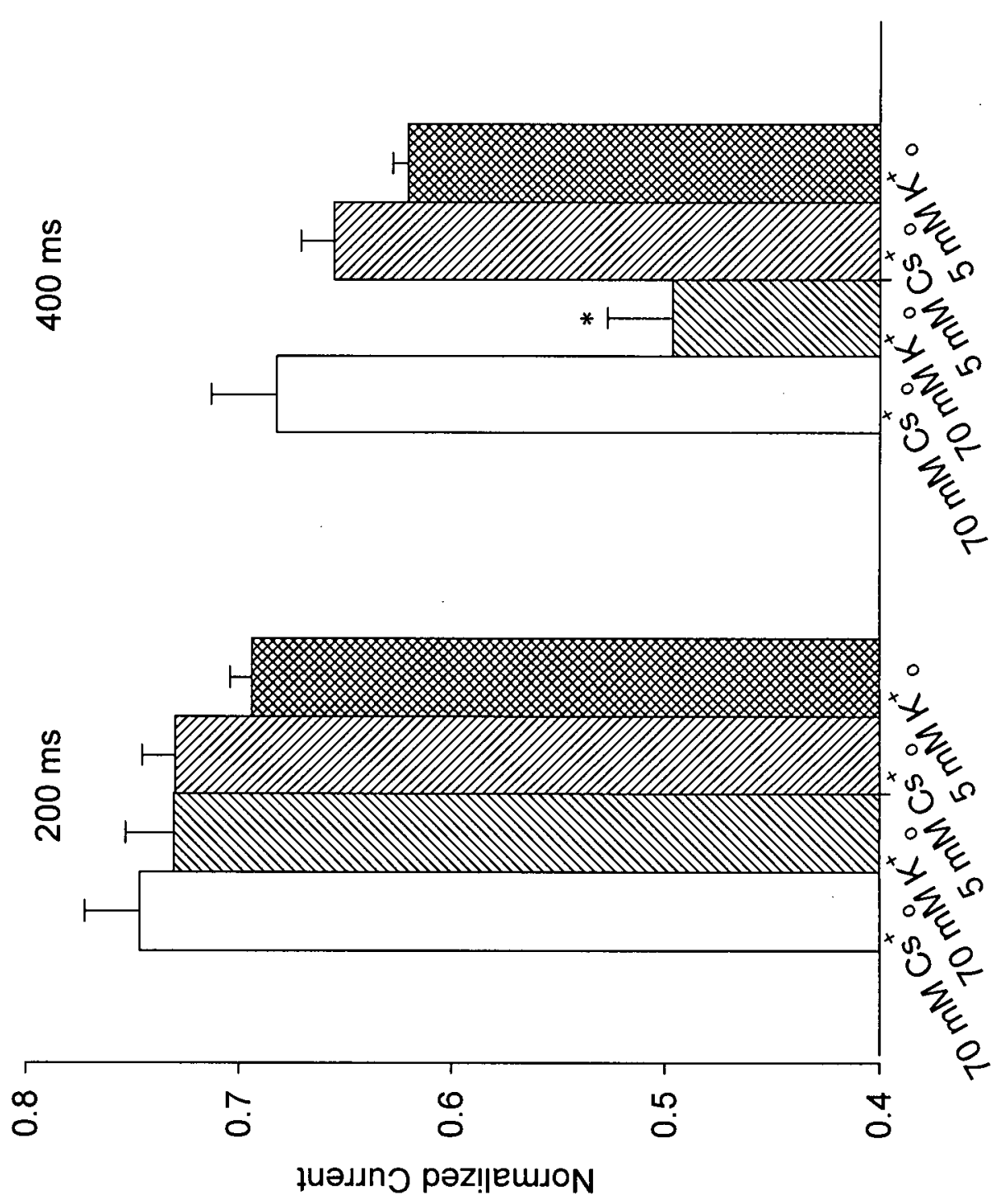


The above experiments strongly support a pore blocking action of nifedipine in Kv1.5. We wished to extend these experiments in a significant way by utilizing deep pore and outer pore mutants of Kv1.5. The first of these was the non-conducting mutant (NCM) of Kv1.5, W472F. This single point mutant prevents ion permeation through the pore but otherwise gates normally as demonstrated in Kv1.5 (Chen et al., 1997) and in Drosophila Shaker channels (Perozo et al., 1993). This mutant allows ions to be changed independently on each side of the membrane with the knowledge that they cannot cross the pore to influence nifedipine block on the other side. NCM function is measured by recording gating currents as an index of channel gating and opening, as we have shown before (Hesketh \& Fedida, 1999; Wang et al., 1999).

In these experiments the cation species on each side of the membrane was changed independently and the action of nifedipine tested on the return of gating current ( $\operatorname{Ig}_{\mathrm{off}}$ ) on repolarization. Channel block can be measured as a slowed return of gating charge on repolarization, as channel closing is slowed until the drug dissociates (Zhang et al., 1997). Such effects are clearly seen in the original data in panels A-F of Fig. 2.7. There is a prominent cross over of off-gating currents as they decay to the baseline in control and nifedipine (e.g. Fig. 2.7AC) as a result of slowed closing of the channel in the presence of drug. With $\mathrm{K}_{\mathrm{i}}^{+}$or $\mathrm{K}^{+}{ }_{\mathrm{o}}$ (Fig. 2.7A,D) the off-gating currents were greatly reduced and slowed in the presence of nifedipine, and mean data in Fig. 2.7F show that the reduction of $\operatorname{Ig}_{\text {off }}$ was significantly $(\mathrm{P}<0.05)$ greater when extracellular $\mathrm{K}^{+}$was present $(72.9 \pm 3.5 \%)$ than when intracellular $\mathrm{K}^{+}$was present $(59.6 \pm$ $4.3 \%$ ). When other cations were present in the bath or pipette solutions, less block of $\operatorname{Ig}_{\text {off }}$ was observed (Fig. 2.7H, I). For $\mathrm{Rb}^{+}{ }_{\mathrm{i}}$ and $\mathrm{Rb}^{+}{ }_{0}$ the reductions were $50.1 \pm 3.5 \%$, and $57.9 \pm 3.1 \%$ respectively, and for $\mathrm{Cs}^{+}{ }_{\mathrm{i}}$ and $\mathrm{Cs}^{+}{ }_{\mathrm{o}}$ the reductions were $41.1 \pm 3.8 \%$, and $35.1 \pm 6.4 \%$ respectively. These differences were also statistically significant by ANOVA $(\mathrm{P}<0.001)$ between all external cations, and between $\mathrm{Cs}^{+}{ }_{\mathrm{i}}$ and $\mathrm{K}_{\mathrm{i}}^{+}$or $\mathrm{Rb}^{+}{ }_{\mathrm{i}}$. These data confirm the ionic current data described earlier, that nifedipine is a more potent blocker of $\mathrm{Kv} 1.5$ channels when $\mathrm{K}^{+}$is present 
Figure 2.7. Ion modulation of nifedipine block of gating current in Kv1.5-W427F. A-F, offgating currents in control and in the presence of $100 \mu \mathrm{M}$ nifedipine under different ionic conditions as indicated above each panel. In each case on-gating currents were unchanged in the presence of nifedipine (data not shown). G-H, mean peak off-gating current data from panels AF. Data are shown normalized to peak Igoff in control. * significant difference between intracellular and extracellular data, $\mathrm{P}<0.05$. One way ANOVA was performed on all data and revealed that $\mathrm{K}_{\mathrm{i}}^{+}$was significantly different from $\mathrm{Cs}_{\mathrm{i}}^{+}$, and that $\mathrm{Cs}^{+}{ }_{\mathrm{o}}$ was significantly different from $\mathrm{K}_{\mathrm{o}}^{+}$and $\mathrm{Rb}^{+}{ }_{0}$. 

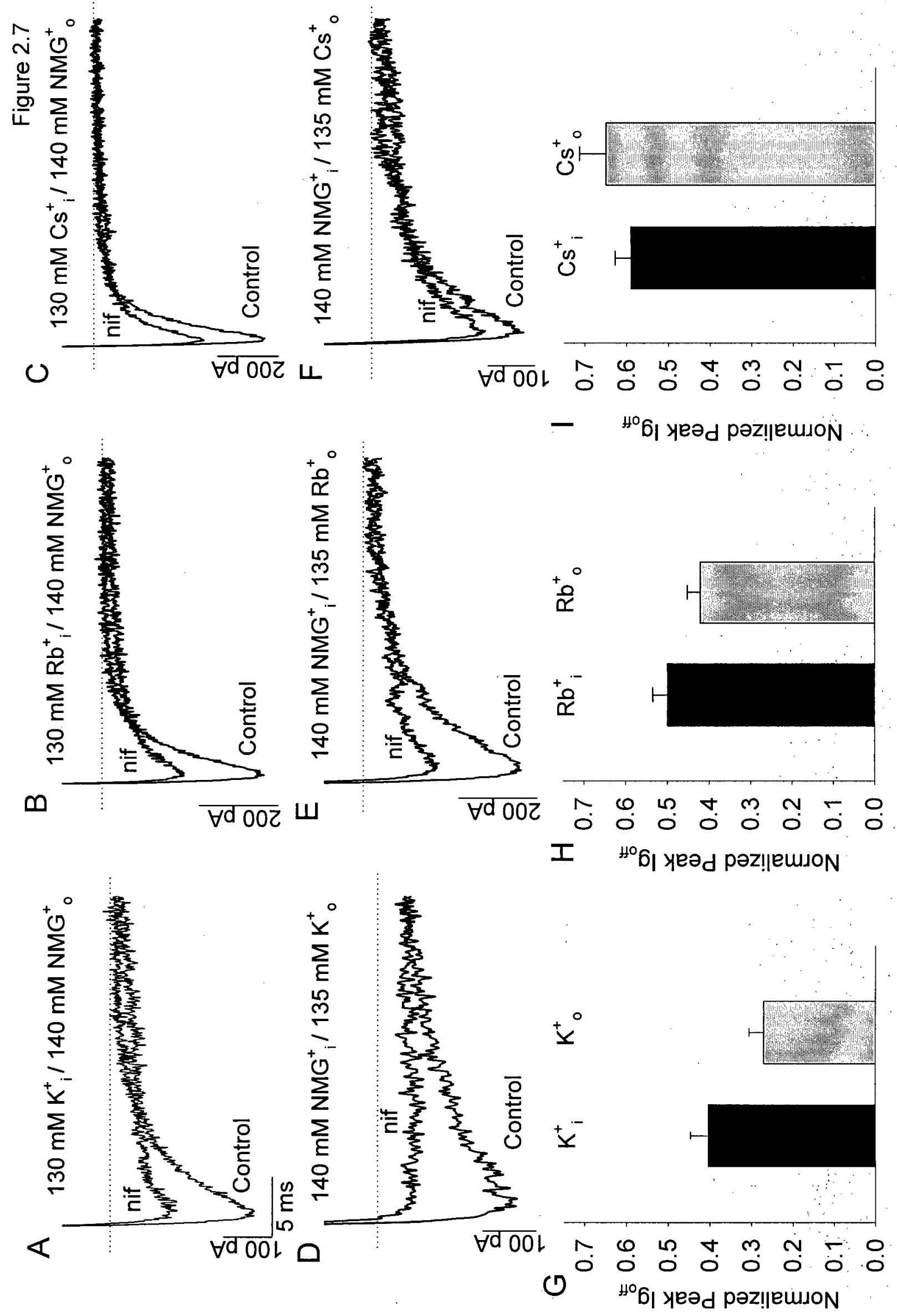
than when $\mathrm{Rb}^{+}$or $\mathrm{Cs}^{+}$are present. They also indicate that extracellular $\mathrm{K}^{+}$allows greater block of Kv1.5 by nifedipine than intracellular $\mathrm{K}^{+}$.

The second mutant series that we have analyzed changes the outer mouth R487. This charged residue in Shaker channels is T449 (Lopez-Barneo et al., 1993) and is known to be a potent modulator of C-type inactivation as well as external TEA ${ }^{+}$block in Shaker channels (Heginbotham \& MacKinnon, 1992). A number of these mutants failed to express measurable current when transiently transfected into HEK cells, but two notable mutants were R487V and R487Y. Interestingly these two mutants were those found by Lopez-Barneo et al. (Lopez-Barneo et al., 1993) to inhibit the development of C-type inactivation most strongly. The effects of nifedipine on

$\mathrm{Cs}^{+}, \mathrm{Rb}^{+}$, and $\mathrm{K}^{+}$currents through $\mathrm{R} 487 \mathrm{~V}-\mathrm{Kv} 1.5$ expressed in HEK cells are shown in Fig. 2.8. At $+40 \mathrm{mV}$ it is immediately apparent that the effect of nifedipine was reduced in this mutant compared with the wild-type channel where the $\mathrm{IC}_{50}$ for inhibition of $\mathrm{K}^{+}$current was $7.3 \mu \mathrm{M}$. Similarly, nifedipine was a less potent blocker of $\mathrm{Rb}^{+}$and $\mathrm{Cs}^{+}$currents than in the WT channel. Overall, the $\mathrm{IC}_{50}$ values were increased to $20.2,30.4$, and $50.7 \mu \mathrm{M}$ for $\mathrm{K}^{+}, \mathrm{Rb}^{+}$, and $\mathrm{Cs}^{+}$currents respectively. Along with the increased $\mathrm{IC}_{50}$ values, the Hill slope was increased from that seen in the wild-type channel (Fig. 2.3) to $\sim 1.6$. The block of R487Y-Kv1.5 $\mathrm{K}^{+}$currents by nifedipine was also tested. The $\mathrm{IC}_{50}$ value was $21.6 \pm 0.4 \mu \mathrm{M}$ and the Hill coefficient was $1.4 \pm 0.03(\mathrm{n}=6)$. These values are in close agreement with those obtained from the R487 mutant. It is known that these changes to the equivalent residue in Shaker channels results in quite local changes at the outer pore mouth which supports the idea that nifedipine effects on the channel depend upon interactions in this outer mouth region of the channel.

\section{4d. A less potent action of nifedipine on Kv4.2}

The observation that substitution of valine or tyrosine for arginine in the outer pore mouth of Kv1.5 reduced the $\mathrm{IC}_{50}$ for nifedipine action significantly to $20 \mu \mathrm{M}$, prompted us to examine other $\mathrm{Kv}$ 
Figure. 2.8. An external pore $\mathrm{R} 487 \mathrm{~V}$ mutant reduces nifedipine block. In all cases pulses were from $-80 \mathrm{mV}$ to $+40 \mathrm{mV}$ for $400 \mathrm{~ms}$. A) $\mathrm{K}^{+}$currents; B) $\mathrm{Rb}^{+}$currents; C) $\mathrm{Cs}^{+}$currents. As indicated adjacent to the tracings in each panel, currents show block by different concentrationis of nifedipine between 2 and $500 \mu \mathrm{M}$. In each panel data are from the same cell. D) The concentration-response curve for steady-state block of $\mathrm{K}^{+}, \mathrm{Rb}^{+}$, and $\mathrm{Cs}^{+}$currents, lines were fit to the data using the Hill equation. The $\mathrm{IC}_{50}$ values for each ion are indicated. The Hill coefficients were $1.64,1.66$, and 1.57 for $\mathrm{K}^{+}, \mathrm{Rb}^{+}$, and $\mathrm{Cs}^{+}$respectively. The dotted lines represent the concentration-response relations for WT channels redrawn from Fig. 2.3. 


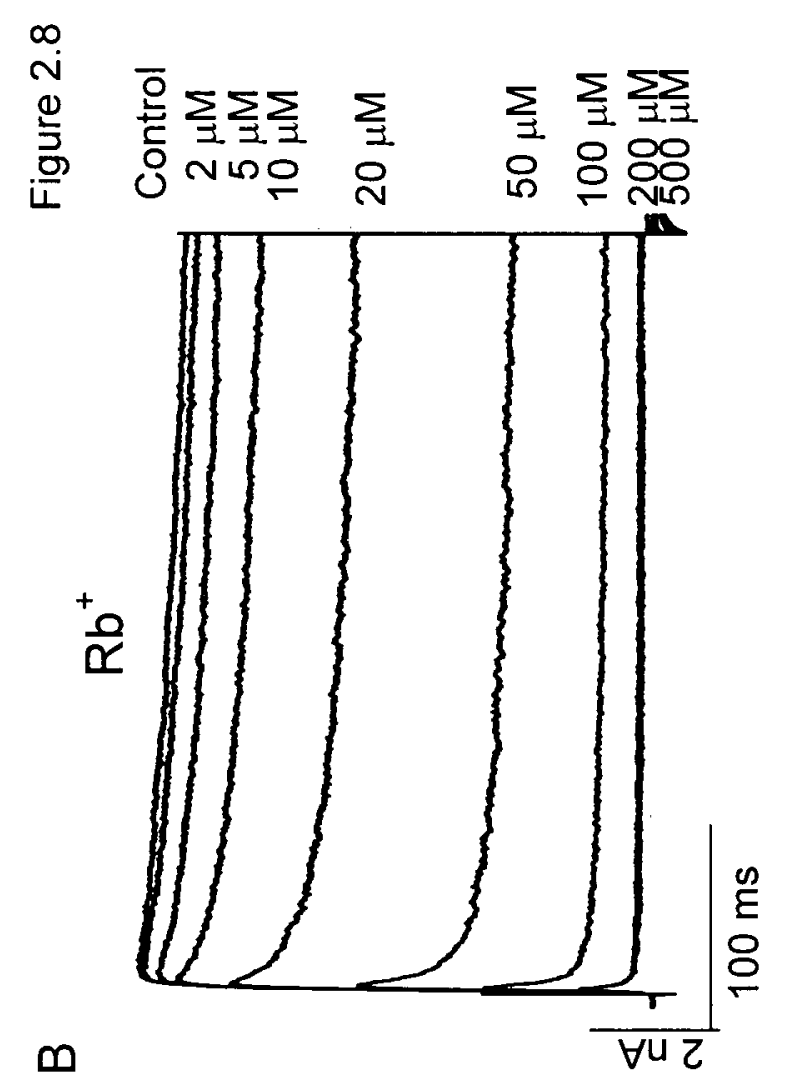

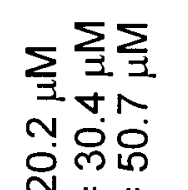

तั

11 웅요

ง

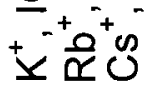

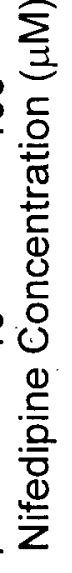

$\infty$
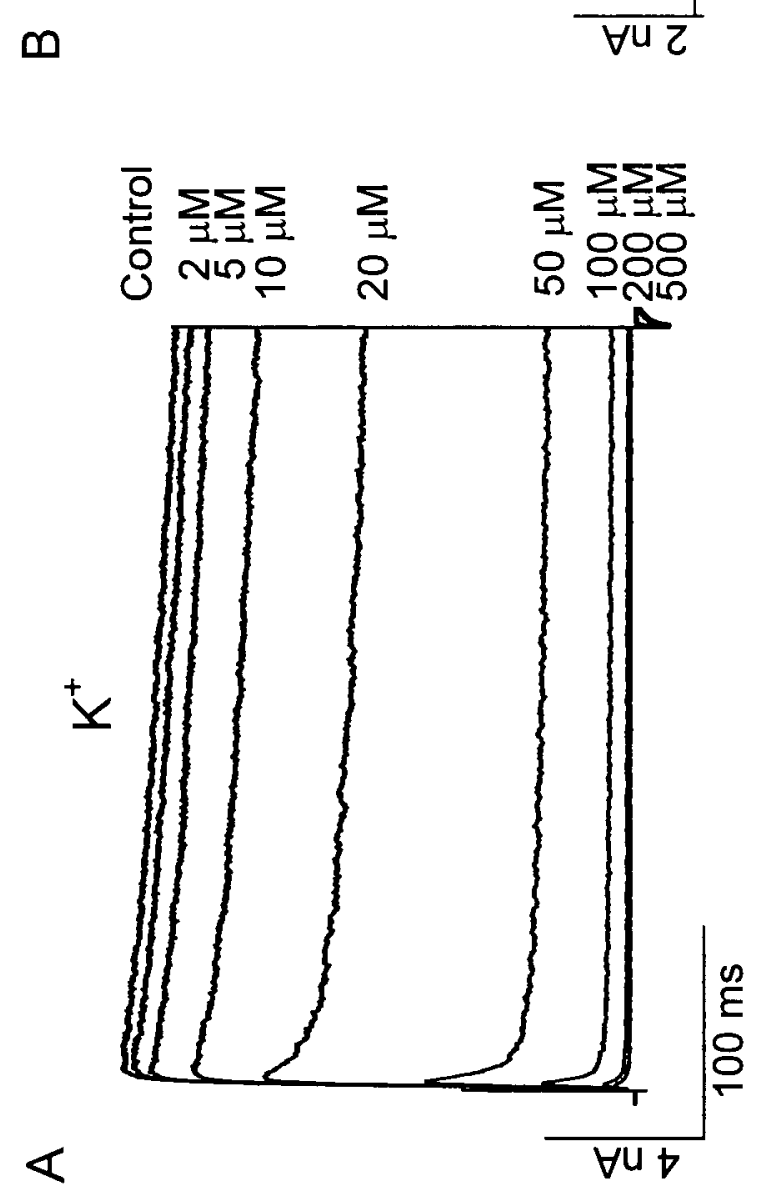

就

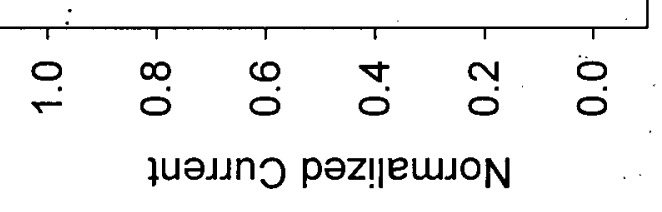

응
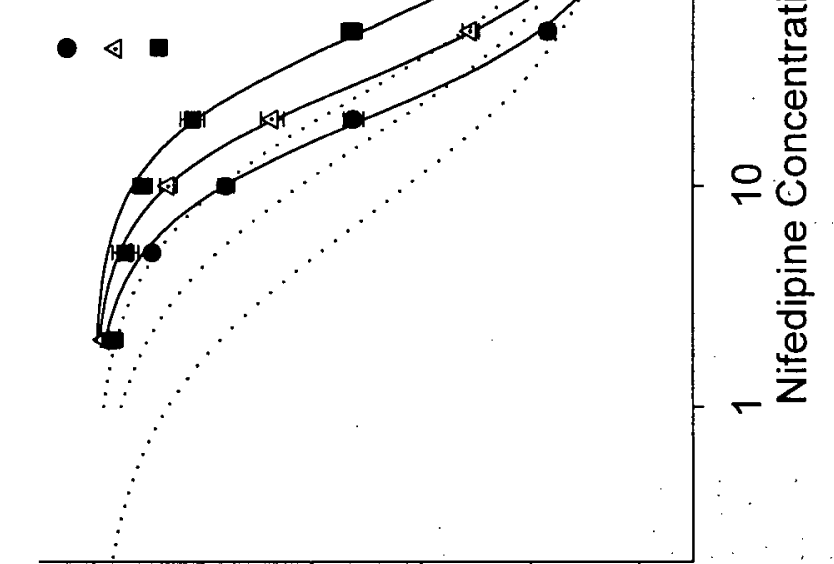

is
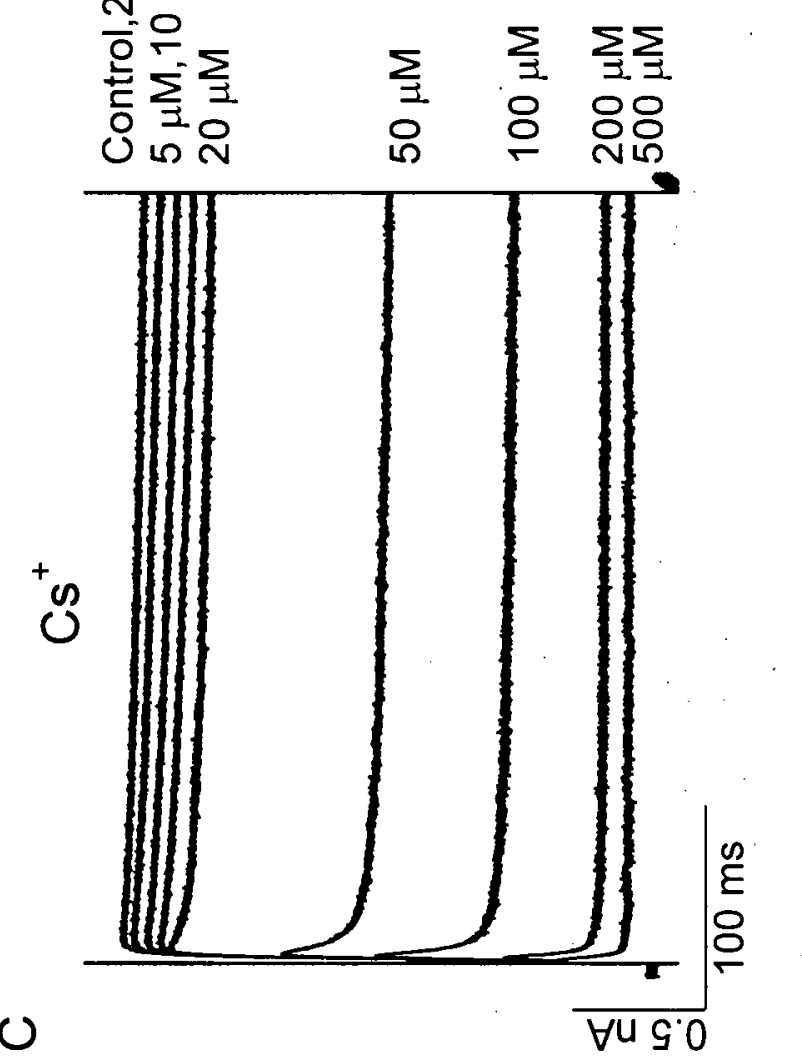
channels with a valine at this position. In a Shaker B $\mathrm{T} 449 \mathrm{~V}$ mutant channel an $\mathrm{IC}_{50}$ of $\sim 30 \mu \mathrm{M}$ was noted (Avdonin et al., 1997). The Shal channel Kv4.2 also has a valine at this equivalent position and so we tested the ability of nifedipine to block this channel (Fig. 2.9). The rat Kv4.2 gene was stably expressed in HEK cells, and currents were recorded in the whole cell configuration as for Kv1.5. The Kv4.2 gene encodes an A-type rapidly inactivating outward $\mathrm{K}^{+}$current and block by nifedipine can be measured as peak current reduction (as nifedipine block is of rapid onset), or as an overall reduction in charge during the pulse. When currents were integrated over time, we obtained charge records as shown in Fig. 2.9B, obtained from the current recordings in Fig. 2.9A. The concentration-response relations for peak current block and charge reduction by nifedipine are shown in Fig. 2.9C. Both relations have similar $\mathrm{IC}_{50}$ values of 32 and $29 \mu \mathrm{M}$ for peak current and charge reduction respectively with Hill coefficients of 0.9 . We applied the same single binding site model to the Kv4.2 data as was applied to results from Kv1.5 (Fig. 2.4). For $\mathrm{Kv} 4.2 \mathrm{~K}^{+}$currents, bi-exponential functions were required to fit the current decay both in the control and presence of nifedipine. Table 2.2 shows the slow component of Kv4.2 inactivation did not change with the addition of nifedipine, suggesting that the drug did not change the inactivation rate. However, the time constant of the initial fast component was decreased depending on drug concentration, suggesting an overlap between drug block and the initial fast inactivation component. If nifedipine block and inactivation are independent, the rate constants of the initial fast-decaying phase of Kv4.2 currents $\left(1 / \tau_{\text {decay }}\right)$ in the presence of nifedipine should be a sum of the rate constants of channel inactivation $\left(1 / \tau_{\text {inactivation }}\right)$ and of channel block $\left(1 / \tau_{\text {block }}\right)$ (Slawsky \& Castle, 1994) as follows:

$$
1 / \tau_{\text {decay }}=1 / \tau_{\text {block }}+1 / \tau_{\text {inactivation }}
$$


Figure 2.9. Nifedipine block of $\mathrm{Kv} 4.2$. A) $\mathrm{Kv} 4.2 \mathrm{~K}^{+}$currents at $+60 \mathrm{mV}$ from the $-80 \mathrm{mV}$ holding potential in control and the presence of different nifedipine concentrations as indicated. B) Kv4.2 charge at each concentration obtained by time integration of current records in panel A. C) Concentration-response curve for peak Kv4.2 current and charge block by nifedipine. Lines were fit to the data using the Hill equation with $\mathrm{IC}_{50}$ and $\mathrm{n}_{\mathrm{H}}$ values respectively of $28.7 \pm 2.0 \mu \mathrm{M}$, $0.9 \pm 0.1$ (integrated current), and $32.2 \pm 3.2 \mu \mathrm{M}, 0.9 \pm 0.1$ (peak current). Data are mean \pm S.E. $(\mathrm{n}=2-7)$. D) Time constants of Kv4.2 current block by nifedipine. $1 / \tau_{\text {block }}$ at $+60 \mathrm{mV}$ is plotted against concentration. From the fit line, the association rate constant $\left(k_{+1}\right)$ is $2.09 \times 10^{6} \mathrm{M}^{-1} \mathrm{~s}^{-1}$, and the dissociation rate constant $\left(\mathrm{k}_{-1}\right)$ is $57.9 \mathrm{~s}^{-1}$. The $\mathrm{K}_{\mathrm{d}}$ is $27.7 \mu \mathrm{M}$. Data points are means \pm S.E. $(n=2-10)$ 

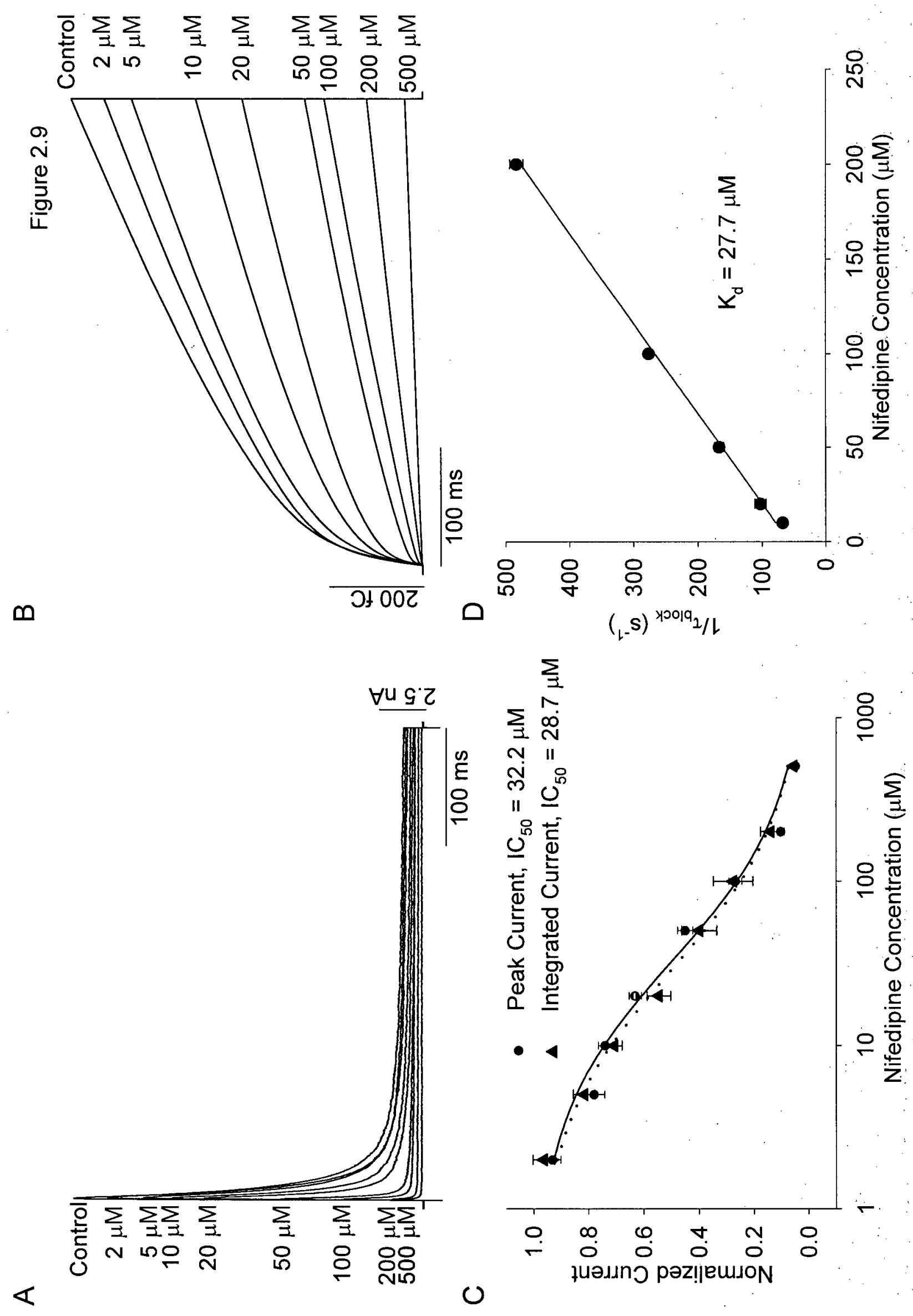
Table 2.2. The time constants of Kv4.2 current decay in the absence or presence of nifedipine

\begin{tabular}{ccc}
\hline $\begin{array}{c}\text { Nifedipine } \\
\text { concentration }(\mu \mathrm{M})\end{array}$ & $\tau_{1}(\mathrm{~ms})$ & $\tau_{2}(\mathrm{~ms})$ \\
\hline 0 & $62.6 \pm 1.4$ & $9.0 \pm 0.2$ \\
10 & $60.3 \pm 1.7$ & $5.5 \pm 0.2$ \\
20 & $55.9 \pm 4.0$ & $4.7 \pm 0.2$ \\
50 & $61.0 \pm 5.9$ & $3.5 \pm 0.1$ \\
100 & $69.2 \pm 9.1$ & $2.5 \pm 0.04$ \\
200 & $74.9 \pm 10.5$ & $1.7 \pm 0.03$ \\
\hline
\end{tabular}

The Kv4.2 currents in the absence or presence of nifedipine were fit by a double exponential.

The two time constants were shown in the table with different concentrations of nifedipine. The time constants of slow component were not significantly different in the absence or presence of nifedipine $(P>0.05)$. The data are means \pm S.E $(\mathrm{n}=3-7)$. 
Thus, the value of $1 / \tau_{\text {block }}$ can be estimated by subtracting the rate constant of the inactivation $\left(1 / \tau_{\text {inactivation }}\right)$ from $1 / \tau_{\text {decay. }}$. Assuming the inactivation process was not changed by nifedipine, we calculated $1 / \tau_{\text {block }}$ and plotted it as a function of nifedipine concentration in Fig. 2.9D. We fit the data with equation [2a] and extracted $\mathrm{k}_{+1}\left(2.09 \times 10^{6} \mathrm{M}^{-1} \mathrm{~s}^{-1}\right), \mathrm{k}_{-1}\left(57.9 \mathrm{~s}^{-1}\right)$ and the $\mathrm{K}_{\mathrm{d}}(27.7 \mu \mathrm{M})$ from the straight line fits. The $\mathrm{K}_{\mathrm{d}}$ value matched that obtained from the concentration-response relation (Fig. 2.9C), and suggested that the assumption of the model was correct. These Kv4.2 results support the idea that a valine (or a tyrosine in Kv1.5), rather than arginine at the outer pore mouth can reduce the affinity of $\mathrm{Kv}$ channels for nifedipine. 


\subsection{DISCUSSION}

\section{5a. Influence of permeating ions on Kv1.5 channel block by nifedipine}

It has been reported that permeating ions can affect the efficacy of channel block by TEA ${ }^{+}$ (Ikeda \& Korn, 1995; Block \& Jones, 1997). In cloned Kv2.1 channels, external application of 30 $\mathrm{mM} \mathrm{TEA}^{+}$can block $\mathrm{K}^{+}$currents by $87 \%$, while the same external concentration of TEA ${ }^{+}$has no effects on $\mathrm{Na}^{+}$currents through the same channel (Ikeda \& Korn, 1995). As well, in the native delayed rectifier $\mathrm{K}^{+}$channel from bullfrog sympathetic neurons, $\mathrm{K}^{+}$and $\mathrm{Cs}^{+}$currents were blocked by TEA $^{+}$with $\mathrm{K}_{\mathrm{d}}$ 's of 1.8 and $3.4 \mathrm{mM}$, respectively (Block \& Jones, 1997), showing that cation species has significant effects on the blocking affinity of charged drugs. The influence of $\mathrm{K}^{+}, \mathrm{Rb}^{+}$ and $\mathrm{Cs}^{+}$on Kv1.5 channel block by nifedipine has not been studied before. Here we have shown that, like TEA $A^{+}$, nifedipine also has a different potency for block of $\mathrm{K}^{+}, \mathrm{Rb}^{+}$and $\mathrm{Cs}^{+}$currents through another Kv channel, Kv1.5 (Figs. 2.1-4). It is possible that nifedipine binds with the same affinity to channels that pass both $\mathrm{K}^{+}$and $\mathrm{Cs}^{+}$, and that the larger cation can more easily escape the blocker and pass through the channels. The pore configuration that would allow this possibility is uncertain, and data in Fig. 2.5B showed increasing block of the inward current during the switch from outward $\mathrm{Cs}^{+}$to inward $\mathrm{K}^{+}$current. It suggested that the nifedipine binding affinity was different in the presence of different ions.

In Kv1.5 the differences in block of the different cation currents can be explained based on changes in the nifedipine binding site, or availability of the site for nifedipine. When $\mathrm{K}^{+}, \mathrm{Rb}^{+}$and $\mathrm{Cs}^{+}$ions permeate through $\mathrm{Kv} 1.5$ channels their different sizes induce unique conformational changes in the structure of the pore which might affect the binding site of nifedipine itself, or the ability of nifedipine to access such a site. In the latter case, the binding site(s) of permeating ions within the channel pore could be close to the binding site of nifedipine, and the larger cations might 
affect access of nifedipine to its binding site, by steric hindrance. We had previously reported that nifedipine blocked Kv1.5 with an apparent distance of $12-16 \%$ of the electric field from the outside (Zhang et al., 1997). It was suggested in Fig. 2.2 that there was no apparent change in the voltagedependence of block with the three different cations, which suggests that nifedipine's site of action in the outer pore mouth had not significantly moved. A single binding site model was still appropriate to describe the kinetics of nifedipine block by the three different cations. The slopes of the concentration-response relations had Hill coefficients close to 1.0 (Fig. 2.3), and the concentration-dependence of the acceleration of current decay by the drug produced values for onand off-drug binding rates and $\mathrm{K}_{d}$ that closely fitted a single site model (Fig. 2.4). This also validated an open-channel block mechanism by nifedipine in the presence of the three different cations.

\section{5b. Site of nifedipine action on Kv1.5}

Nifedipine action on Kv1.5 appears to be closely tied to the ion conduction pathway. The drug does not block closed channels, but rapidly blocks open channels causing a rapid current decay superimposed on slower inactivation, when activation is sufficiently rapid to allow this to be seen (Fig. 2.1). The influence of different permeating cations on the rate and potency of the block of ionic and gating currents is further evidence for effects within the open pore. In conducting channels, when $\mathrm{K}^{+}$was the permeating cation as in Fig. $2.5 \mathrm{~B}$ at $+30 \mathrm{mV}$, block was more extensive than when $\mathrm{Cs}^{+}$was the permeating cation. Overall, the data showed that the permeating cation was the most important determinant of block (Fig. 2.6). When ion permeation was prevented in the W472F non-conducting mutant, and gating currents were measured (Fig. 2.7), it was shown that extracellular $\mathrm{K}^{+}$allows greater block of $\mathrm{Kv} 1.5$ by nifedipine than other extracellular cations. The potency of nifedipine used to block off-gating currents is lower than that for ionic currents. In the presence of external $135 \mathrm{mM} \mathrm{Cs}^{+}$, the $\mathrm{IC}_{50}$ of nifedipine is about 80 
$\mu \mathrm{M}$ (Data not shown). The change of nifedipine binding affinity in the NCM may be related to the conformational changes in the deep pore of the channels, which extend into the external mouth of the pore and affect the access of nifedipine to the binding site. This evidence suggests that deep pore conformation is important in determining the nifedipine binding affinity. In the presence of $100 \mu \mathrm{M}$ nifedipine, the gating currents were measured under different ion conditions. Here extracellular $\mathrm{K}^{+}$was able to co-ordinate a more potent action of nifedipine than intracellular $\mathrm{K}^{+}$(Fig. 2.7G), although the pore mutant reduced the effect of ions on nifedipine block. Interestingly, though, in these experiments, addition of only intracellular $\mathrm{K}^{+}$or $\mathrm{Rb}^{+}$was able to coordinate a relatively potent block of off-gating current by nifedipine. This suggested that even intracellular ions were able to have long range effects on overall pore conformation and affect the formation of the nifedipine binding site in the outer channel mouth, without being present there.

\section{5c. Pore mutants and their effects}

Two outer pore mutants, R487V, and R487Y-Kv1.5 both affected the concentrationdependence of nifedipine block of the channel. Low concentrations of nifedipine were much less effective on these mutant channels, regardless of the ionic species, but there was a steepening of the concentration-response relationships so that at higher concentrations nifedipine apparently blocked the channel to the same degree as the wild-type channels, and the overall efficacy was unchanged (Fig. 2.8). The ion-dependent shift in the $\mathrm{IC}_{50}$ of the concentration-response relations was maintained but reduced in relative terms, so that whereas $\mathrm{Cs}^{+}$was four-fold less potent in the WT channels, it was two and a half times less potent in the R487V mutant. This result suggested that the ion effects on nifedipine potency could be separated to a large degree from effects of outer pore mutations on nifedipine binding to Kv1.5, and that ion species effects were not caused 
by ion interaction directly at the nifedipine binding site. This argues against a common site for nifedipine block and ion modulation of block in Kv1.5.

The steepening of the concentration-response relations in the R487V mutant increased the Hill coefficients from $\sim 1$ to $\sim 1.6$ and suggested that the mutation was able to significantly alter the mechanism by which nifedipine binds to Kv1.5. It is possible that substitution of the positively charged arginine by the hydrophobic valine or the planar ring of tyrosine residues facilitates additional molecules of nifedipine binding to the channel. Overall affinity is reduced as evidenced by the decreased potency, but once a raised nifedipine concentration is present at the outer pore mouth, it is possible that the binding of a second nifedipine is facilitated and channel block is enhanced. The valine substitution in Shaker channels results in a similar potency to that in Kv1.5 (Avdonin et al., 1997), and a similarly low potency was observed in our experiments in Kv4.2 channels which have a valine at the equivalent site to R487 in Kv1.5 (Fig. 2.9). In this situation, though, the presence of valine per se does not confer a co-operative action of nifedipine, and the concentration-response relation had a Hill coefficient close to 1.0 (Fig. 2.9C). Analysis of decay time constants of Kv4.2 currents in nifedipine confirmed that a single binding site model was adequate to explain nifedipine block of Kv4.2 (Fig. 2.9D). 
CHAPTER III

NIFEDIPINE BLOCK AND C-TYPE INACTIVATION 


\subsection{ABSTRACT}

In the previous chapter, we showed that external pore mutants affected nifedipine block of Kv1.5. Our lab has also reported that ion species can affect C-type inactivation of Kv1.5. Further experimental data suggested that nifedipine block can be separated from C-type inactivation of $\mathrm{Kv} 1.5$. Although changing the external pore residue can affect C-type inactivation of $\mathrm{Kv}$ channels, the normalized reduction and time course of currents blocked by nifedipine in $5 \mathrm{mM} \mathrm{K}_{0}^{+}, 135$, and $300 \mathrm{mM} \mathrm{K}^{+}$was the same. Similarly, a mean recovery time constant from nifedipine block of 316 ms was unchanged ( $332 \mathrm{~ms}$ ) after $5 \mathrm{~s}$ prepulses to allow C-type inactivation. This is consistent with the conclusion that nifedipine block and C-type inactivation in the Kv1.5 channel can coexist, but are mediated by distinct mechanisms coordinated by outer pore conformation. 


\subsection{INTRODUCTION}

As described in Chapter I, $\mathrm{Kv}$ channels show a rapid $\mathrm{N}$-type inactivation or a slower C-type inactivation. One property of $\mathrm{Kv} 1.5$ channel current was the slow C-type inactivation that occurs during a maintained depolarizing voltage step. C-type inactivation can be affected by factors such as elevation of $\mathrm{K}^{+}{ }_{0}$ concentration (Baukrowitz \& Yellen, 1995; Lopez-Barneo et al., 1993), external application of TEA ${ }^{+}$(Grissmer \& Cahalan, 1989; Choi et al., 1991) and mutations of particular amino acids in the channel pore (DeBiasi et al., 1993; Lopez-Barneo et al., 1993; Panyi et al., 1995). These effects have been incorporated into a physical model where C-type inactivation is caused by the constriction of the outer mouth of the channel pore in a co-operative action of all four subunits (Yellen et al., 1994), that restricts $\mathrm{K}^{+}$flux (Ogielska et al., 1995; Panyi et al., 1995). This rearrangement of the outer mouth of the pore greatly reduces the permeability of $\mathrm{K}^{+}$relative to the permeability of $\mathrm{Na}^{+}$, altering the ion selectivity of the channel (Starkus et al., 1997). Recently it has been further proposed that during C-type inactivation the channels dwell in at least three conformational states; an initial open state that is highly selective for $\mathrm{K}^{+}$, a state that is less permeable to $\mathrm{K}^{+}$and more permeable to $\mathrm{Na}^{+}$, and then a state that is non-conducting (Immke et al., 1999; Loots \& Isacoff, 1998). In earlier work during this project, in collaboration with others, I carried out experiments to show that ion species can affect C-type inactivation in Kv1.5 (Fedida et al., 1999).

In the previous chapter, we argued that the nature of the permeant ion does affect the dosedependence and kinetics of nifedipine block of Kv1.5 channels. Outer pore mutations of R487 reduce the nifedipine affinity for Kv1.5 channel in a manner consistent with other channels that have a valine at equivalent sites. The ion species and external pore residues can also affect C-type inactivation of Kv1.5. Here we show that nifedipine block, although affected by mutations similar to those known to affect outer pore C-type inactivation, can be shown to be kinetically separate 
from this slow inactivation process. This is based on nifedipine block of Kv1.5 carried out in different $\left[\mathrm{K}^{+}\right]_{\text {o, }}$, and also on the effects of nifedipine on the recovery rates from C-type inactivation. 


\subsection{MATERIALS AND METHODS}

Cell culture methods, electrophysiological solutions, and electrophysiological procedures are similar with those in Chapter II, except the elevated external $\mathrm{K}^{+}$solutions contained (in $\mathrm{mM}$ ) $\mathrm{KCl}, 5,135$, or $300 \mathrm{Na}^{+}$o was reduced accordingly, except for $300 \mathrm{mM}\left[\mathrm{K}_{\mathrm{o}}^{+}\right]$, which was hypertonic compared with the pipette solution.); HEPES, $10 ; \mathrm{MgCl}_{2}, 1 ; \mathrm{pH} 7.4$.

\section{3a. Data Analysis:}

The data for recovery from inactivation with a short initial depolarization was fit using a single exponential equation:

$$
y=A * \exp (-t / \tau)+C
$$

where $\mathrm{A}$ is the amplitude, $\mathrm{t}$ is time from the beginning of the repolarization, $\tau$ is the time constant for the rising phase of the curve and $\mathrm{C}$ is the offset constant. Recovery from C-type inactivation (with a long initial pulse) and nifedipine block were fit using a double exponential equation:

$$
y=A_{2} * \exp \left(-t / \tau_{2}\right)+A_{1} * \exp \left(-t / \tau_{1}\right)+C
$$

in which $\tau_{2}$ and $\tau_{1}$ are the fast and slow time constants of current recovery or block, $\mathrm{A}_{2}$ and $A_{1}$ are the corresponding amplitudes and $C$ indicates the non-inactivating or nifedipine insensitive current. 
Experimental values are given as means \pm S.E.. ANOVA and multiple pairwise comparison were used to test for significant differences between groups. A value of $\mathrm{P}<0.05$ was considered statistically significant. 


\subsection{RESULTS}

\section{4a. Effects of $\mathbf{K}^{+}$on nifedipine block}

Whole-cell $\mathrm{K}^{+}$currents during $5 \mathrm{~s}$ depolarizations to $+40 \mathrm{mV}$ are shown in Fig. 3.1. The current trace in $5 \mathrm{mM} \mathrm{K}^{+}$shows a slow inactivation, which is not complete at the end of a $5 \mathrm{~s}$ depolarizing step. The inactivation process can be fit using a double exponential function (equation [3] in Methods). The resulting fast $\left(\tau_{2}\right)$ and slow $\left(\tau_{1}\right)$ time constants were $250 \mathrm{~ms}$ and $1500 \mathrm{~ms}$ respectively. Increasing $\mathrm{K}_{0}^{+}$to $135 \mathrm{mM}$ slowed the inactivation process in parallel with an obvious reduction in current amplitude due to the decreased $\mathrm{K}^{+}$driving force. After changing to $135 \mathrm{mM}$ $\mathrm{K}_{\mathrm{o}}^{+}$, the time constants of inactivation were $400 \mathrm{~ms}\left(\tau_{2}\right)$ and $1490 \mathrm{~ms}\left(\tau_{1}\right)$, respectively by applying the same double exponential function. Averaged time constants $\tau_{2}$ and $\tau_{1}$ in $5 \mathrm{mM} \mathrm{K}^{+}$and $135 \mathrm{mM}$ $\mathrm{K}^{+}$owere $265 \pm 23 \mathrm{~ms}, 365 \pm 32 \mathrm{~ms}(\mathrm{p}<0.05)$ and $1750 \pm 141 \mathrm{~ms}, 1946 \pm 146 \mathrm{~ms}$, respectively. Data are means \pm SEM from 3-4 experiments. These data support the conclusion that C-type inactivation was slowed somewhat by elevation of $\mathrm{K}^{+}$, and this was caused by an effect on $\tau_{2}$. Current traces from Fig. 3.1A were normalized to peak current and are shown in Fig. 3.1B. This clearly showed that the C-type inactivation process was slower in $135 \mathrm{mM} \mathrm{K}_{\mathrm{o}}^{+}$than in $5 \mathrm{mM} \mathrm{K}^{+}$. In contrast with the effects of external $\mathrm{K}^{+}$on C-type inactivation, activation kinetics were not significantly altered by different external $\mathrm{K}^{+}$concentrations (data not shown).

To investigate whether the time course and reduced C-type inactivation in high $\mathrm{K}^{+}$affected nifedipine block, $20 \mu \mathrm{M}$ nifedipine was applied externally in the presence of $135 \mathrm{mM} \mathrm{K}^{+}$or $5 \mathrm{mM}$ $\mathrm{K}^{+}$. In both conditions, external application of $20 \mu \mathrm{M}$ nifedipine not only markedly inhibited $\mathrm{K}^{+}$ current amplitudes, but also apparently accelerated the decay rates of currents. These are shown clearly in Fig. 3.1A inset on an enlarged time scale. To clarify the relative rates of current decay, 
Figure 3.1. Nifedipine block and C-type inactivation of the $\mathrm{Kv} 1.5$ channel. A) $\mathrm{K}^{+}$currents were elicited from $-80 \mathrm{mV}$ to $+40 \mathrm{mV}$ for $5 \mathrm{~s}$. Current traces were recorded with normal external solution $\left(5 \mathrm{~K}_{\mathrm{o}}^{+}\right)$and in the presence of $20 \mu \mathrm{M}$ nifedipine $\left(5 \mathrm{~K}_{\mathrm{o}}^{+}+\right.$nif), or with $135 \mathrm{~K}_{\mathrm{o}}^{+}$and in the presence of $20 \mu \mathrm{M}$ nifedipine $\left(135 \mathrm{~K}_{\mathrm{o}}^{+}+\right.$nif). inset: traces on an enlarged time scale. B) Current traces from panel A scaled to the peak current level to illustrate inactivation in $5 \mathrm{~K}_{0}^{+}, 135 \mathrm{~K}^{+}$o solutions or block in the presence of $20 \mu \mathrm{M}$ nifedipine under both $\mathrm{K}_{0}^{+}$conditions. C) Nifedipinesensitive currents in $5 \mathrm{~K}_{\mathrm{o}}^{+}$and $135 \mathrm{~K}_{\mathrm{o}}^{+}$solutions. Current traces were obtained from panel A by subtracting control currents in each $\mathrm{K}_{\mathrm{o}}^{+}$and corresponding currents in the presence of $20 \mu \mathrm{M}$ nifedipine. D) Scaled nifedipine-sensitive traces from panel C indicate the similar blocking rate in $5 \mathrm{~K}_{\mathrm{o}}^{+}$and $135 \mathrm{~K}_{\mathrm{o}}^{+}$solutions. 

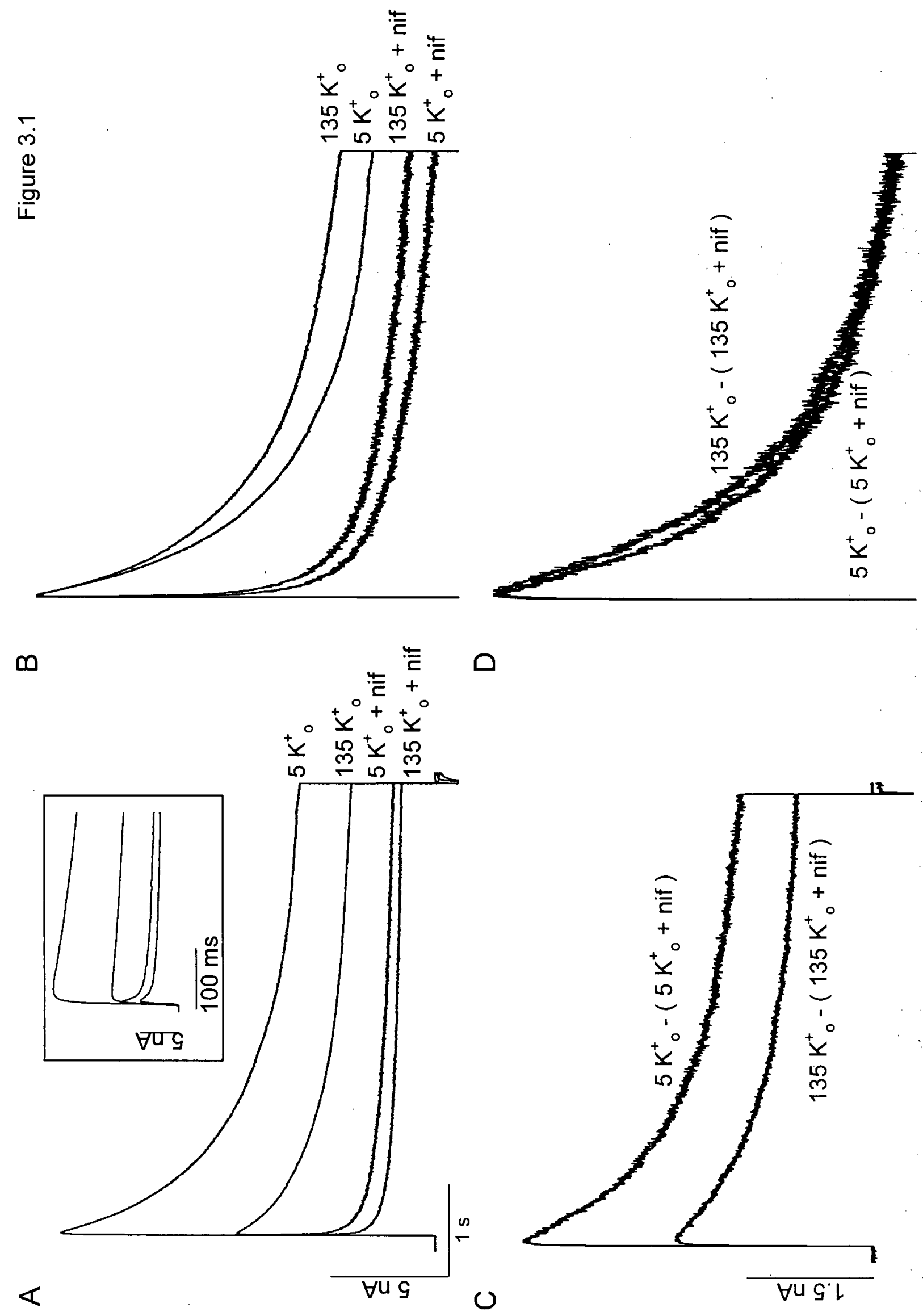
the current traces from Fig. 3.1A were normalized in Fig. 3.1B. In the absence of nifedipine, C-type inactivation in $135 \mathrm{mM} \mathrm{K}^{+}$was slower than that in $5 \mathrm{mM} \mathrm{K}^{+}$. After exposure to $20 \mu \mathrm{M}$ nifedipine, about $70 \%$ of steady-state currents were blocked, regardless of the $\mathrm{K}^{+}$. This observation indicated that the efficacy of current block by nifedipine was not dependent on the external $\mathrm{K}^{+}$concentration. Besides effects on current amplitudes, $20 \mu \mathrm{M}$ nifedipine obviously accelerated current decay in both $5 \mathrm{~K}^{+}$and $135 \mathrm{~K}^{+}$, but the decay was slower in $135 \mathrm{~K}^{+}$than that in $5 \mathrm{~K}_{\mathrm{o}}^{+}$. This could be due to the existence of residual C-type inactivation whose time course was modulated (or slowed) by the elevated external $\mathrm{K}^{+}$concentration. Alternatively, $\mathrm{K}^{+}$might directly influence nifedipine block. Nifedipine-sensitive currents shown in Fig. 3.1C were obtained by subtracting currents in nifedipine from currents in control. When normalized as in Fig. 3.1D, nifedipine sensitive currents showed identical rates of decay. This was consistently observed in three other experiments with $20 \mu \mathrm{M}$ nifedipine, and in experiments with lower and higher nifedipine concentrations. Nifedipinesensitive currents were fit well by a single exponential function (equation [3a]), and the resulting time constants were $1259 \mathrm{~ms}$ and $1150 \mathrm{~ms}$. These comparable time constants in both 5 and 135 $\mathrm{mM} \mathrm{K}^{+}$suggested that the fraction of $\mathrm{K}^{+}$current blocked by nifedipine was independent of the external $\mathrm{K}^{+}$concentration. Therefore, the different decay rates of currents after exposure to $20 \mu \mathrm{M}$ nifedipine shown in Fig. 3.1B resulted from different C-type inactivation kinetics caused by different $\mathrm{K}_{0}^{+}$concentrations rather than an alteration in the kinetics of nifedipine block.

The study was extended to test higher concentrations of $\mathrm{K}^{+}{ }_{0}$ as shown in Fig. 3.2. The aim was to test a series of $\mathrm{K}^{+}$o concentrations in each cell, and this was done by using shorter $400 \mathrm{~ms}$ voltage clamp pulses, and changing the external $\mathrm{K}^{+}$concentration while cells were exposed to a single nifedipine concentration. The normalized current records in Fig. 3.2A, and the bar graph in panel $\mathrm{B}$, summarizing the amount of block caused by $10 \mu \mathrm{M}$ nifedipine at each extracellular $\mathrm{K}^{+}$concentration, show that there was little effect of changing $\mathrm{K}^{+}{ }_{\mathrm{o}}$ on the amount of block 
Figure 3.2. Summary of external $\mathrm{K}^{+}$-dependence of nifedipine block of Kv1.5. A) Currents during $400 \mathrm{~ms}$ voltage steps to $+40 \mathrm{mV}$ from $-80 \mathrm{mV}$. Currents were recorded in 5,135 , and $300 \mathrm{mM} \mathrm{K}^{+}$during exposure to $10 \mu \mathrm{M}$ nifedipine, the tracings were normalized to peak current and are superimposed. B) At different concentrations of $\mathrm{K}_{0}^{+}$, bars show relative block at the end of the voltage pulse. This was calculated from steady nifedipine block (1-(steady-state current in nifedipine / steady-state current in control)). Bars are means \pm S.E., and differences were not significant at the 5\% level (one-way ANOVA). 
ํㅗㅁ

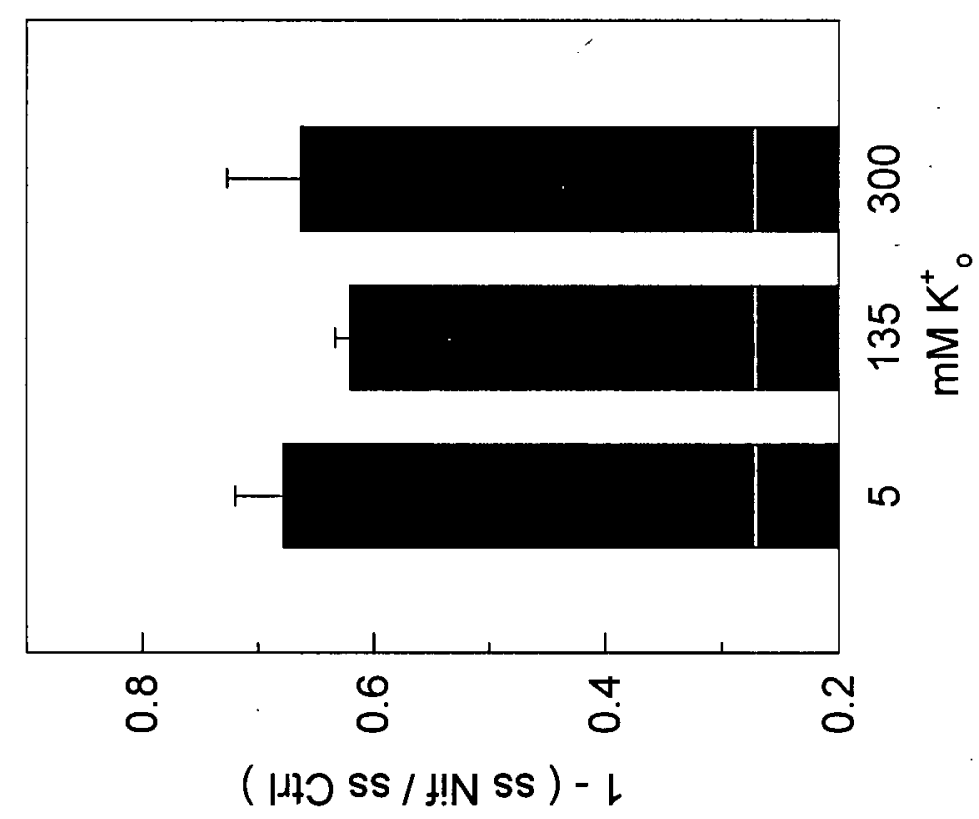

$m$

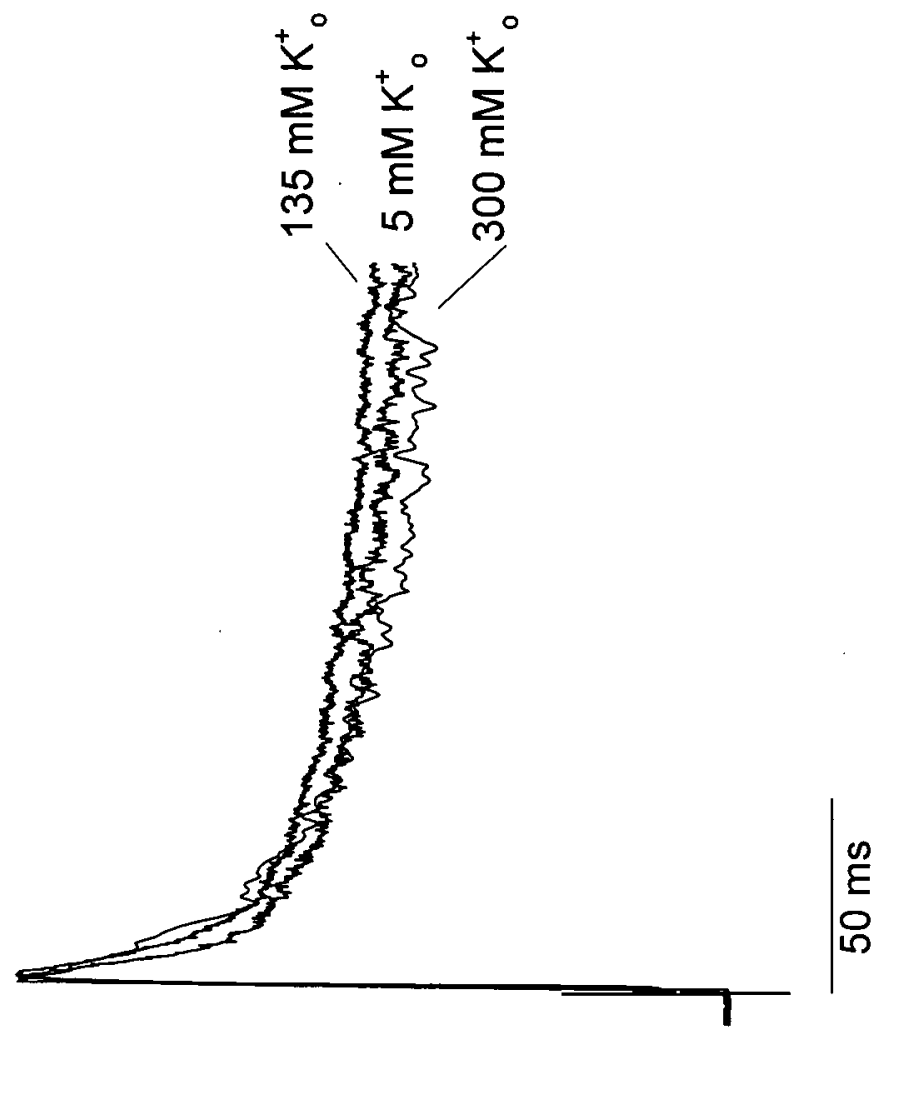


induced by nifedipine. All these results are consistent with the idea that nifedipine block is a distinct process from C-type inactivation. This is further supported by our experiments on recovery from C-type inactivation.

\section{4b. Effects of nifedipine on recovery from C-type inactivation}

To study recovery from C-type inactivation in the absence and presence of nifedipine, a double-pulse voltage protocol was used. The purpose of the first pulse (prepulse) was to predominantly activate (during short prepulses), or to activate and then inactivate the channel (during long prepulses). After a variable interpulse duration, the second pulse (test pulse) was applied to test how many channels had recovered from the inactivated state induced by the prepulse. The fractional recovery was therefore defined as follows: fractional recovery $=I_{\text {peak } 2} / I_{\text {peak } 1}$, where $I_{\text {peak } 1}$ and $I_{\text {peak } 2}$ represent the peak currents elicited by the pre- and test pulse depolarizations, respectively. Current traces shown in Fig. 3.3 were elicited by double-pulse protocols with long and short pulse durations, over a range of interpulse intervals. All pulses were to $+40 \mathrm{mV}$. The holding potential and the potential during the interpulse intervals were $-80 \mathrm{mV}$. The interval between each trace was 30 seconds to ensure that no inactivation accumulated between each cycle of the protocol. In Fig. 3.3A, B are currents in response to a long $5 \mathrm{~s}$ prepulse with interpulse intervals of variable duration from $180 \mathrm{~ms}$ to $3 \mathrm{~s}$ in increments of $400 \mathrm{~ms}$.

In the absence of nifedipine (Fig. 3.3A), more than $50 \%$ of the current inactivated during the $5 \mathrm{~s}$ prepulse to $+40 \mathrm{mV}$. After a brief interval, peak current amplitudes recorded during test pulses $\left(I_{\text {peak2 }}\right)$ were smaller than that of the first prepulse $\left(I_{\text {peak } 1}\right) . \quad I_{\text {peak2 }}$ recovered slowly with increasing interpulse intervals and reached only $85 \%$ of $I_{\text {peak } 1}$ after an interpulse interval of 3 seconds. When $20 \mu \mathrm{M}$ nifedipine was applied externally, (Fig. 3.3B), both peak and steady-state currents at +40 $\mathrm{mV}$ were rapidly inhibited during the prepulse. In the absence and presence of $20 \mu \mathrm{M}$ nifedipine, averaged fractional recovery (each from 4 experiments) was plotted against the interpulse intervals 
Figure 3.3. The effects of nifedipine on recovery from C-type inactivation. A-B) Superimposed whole-cell current traces were elicited by a double-pulse to $+40 \mathrm{mV}$ separated by a variable interpulse interval from $180 \mathrm{~ms}$ to $3 \mathrm{~s}$ with increments of $400 \mathrm{~ms}$. The duration of the prepulse was $5 \mathrm{~s}$ and the test pulse was $60 \mathrm{~ms}$. The interval between pairs of pulses was $30 \mathrm{~s}$ at $-80 \mathrm{mV}$. Current traces shown were recorded in the absence, A, and presence, B, of $20 \mu \mathrm{M}$ nifedipine. CD) Currents elicited by pairs of $60 \mathrm{~ms}$ steps to $+40 \mathrm{mV}$ separated by a variable interpulse interval from $120 \mathrm{~ms}$ to $1920 \mathrm{~ms}$ in increments of $200 \mathrm{~ms}$. The interval between pairs of pulses was $30 \mathrm{~s}$. Current traces were recorded in control, C, and $20 \mu \mathrm{M}$ nifedipine, D. Results in A-D were from the same cell. E-F) Fractional recovery $\left(I_{\text {peak } 2} / I_{\text {peak } 1}\right)$ from inactivation plotted as a function of interpulse interval. Data points in $\mathrm{E}$ and $\mathrm{F}$ were averaged from data using the same voltage protocols as in A-B and C-D respectively. Data points represent means \pm S.E. from 3-19 experiments. Solid lines are best fits to data points using equation [3a] in $\mathrm{E}$ and [3b] in $\mathrm{F}$. 
A

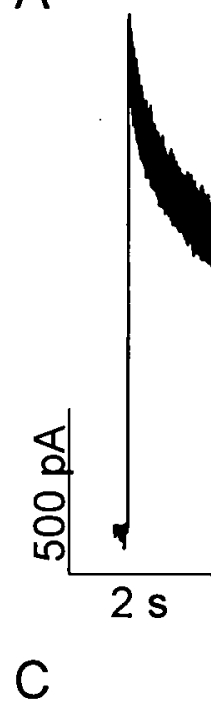

C

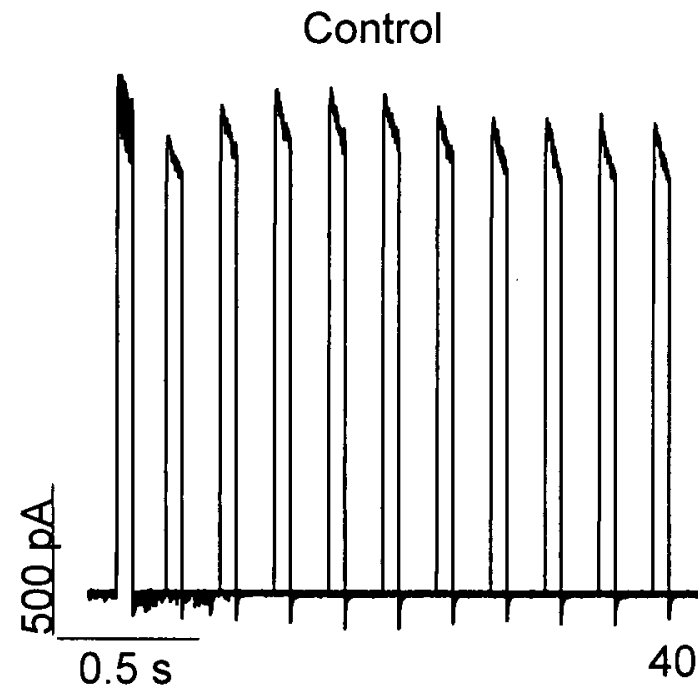

E

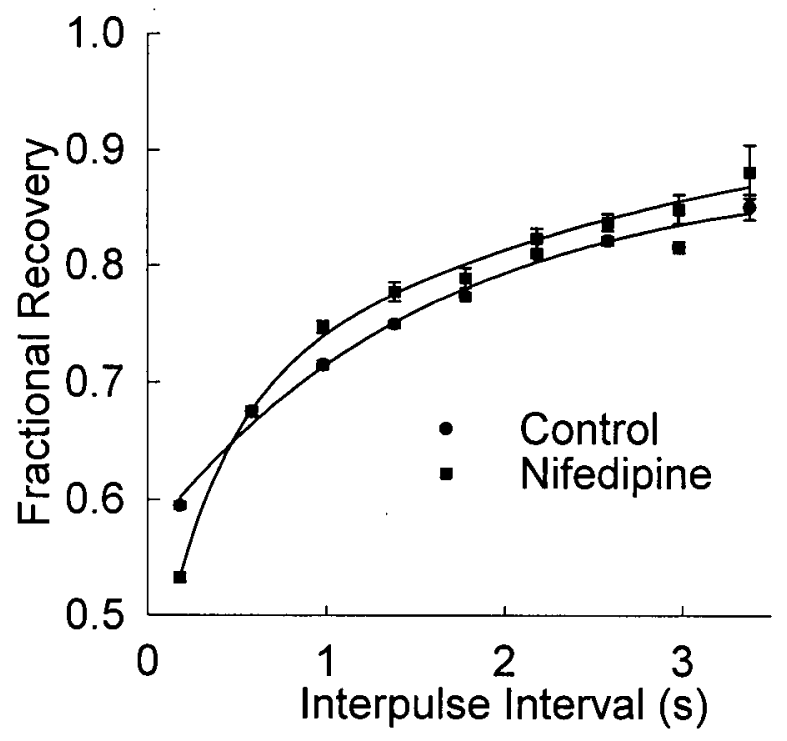

B

Figure 3.3
$20 \mu \mathrm{M}$ Nifedipine

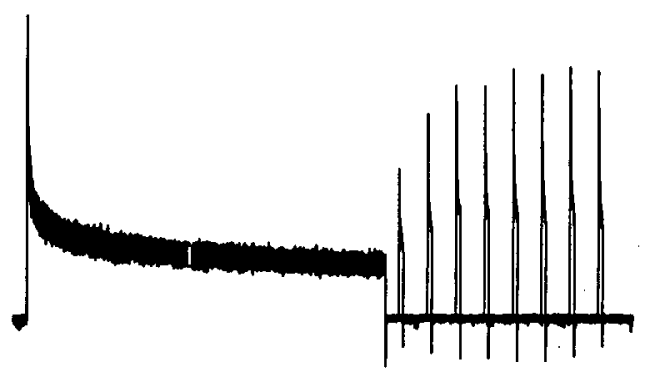

$20 \mu \mathrm{M}$ Nifedipine

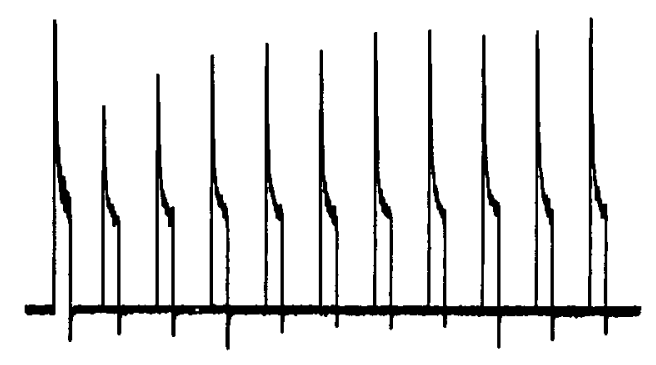

$\mathrm{F}$

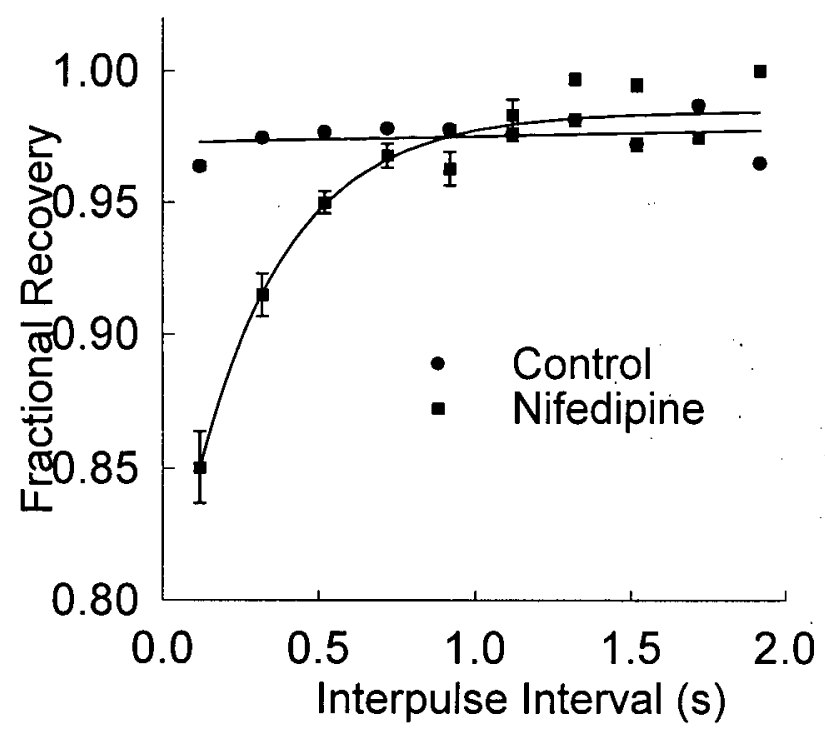


(Fig. 3.3E). Control data points were well fit by a single exponential function, with a mean recovery rate of $1.8 \pm 0.1 \mathrm{~s}$ (mean $\pm \mathrm{SE}, \mathrm{n}=8$ ), which reflected the slow recovery from C-type inactivation. In the presence of $20 \mu \mathrm{M}$ nifedipine, data points were fit by a double exponential equation, and the mean recovery rates were $2.8 \pm 0.3 \mathrm{~s}\left(\tau_{1}\right)$ and $0.33 \pm 0.02 \mathrm{~s}\left(\tau_{2}\right.$, mean $\left.\pm \mathrm{SE}, \mathrm{n}=7\right)$. Although the slow time constants $\left(\tau_{1}\right)$ in control and nifedipine are not in exact agreement, the data suggest that in the presence of nifedipine, recovery after long pulses comprised two processes. One of these was the slow recovery from C-type inactivation $\left(\tau_{1}\right)$ seen in control, and the second, additional fast recovery was likely to be recovery of non-inactivated channels from open-channel nifedipine block $\left(\tau_{2}\right)$ during the repolarization (interpulse) interval. The initial rapid phase of recovery from block was small and most of the recovery in the presence of nifedipine consisted of a slow recovery from C-type inactivation with similar amplitude to that observed in control. This clearly indicated that most of the channels rapidly blocked by nifedipine had subsequently inactivated during the prepulse (Fig. 3.3B), and these channels recovered slowly. The fewer channels in the nifedipine-blocked but non-inactivated state were able to recover rapidly on repolarization.

The separate nature of recovery from nifedipine block and C-type inactivation was further illustrated by applying a short double pulse protocol as indicated in Fig. 3.3C. Here, currents were elicited by pairs of $60 \mathrm{~ms}$ depolarizing pulses to $+40 \mathrm{mV}$ with a variable interpulse interval from $120 \mathrm{~ms}$ to $1920 \mathrm{~ms}$ in increments of $200 \mathrm{~ms}$. The prepulse activated Kv1.5 channels and allowed nifedipine block, while letting as few channels as possible become C-type inactivated. Data in Fig. $3.3 \mathrm{C}$ shows that in the absence of nifedipine, currents activated at $+40 \mathrm{mV}$ minimally inactivated during the prepulse, and were fully recovered after an interpulse interval of $120 \mathrm{~ms}$. In the presence of $20 \mu \mathrm{M}$ nifedipine, current was significantly blocked during the $60 \mathrm{~ms}$ prepulse. Currents only partially recovered during test pulses after an interval of $120 \mathrm{~ms}$. Mean data for fractional recovery 
during short double-pulse experiments are shown in Fig. 3.3F. Data points clearly showed that in the absence of nifedipine little inactivation occurred during the prepulse, and data could be fit using a straight line. In the presence of $20 \mu \mathrm{M}$ nifedipine, data were fit by a single exponential equation to give a recovery rate of peak current from nifedipine block of $316 \pm 19 \mathrm{~ms}$. Since little inactivation occurred over this duration, this time constant reflected the recovery from nifedipine block and was consistent with the faster of the two rates obtained from Fig. 3.3E (332 ms). It seems, then, that whether inactivation was permitted, as during the long prepulse (Fig. 3.A, B), or not given time to develop during the short prepulse (Fig. 3.3C, D), nifedipine block and recovery occurred at the same rates. This strongly suggested that nifedipine block of Kv1.5 channels and Ctype inactivation were independent processes. 


\subsection{DISCUSSION}

\section{5a. Nifedipine block and C-type inactivation}

The principal action of nifedipine on Kv1.5 was to accelerate the rate of current decay once channel opening rate significantly exceeded blocking rate. The possibility existed since permeant cations modulated the degree of nifedipine block, that nifedipine's action was in some way related to an acceleration of C-type inactivation. This is based on the knowledge that permeant cations, and especially extracellular cation concentrations are effective modulators of the rate of C-type inactivation (Lopez-Barneo et al., 1993), and the recovery from inactivation. In addition, the residue R487 in Kv1.5 is analogous to T449 in Shaker channels in that both are important determinants of the inactivation rate. In Kv1.5, though, the role for this residue is less critical (Fedida et al., 1999) and as discussed below, quite large changes in $\mathrm{K}^{+}$o have less pronounced effects on the inactivation rate than in Shaker channels. Modulation of C-type inactivation by channel blockers has been extensively studied by internal or external applications of $\mathrm{TEA}^{+}$, where external TEA ${ }^{+}$competed for C-type inactivation (Choi et al., 1991; Grissmer \& Cahalan, 1989). Interactions between C-type inactivation and channel blockers are manifested in many ways. In Kv1.3 channels in T lymphocytes, slowed C-type inactivation via exposure to 160 $\mathrm{mM}\left[\mathrm{K}^{+}\right]_{\mathrm{o}}$ greatly diminished the potency of CP-339, 818, a channel blocker of Kv1.3 (Nguyen et al., 1996), suggesting that CP-339,818 preferentially bound to the inactivated state of Kv1.3. In mutant ShB $\Delta 6-46$ expressed in Xenopus oocytes, nifedipine block was found to be insensitive to $\mathrm{K}^{+}$(Avdonin et al., 1997) suggesting that it could be separated from C-type inactivation.

We were able to clearly demonstrate that nifedipine block is not coupled to the process of Ctype inactivation. Increased $\mathrm{K}^{+}{ }_{\mathrm{o}}$ slowed C-type inactivation of Kv1.5 channels (Fig. 3.1), consistent with observations in ShB expressed in Xenopus oocytes (Lopez-Barneo et al., 1993) and Kv1.3 in 
T-lymphocytes (Nguyen et al., 1996). These results implied that the mechanistic basis for C-type inactivation occurring in these different channels is similar. However, the time courses of net currents blocked by nifedipine were unchanged by increased $\mathrm{K}_{0}^{+}$(Fig. 3.1, 3.2). This was supported by data showing that the level of block was not altered by large changes in the concentration of $\mathrm{K}^{+}$。 (Fig. 3.2), confirming that nifedipine block was independent of $\mathrm{K}_{\mathrm{o}}^{+}$and thus distinct from C-type inactivation. If channels that were already nifedipine-bound were also prevented from undergoing C-type inactivation, then scaled current traces in $5 \mathrm{~K}^{+}{ }_{\mathrm{o}}$ and $135 \mathrm{~K}_{\mathrm{o}}^{+}$(Fig. $3.1 \mathrm{~B}$, at the same concentration of nifedipine) should have been superimposed. However, with $20 \mu \mathrm{M}$ nifedipine, residual current decay in $135 \mathrm{~K}^{+}$was still slower than that in $5 \mathrm{~K}^{+}$, which indicated that nifedipineblocked channels still underwent normal C-type inactivation dependent on the respective $\mathrm{K}_{0}^{+}$. The proportion of channels undergoing C-type inactivation was not greatly different before and after nifedipine, as evidenced by the difference in decay of normalized records in 5 and $135 \mathrm{mM} \mathrm{K}^{+}$in Fig. 3.1B. This suggests that nifedipine-induced current decay and C-type inactivation were mediated by distinct mechanisms, but both coexisted in the presence of nifedipine.

Based on the observation that the onset of nifedipine block was much faster than development of C-type inactivation, we expected that recovery from nifedipine block should be much faster than from C-type inactivation. This also allowed a test of whether nifedipineblocked channels subsequently C-type inactivated, and thus recovered slowly. If both processes were independent, they should be distinguished by their apparently different recovery rates. Our data indicated that in the presence of nifedipine, during a long depolarizing pulse, two recovery rates were obtained. The fast recovery rate represented nifedipine dissociation from blocked channels, but the slow recovery rate, which most of the channels underwent, represented reversal of channel inactivation. The experiments indicated that nifedipine-blocked channels could freely C-type inactivate, and also the unchanged fast time constant of recovery in the presence or absence of C-type inactivation supported the separate nature of unblock and C-type inactivation. 
Overall the experiments indicate that the outer pore mouth block is mediated at a nifedipinebinding site that is relatively unaffected by the processes involved in the onset and development of C-type inactivation in this channel. 
CHAPTER IV

GENERAL CONCLUSIONS 


\section{Conclusion and recommendations for further experiments}

\subsection{Conclusion}

A series of experiments were carried out on Kv1.5 and Kv4.2 channels expressed in human embryonic cells to investigate the modulating effect of permeating ions on nifedipine block of Kv1.5 channel, and the interaction between drug block and channel inactivation. The major findings were as follows: 1) The potency of nifedipine block in the Kv1.5 channel is influenced by the species of permeating ion. 2) Nifedipine block of Kv1.5 was conditioned by the ion permeating the pore, and to a lesser extent by the extracellular ion species alone. 3) In the presence of ions, nifedipine also affected the off-gating currents, but the ion species could still modulate the nifedipine binding affinity. 4) The outer pore mutant R487V of Kv1.5 reduced nifedipine potency close to that of Kv4.2, and other $\mathrm{Kv}$ channels with an equivalent valine. 5) Nifedipine block of Kv1.5 is an independent process from intrinsic C-type inactivation of Kv1.5 channels.

\subsection{Nifedipine clinical use and possible $\mathrm{K}^{+}$channel block for morbidity at high doses.}

Nifedipine can inhibit the transmembrane influx of calcium ions into cardiac muscle and smooth muscle. It has been widely used for two decades in the control of angina pectoris and hypertension. The precise mechanisms of nifedipine have not been fully determined, but include at least two mechanisms: 1) Nifedipine can dilate the main coronary arteries and coronary arterioles, both in normal and ischemic regions, and is effective to treat vasospastic angina. 2) Nifedipine can also dilate peripheral arterioles and reduce the total peripheral vascular resistance at rest and at a given level of exercise, thus reduce myocardial energy consumption and oxygen requirement. These properties can account for the effectiveness of nifedipine in chronic stable angina and hypertension. 
It is suggested that nifedipine dosage must be adjusted according to each patient's needs. Therapy for either hypertension or angina should be initiated with 30 or $60 \mathrm{mg}$ once daily. Doses above $120 \mathrm{mg}$ are not recommended. There are two forms of nifedipine, one is a shortacting formation of nifedipine, such as procardia capsules (Pfizer, USA), another one is longacting nifedipine, such as procardia $\mathrm{XL}$ extended release tablets (Nifedipine gastrointestinal therapeutic system (GITS), Pfizer, USA). Nifedipine is completely absorbed after oral administration and undergoes extensive first pass metabolism (Renwick et al., 1988). The systemic bioavailability of nifedipine following oral administration has been reported to be between $45-70 \%$ (Foster et al., 1983; Raemsch \& Sommer, 1983). After administration of a nifedipine capsule, plasma nifedipine concentration peaks rapidly and then falls rapidly. After sublingual or oral administration of one nifedipine $10 \mathrm{mg}$ procardia capsule, peak nifedipine serum concentrations following sublingual and oral administration are $41.9 \pm 24.9 \mathrm{ng} / \mathrm{ml}(121 \pm$ $72 \mathrm{nM}), 99.6 \pm 49.8 \mathrm{ng} / \mathrm{ml}(288 \pm 144 \mathrm{nM})$, respectively (Brown et al., 1986). It also has been shown by others that sublingual and oral nifedipine can reach concentrations of 300 to $600 \mathrm{nM}$ (McAllister, Jr., 1986; Taburet et al., 1983). In contrast, nifedipine GITS reach a plateau plasma concentration at approximately 6 hours, and relative constant drug concentration is maintained over 24 hours. Nifedipine is initially oxidized to the pyridine analogue, then converted to acid metabolites which are excreted in the urine (Horster et al., 1972). The elimination half-life of nifedipine is approximately two hours (Renwick et al., 1988). Experience with nifedipine overdose is limited. The main effects of massive overdose with procardia XL tablets (4800 mg) reported in one case are dizziness, palpitations, flushing, nervousness, nausea, vomiting, and generalized edema. The effect of a single $900 \mathrm{mg}$ ingestion of procardia capsules in an anginal patient with a history of bundle branch block was loss of consciousness, and hypotension. A variety of ECG abnormalities, including sinus bradycardia and varying degrees of AV block, were also seen in this patient. 
The main adverse reactions of nifedipine are headache, fatigue, dizziness, constipation, and nausea. Furberg et al. reported the dose of nifedipine was associated with the risk of mortality (Furberg et al., 1995). It suggested that the risk of mortality rise sharply in trials that used $\geq 80 \mathrm{mg}$ of nifedipine per day. The potentially harmful mechanisms include marked hypotension, negative inotropy, proarrhythmia, proischemic (an antianginal drug occasionally worsen ischemia in an unpredictable and dangerous manner) and prohemorrhagic effect (Furberg et al., 1995). Zhang et al. highlighted a possible mechanism that $\mathrm{K}$ channel, especially Kv1.5, block by nifedipine could exacerbate the likelihood of serious arrhythmias (Zhang \& Fedida, 1998). The following evidences support this hypothesis. 1) Nifedipine blocks calcium channels in myocardium with a relatively high affinity $\left(\mathrm{K}_{\mathrm{d}}=200\right.$ to $\left.300 \mathrm{nM}\right)$, and it also blocks myocardial $\mathrm{K}^{+}$channels in mammalian ventricular myocytes with $\mathrm{K}_{\mathrm{d}}$ 's of $0.5-1 \mu \mathrm{M}$, and in cloned channels (Rampe et al., 1993; Zhang et al., 1997). 2) Sublingual and oral nifedipine have been shown to reach 300 to $600 \mathrm{nM}$ plasma concentration, which can cause significant $\mathrm{K}^{+}$ channel blockade in vitro because the threshold of nifedipine on Kv1.5 is at 100nM (Zhang et al., 1997). 3) The plateau phase of the cardiac action potential is normally terminated by repolarizing outward potassium fluxes. Therefore, nifedipine block can prolong the action potential, cause a dispersion of refractoriness as these channels differ in their regional distribution across the myocardial wall (Liu et al., 1993), and lead to instability of the resting potential of the ventricular muscle. T-wave inversion caused by short-acting nifedipine may be related to nifedipine block of epicardial potassium currents. Raised catecholamine levels and activated renin-angiotensin system caused by short-acting nifedipine, in combination with the instability of resting potential, predispose to the occurrence of complex ventricular tachyarrhythmias. 4) Nifedipine inhibits a variety of $\mathrm{K}^{+}$channels, among the more sensitive of these are two type: $I_{\text {то }}\left(I_{\text {то }}\right.$ was blocked by micromolar concentrations of nifedipine) and $\mathrm{Kv1.5}$ $\left(\mathrm{IC}_{50}=7 \mu \mathrm{M}\right)$. The currents inhibited by higher nifedipine concentration includes $\mathrm{I}_{\mathrm{K} 1}\left(\mathrm{IC}_{50}=\right.$ 
$260 \mu \mathrm{M}), \mathrm{I}_{\mathrm{Kr}}\left(\mathrm{IC}_{50}=275 \mu \mathrm{M}\right)$, and $\mathrm{I}_{\mathrm{Ks}}\left(\mathrm{IC}_{50}=360 \mu \mathrm{M}\right)($ Zhabyeyev et al., 2000). Zhang et al. reported that $\mathrm{I}_{\mathrm{Kr}}$-type current carried by the $H E R G$ gene product was unaffected by exposure to $30 \mu \mathrm{M}$ nifedipine (Zhang et al., 1999).

\subsection{Nifedipine binding sites in the potassium channel}

Nifedipine is a classical $\mathrm{Ca}^{2+}$ channel antagonist and is thought to act on open $\mathrm{Ca}^{2+}$ channels (Kass et al., 1991; Kass \& Arena, 1989). Our lab has reported that nifedipine produced open channel block of Kv1.5 channel (Zhang et al., 1997). A similar conclusion that nifedipine acted as an open $\mathrm{K}^{+}$channel blocker has been drawn in Shaker B $\Delta 6-46$ channels (Avdonin et al., 1997). In the latter study, though, it was suggested that the nifedipine binding site was located at the intracellular side of the pore, a conclusion that is not well supported by our observation.

The binding sites of dihydropyridine (DHPs) in $\mathrm{Ca}^{2+}$ channels are not thoroughly understood. Kass et al. suggested that the dihydropyridine binding site in the L-type $\mathrm{Ca}^{2+}$ channel was close to the extracellular surface of the cell membrane (Kass et al., 1991; Kass \& Arena, 1989). With the aid of antibody mapping and chimeric studies, IIIS5, IIIS6 and IVS6 were shown to be critical for the actions of DHPs within the L-type $\mathrm{Ca}^{2+}$ channel (Grabner et al., 1996; Striessnig et al., 1998). Thr1039 and Gln1043 in IIIS5 of L-type $\mathrm{Ca}^{2+}$ channels (numbering according to anc-II, Genebank accession number M67515) are required for DHP binding (Mitterdorfer et al., 1996). There are five important residues, four in IIIS6 (Tyr1152, Ile1153, Ile1156, and Met1161) and one in IVS6 (Asn1472). These five residues decreased apparent DHP antagonist affinity in binding or functional experiments by more than five-fold when singly mutated. There are also at least six additional IIIS6 and IVS6 residues (Phe1158, Phe1159, Met1160, Tyr1463, Met1464, Ile1471) in $\alpha 1_{C}$, which caused smaller (about two- to fivefold) decreases in DHP affinity when mutated 
(Striessnig et al., 1998). Although a portion of the above amino acids (comprising residues Tyr1152, Phe1158, Phe1159, and Asn1472) is conserved in non-L channels, it was proposed that these amino acids not present in the non-L channels play a more important role to confer high affinity DHP interaction in L channels.

$\mathrm{K}^{+}$channels and $\mathrm{Ca}^{2+}$ channels are both voltage dependent channels with a high amino acid homology with the pore region (Catterall, 1988; Jan \& Jan, 1989; Rampe et al., 1993; Nakayama et al., 1991). An alignment of amino acid sequences between proposed DHPs binding sites in $\mathrm{Ca}^{2+}$ channel $\alpha 1$ subunits in skeletal muscle (Nakayama et al., 1991; Vega-Saenz de Miera et al., 1994) and the Kv1.5 channel demonstrated that sequence GLLIFFLFIG in the S5 segment of the Kv1.5 channel shared high homology with the DHP binding site in the skeletal muscle (Fig. 4.1). Therefore, we postulate that the GLLIFFLFIG sequence in the S5 segment of the Kv1.5 channel may be involved in the binding of nifedipine to the Kv1.5 channel. As nifedipine is highly lipidsoluble, when extracellularly applied, it could approach the receptor site by lateral diffusion after partition into the lipid bilayer of the membrane.

Our data in chapter II demonstrated that the permeating ions, $\mathrm{K}^{+}, \mathrm{Rb}^{+}$, and $\mathrm{Cs}^{+}$influenced the potency of nifedipine block of the Kv1.5 channel. Varying the ionic species at the intracellular and extracellular mouth of the channel, and using a non-conducting W472F-Kv1.5 mutant, demonstrated that block was conditioned by the ion permeating the pore, and to a lesser extent by the extracellular ion species alone. In Kv1.5 the outer pore mutant R487V (Fig. 4.1) reduced nifedipine potency close to that of $\mathrm{Kv} 4.2$, and other $\mathrm{Kv}$ channels with an equivalent valine. This confirmed that the binding site of nifedipine was within the ion permeation pathway, and the outer mouth residue R487 was involved in the binding of nifedipine to the Kv1.5 channel. To investigate the roles of the other sites, extensive mutagenesis experiments, or the use of outer pore chimeras may help in the further localizing where nifedipine acts on $\mathrm{K}^{+}$channels. As DHPs bind with $\mathrm{Ca}^{2+}$ channels within the pore-associated drug-binding pocket, nifedipine may also bind to $\mathrm{K}^{+}$channels 
Figure 4.1. The proposed structure of the S5, pore region, and S6 segments of the hKv1.5 channel. Charged amino acids are shown shaded. The GLLIFFLFIG sequence (between dashed lines) in the S5 segment of the hKv1.5 channel are amino acid residues that are homologous to the DHP binding site in the L-type $\mathrm{Ca}^{2+}$ channel. Unfilled arrow indicates the amino acid that affects nifedipine block if it is mutated from $R$ to $V$. The GYG sequence (dashed box) in the loop between the S5 and the S6 segment is (at least part of) the selectivity filter for $\mathrm{K}^{+}$. Filled arrow indicates those amino acid residues that are closely related to C-type inactivation. 


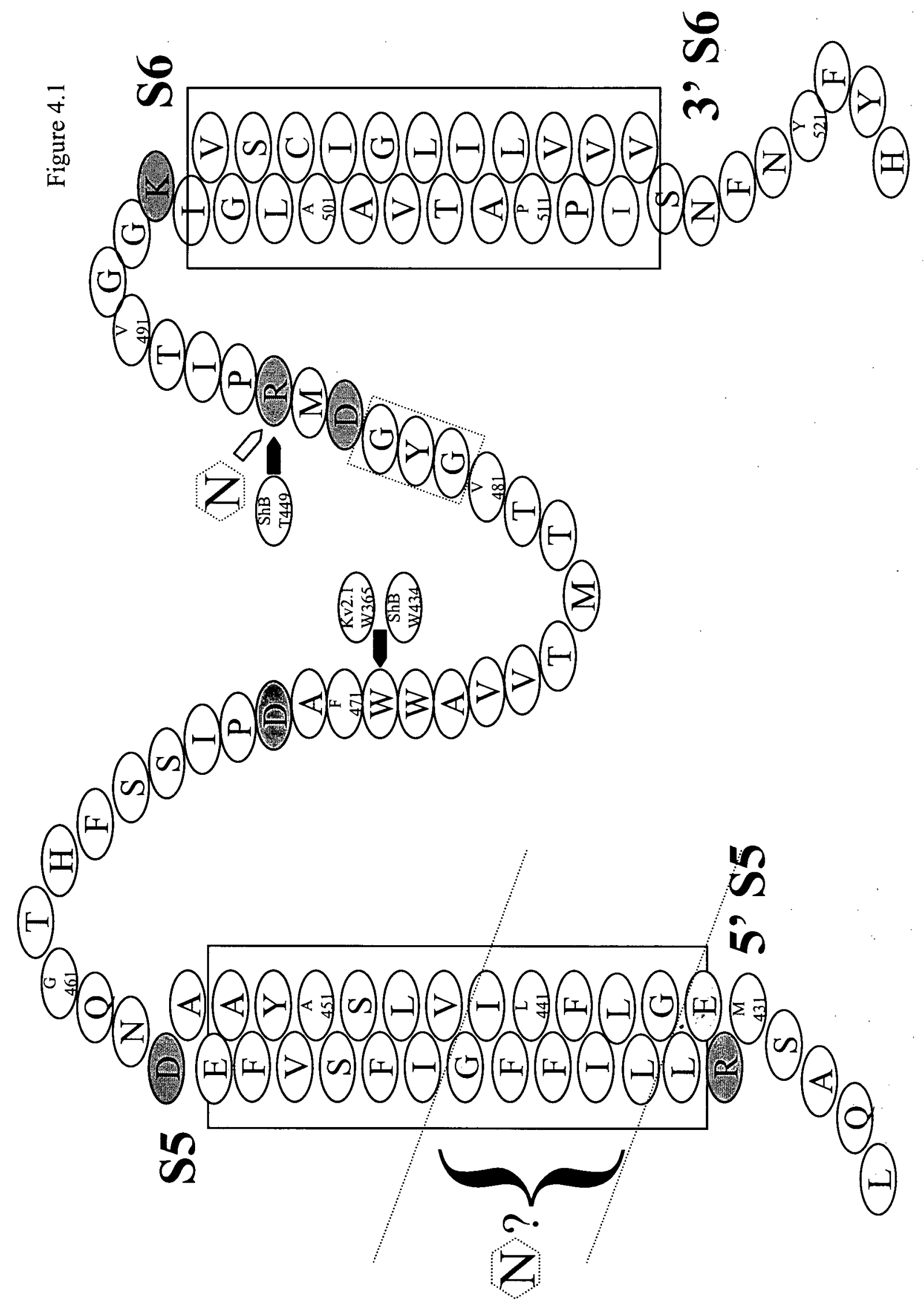


within the pore-associated drug-binding pocket, which is constructed by the S5, P region, and even the S6 subunit.

\subsection{Permeating ions modulate nifedipine block of Kv1.5}

Varying ion species at the intracellular and extracellular mouth of the channel demonstrated that the nifedipine binding affinity was different in the presence of different ions. Further, it suggested that block was conditioned by the ion permeating the pore, and to a lesser extent by the extracellular ion species alone. This is in agreement with electrophysiological data previously reported from our laboratory that nifedipine binding was located at the extracellular mouth of the pore. In the open state, when an ion occupies the pore, the conformation of the pore or the steric obstruction would affect nifedipine accesses to its binding site, which may be very close to the pore. The extracellular ions effects suggest the presence of an outer mouth ion binding site, not identical to nifedipine binding site, but which still can affect nifedipine blocking affinity.

When ion permeation was prevented in the W472F mutant of Kv1.5, a non-conducting mutant, gating currents were measured (Fig. 2.7). The potency of nifedipine block of off-gating currents is lower than for ionic currents. In the presence of external $135 \mathrm{mM} \mathrm{Cs}^{+}$, the $\mathrm{IC}_{50}$ of nifedipine block is about $80 \mu \mathrm{M}$ (Data not shown). This may be the result of conformational changes in the deep pore of $\mathrm{W} 472 \mathrm{~F}$ due to the absence of permeating ions, and the consequent alteration of the nifedipine binding site. This evidence suggests that deep pore conformation is important in determining the nifedipine binding affinity. Still, in the presence of $100 \mu \mathrm{M}$ nifedipine, when the gating currents were measured, extracellular $\mathrm{K}^{+}$was able to co-ordinate a more potent action of nifedipine than intracellular $\mathrm{K}^{+}$(Fig. $2.7 \mathrm{G}$ ). It confirmed the previous observation that extracellular ions had a secondary effect on nifedipine block. Interestingly, though, in these experiments, addition of only intracellular $\mathrm{K}^{+}$or $\mathrm{Rb}^{+}$was able to coordinate a 
relatively potent block of off-gating current by nifedipine. This suggested that even intracellular ions were able to have long range effects on overall pore conformation and affect the formation of the nifedipine binding site in the outer channel mouth, without being present there.

It has been suggested that the NCM is permanently C-type inactivated, but there is no directed evidence confirming this. Nifedipine can still block gating currents of NCM and delay the return of off-gating charge in this mutant, which suggests two possibilities. One is that nifedipine can bind channels in the C-type inactivated state, and dissociation of nifedipine from channels is responsible for the delayed return of off-gating charge when channel close again. This is not in agreement with data from wild type channels in which it appeared that nifedipine was able to freely associate and dissociate from inactivated channels without affecting the process of recovery from inactivation. Another explanation is that the NCM is not permanently in the C-type inactivated state, at the start of activation, it may dwell in open state for a while but does not allow ion conduction because the W472F mutant disrupts the ion pathway. Nifedipine can then bind with this open state and delay the return of off-gating charge. More experiments are needed to explore this possibility.

\subsection{C-type inactivation is unrelated to nifedipine block}

The Kv1.5 channel exhibits typical slow C-type inactivation, which is thought to be caused by the constriction of the outer mouth of the channel pore (Yellen et al., 1994). Studies have shown that mutations of several amino acids strongly affect the time course of C-type inactivation. These are T449 in the Shaker B channel, A463 in Shaker and Kv1.3, W365 and V369 in Kv2.1, which correspond to R487, A501, W472 and V476 in Kv1.5, respectively (Lopez-Barneo et al., 1993; DeBiasi \& Brown, 1993; Panyi et al., 1995; Kirsch \& Shieh, 1997). From the locations of these amino acids in the primary structure of the Kv1.5 channel (Fig 4.1), it seems that C-type inactivation occurs with the participation of large regions in the pore, or that 
alternately C-type inactivation could be related to a very local region of the pore if these amino acids are very closely related in the three dimensional topology of the pore. Such molecular modeling is not available to us at present time, and may not be sufficiently precise to be helpful.

Our studies illustrated that the time constant of nifedipine block was not affected by experimental manipulation of the time course of C-type inactivation, and also was not affected by external $\mathrm{K}^{+}$concentration. This suggested that nifedipine block seemed to occur independently of the amplitude and time constant of the C-type inactivation. Similarly in Chapter III we demonstrated that recovery from nifedipine block, and the recovery from inactivation were independent processes. On the other hand, we have seen that permeating ion species affects both nifedipine block and C-type inactivation (Fedida et al., 1999). Therefore, we suggested that nifedipine can access to its binding site during the open state, although the outer mouth residue could affect its access (affinity). The mechanism by which nifedipine blocked channels still can enter C-type inactivation is not clear.

Our conclusion is that the nifedipine binding site is likely to be in the outer pore mouth, but spatially unrelated to the rather local conformational changes that occur in the channel during onset and recovery from C-type inactivation. In this way, nifedipine can freely bind and unbind to inactivated channels with little change in recordable affinity as channels open and close. The modulation of nifedipine binding affinity by different permeating ions reflects the more global changes in the pore conformation that occur with the binding of different ions, and gives little information towards the proximity of ion and nifedipine binding sites. 


\section{Reference List}

ADAMS, B. \& TANABE, T. (1997). Structural regions of the cardiac Ca channel $\alpha_{1 C}$ subunit involved in Ca-dependent inactivation. Journal of General Physiology 110, 379-389.

ARMSTRONG, C.M. \& HILLE, B. (1998). Voltage-gated ion channels and electrical excitability. Neuron 20, 371-380.

AVDONIN, V., SHIBATA, E.F. \& HOSHI, T. (1997). Dihydropyridine action on voltagedependent potassium channels expressed in Xenopus oocytes. Journal of General Physiology 109, 169-180.

BALDWIN, T.J., TSAUR, M.-L., LOPEZ, G.A., JAN, Y.N. \& JAN, L.Y. (1991). Characterization of a mammalian cDNA for an inactivating voltage-sensitive $\mathrm{K}^{+}$channel. Neuron 7, 471-483.

BARHANIN, J., LESAGE, F., GUILLEMARE, E., FINK, M., LAZDUNSKI, M. \& ROMEY, G. (1996). $\mathrm{K}_{\mathrm{v}} \mathrm{LQT} 1$ and IsK (minK) proteins associate to form the $I_{\mathrm{Ks}}$ cardiac potassium current. Nature 384, 78-80.

BARRY, D.M. \& NERBONNE, J.M. (1996). Myocardial potassium channels:

Electrophysiological and molecular diversity. Annual Review of Physiology 58, 363-394.

BARRY, D.M., TRIMMER, J.S., MERLIE, J.P. \& NERBONNE, J.M. (1995). Differential expression of voltage-gated $\mathrm{K}^{+}$channel subunits in adult rat heart: Relation to functional $\mathrm{K}^{+}$channels. Circulation Research 77, 361-369. 
BAUKROWITZ, T. \& YELLEN, G. (1995). Modulation of $\mathrm{K}^{+}$current by frequency and external $\left[\mathrm{K}^{+}\right]$: A tale of two inactivation mechanisms. Neuron 15, 951-960.

BAUMANN, A., GRUPE, A., ACKERMANN, A. \& PONGS, O. (1988). Structure of the voltage-dependent potassium channel is highly conserved from Drosophila to vertebrate central nervous system. EMBO Journal 7, 2457-2463.

BENNETT, P.B., PO, S., SNYDERS, D.J. \& TAMKUN, M.M. (1993). Molecular and functional diversity of cloned cardiac potassium channels. Cardiovascular Drugs Therapy 7 Suppl. $3,585-592$.

BLOCK, B.M. \& JONES, S.W. (1997). Delayed rectifier current of bullfrog sympathetic neurons: ion-ion competition, asymmetrical block and effects of ions on gating. Journal of Physiology 499.2, 403-416.

BOYETT, M.R. (1981). A study of the effect of the rate of stimulation on the transient outward current in sheep cardiac Purkinje fibres. Journal of Physiology 319, 1-22.

BRAUNWALD, E. (1997). Heart disease: a textbook of cardiovascular medicine, Philadelphia, Pennsylvania: W.B/ Saunders Company.

BROWN, G.R., FRASER, D.G., CASTILE, J.A., GAUDREAULT, P., PLATT, D.R. \& FRIEDMAN, P.A. (1986). Nifedipine serum concentrations following sublingual and oral doses. International Journal of Clinical Pharmacology, Therapy, \& Toxicology 24, 283-286.

BUSCH, A.E., HURST, R.S., NORTH, R.A., ADELMAN, J.P. \& KAVANAUGH, M.P. (1991). Current inactivation involves a histidine residue in the pore of the rat lymphocyte 
potassium channel RGK5. Biochemical and Biophysical Research Communications. 179, 1384-1390.

BUTLER, A., WEI, A., BAKER, K. \& SALKOFF, L. (1989). A family of putative potassium channel genes in Drosophila. Science 243, 943-947.

CARMELIET, E. \& MUBAGWA, K. (1998). Antiarrhythmic drugs and cardiac ion channels: mechanisms of action. Progress in Biophysics \& Molecular Biology 70, 1-72.

CASTLE, N.A., FADOUS, S., LOGOTHETIS, D.E. \& WANG, G.K. (1994). Aminopyridine block of Kv1.1 potassium channels expressed in mammalian cells and Xenopus oocytes. Molecular Pharmacology 45, 1242-1252.

CATTERALL, W.A. (1988). Structure and function of voltage-sensitive ion channels. Science 242, 50-61.

CHANDY, K.G. (1991). Simplified gene nomenclature. Nature 352, 26

CHEN, F.S.P., STEELE, D. \& FEDIDA, D. (1997). Allosteric effects of permeating cations on gating currents during $\mathrm{K}^{+}$channel deactivation. Journal of General Physiology 110, 87100.

CHOI, K.L., ALDRICH, R.W. \& YELLEN, G. (1991). Tetraethylammonium blockade distinguishes two inactivation mechanisms in voltage-activated $\mathrm{K}^{+}$channels. Proceedings of the National Academy of Sciences of the USA 88, 5092-5095.

CUNNINGHAM, B.C. \& WELLS, J.A. (1989). High-resolution epitope mapping of hGHreceptor interactions by alanine-scanning mutagenesis. Science 244, 1081-1085. 
DEAL, K.K., ENGLAND, S.K. \& TAMKUN, M.M. (1996). Molecular physiology of cardiac potassium channels. Physiology Review 76, 49-67.

DEBIASI, M. \& BROWN, A.M. (1993). Probing potassium channel pores.

DEBIASI, M., HARTMANN, H.A., DREWE, J.A., TAGLIALATELA, M., BROWN, A.M. \& KIRSCH, G.E. (1993). Inactivation determined by a single site in $\mathrm{K}^{+}$pores. Pflugers Archiv 422, 354-363.

DECOURSEY, T.E. (1990). State-dependent interaction of $\mathrm{K}^{+}$currents in rat type II alveolar epithelial cells. Journal of General Physiology 95, 617-646.

DECOURSEY, T.E. (1995). Mechanism of $\mathrm{K}^{+}$channel block by verapamil and related compounds in rat alveolar epithelial cells. Journal of General Physiology 106, 745-779.

DEMO, S.D. \& YELLEN, G. (1992). Ion effects on gating of the $\mathrm{Ca}^{2+}$-activated $\mathrm{K}^{+}$channel correlates with occupancy of the pore. Biophysical Journal 61, 639-648.

DIXON, J.E. \& MCKINNON, D. (1994). Quantitative analysis of potassium channel mRNA expressiön in atrial and ventricular muscle of rats. Circulation Research 75, 252-260.

DIXON, J.E., SHI, W.M., WANG, H.S., MCDONALD, C., YU, H., WYMORE, R.S., COHEN, I.S. \& MCKINNON, D. (1996). Role of the Kv4.3 $\mathrm{K}^{+}$channel in ventricular muscle - A molecular correlate for the transient outward current. Circulation Research 79, 659-668.

DOYLE, D.A., CABRAL, J.M., PFUETZNER, R.A., KUO, A.L., GULBIS, J.M., COHEN, S.L., CHAIT, B.T. \& MACKINNON, R. (1998). The structure of the potassium channel: Molecular basis of $\mathrm{K}^{+}$conduction and selectivity. Science 280, 69-77. 
DREWE, J.A., VERMA, S., FRECH, G. \& JOHO, R.H. (1992). Distinct spatial and temporal expression patterns of $\mathrm{K}^{+}$channel mRNAs from different subfamilies. Journal of Neuroscience 12, 538-548.

FEDIDA, D. \& GILES, W.R. (1991). Regional variations in action potentials and transient outward current in myocytes isolated from rabbit left ventricle. Journal of Physiology 442, 191-209.

FEDIDA, D., MARUOKA, N.D. \& LIN, S. (1999). Modulation of slow inactivation in human cardiac Kv1.5 channels by extra- and intracellular permeant cations. Journal of Physiology 515, 315-329.

FEDIDA, D., WIBLE, B., WANG, Z., FERMINI, B., FAUST, F., NATTEL, S. \& BROWN, A.M. (1993). Identity of a novel delayed rectifier current from human heart with a cloned $\mathrm{K}^{+}$channel current. Circulation Research 73, 210-216.

FISET, C., CLARK, R.B., SHIMONI, Y. \& GILES, W.R. (1997). Shal-type channels contribute to the $\mathrm{Ca}^{2+}$-independent transient outward $\mathrm{K}^{+}$current in rat ventricle. Journal of Physiology 500, 51-64.

FOSTER, T.S., HAMANN, S.R., RICHARDS, V.R., BRYANT, P.J., GRAVES, D.A. \& MCALLISTER, R.G. (1983). Nifedipine kinetics and bioavailability after single intravenous and oral doses in normal subjects. Journal of Clinical Pharmacology 23, $161-170$.

FRECH, G.C., VANDONGEN, A.M., SCHUSTER, G., BROWN, A.M. \& JOHO, R.H. (1989). A novel potassium channel with delayed rectifier properties isolated from rat brain by expression cloning. Nature 340, 642-645. 
FURBERG, C.D., PSATY, B.M. \& MEYER, J.V. (1995). Nifedipine. Dose-related increase in mortality in patients with coronary heart disease. Circulation 92, 1326-1331.

GLOSSMANN, H., FERRY, D.R., GOLL, A., STRIESSNIG, J. \& ZERNIG, G. (1985). Calcium channels and calcium channel drugs: recent biochemical and biophysical findings. Arzneimittel-Forschung 35, 1917-1935.

GLOSSMANN, H. \& STRIESSNIG, J. (1990). Molecular properties of calcium channels. Reviews of Physiology Biochemistry \& Pharmacology 114, 1-105.

GOMEZ-LAGUNAS, F. \& ARMSTRONG, C.M. (1995). Inactivation in Shaker B K ${ }^{+}$channels: A test for the number of inactivating particles on each channel. Biophysical Journal 68, 89-95.

GRABNER, M., WANG, Z., HERING, S., STRIESSNIG, J. \& GLOSSMANN, H. (1996). Transfer of 1,4-dihydropyridine sensitivity from L-type to class A (BI) calcium channels. Neuron 16, 207-218.

GRANT, A.O., Jr. (1992). On the mechanism of action of antiarrhythmic agents. American Heart Journal 123, 1130-1136.

GRISSMER, S. \& CAHALAN, M. (1989). TEA ${ }^{+}$prevents inactivation while blocking open $\mathrm{K}^{+}$ channels in human T lymphocytes. Biophysical Journal 55, 203-206.

GRISSMER, S., NGUYEN, A.N., AIYAR, J., HANSON, D.C., MATHER, R.J., GUTMAN, G.A., KARMILOWICZ, M.J., AUPERIN, D.D. \& CHANDY, K.G. (1994). Pharmacological characterization of five cloned voltage- gated $\mathrm{K}^{+}$channels, types $\mathrm{Kv} 1.1$, $1.2,1.3,1.5$, and 3.1, stably expressed in mammalian cell lines. Molecular Pharmacology 45, 1227-1234. 
GROSSMAN, E., MESSERLI, F.H., GRODZICKI, T. \& KOWEY, P. (1996). Should a moratorium be placed on sublingual nifedipine capsules given for hypertensive emergencies and pseudoemergencies. Journal of the American Medical Association 276, $1328-1331$.

HEGINBOTHAM, L., LU, Z., ABRAMSON, T. \& MACKINNON, R. (1994). Mutations in the $\mathrm{K}^{+}$channel signature sequence. Biophysical Journal 66, 1061-1067.

HEGINBOTHAM, L. \& MACKINNON, R. (1992). The aromatic binding site for tetraethylammonium ion on potassium channels. Neuron 8, 483-491.

HESKETH, J.C. \& FEDIDA, D. (1999). Sequential gating in the human heart $\mathrm{K}^{+}$channel Kv1.5 incorporates Q (1) and Q (2) charge components. American Journal of Physiology 277, H1956-H1966

HILLE, B. (1992). Ionic channels of excitable membranes. Sunderland, Massachusetts: Sinauer Associates Inc.

HOCKERMAN, G.H., JOHNSON, B.D., ABBOTT, M.R., SCHEUER, T. \& CATTERALL, W.A. (1997). Molecular determinants of high affinity phenylalkylamine block of L-type calcium channels in transmembrane segment IIIS6 and the pore region of the alpha1 subunit. Journal of Biological Chemistry 272, 18759-18765.

HODGKIN, A.L. \& HUXLEY, A.F. (1952). A quantitative description of membrane current and its application to conduction and excitation in nerve. Journal of Physiology 117, 500544.

HORSTER, F.A., DUHM, B., MAUL, W., MEDENWALD, H., PATZSCHKE, K. \& WEGNER, L.A. (1972). Clinical study on the pharmacokinetics of radioactively labelled 
4-(2'-nitrophenyl)-2,6-dimethyl-1,4-dihydropyridine-3,5-dicarboxylic acid dimethyl ester. Arzneimittel-Forschung 22, 330-334.

HOSHI, T., ZAGOTTA, W.N. \& ALDRICH, R.W. (1990). Biophysical and molecular mechanisms of Shaker potassium channel inactivation. Science 250, 533-538.

HOSHI, T., ZAGOTTA, W.N. \& ALDRICH, R.W. (1991). Two types of inactivation in Shaker $\mathrm{K}^{+}$channels: Effects of alterations in the carboxy-terminal region. Neuron 7, 547-556.

HUGNOT, J.P., SALINAS, M., LESAGE, F., GUILLEMARE, E., DE WEILLE, J., HEURTEAUX, C., MATTÉI, M.G. \& LAZDUNSKI, M. (1996). Kv8.1, a new neuronal potassium channel subunit with specific inhibitory properties towards Shab and Shaw channels. The EMBO Journal 15, 3322-3331.

HUME, J.R. (1985). Comparative interactions of organic $\mathrm{Ca}^{2+}$ channel antagonists with myocardial $\mathrm{Ca}^{2+}$ and $\mathrm{K}^{+}$channels. Journal of Pharmacology and Experimental Therapeutics 234, 134-140.

IKEDA, S.R. \& KORN, S.J. (1995). Influence of permeating ions on potassium channel block by external tetraethylammonium. Journal of Physiology 486, 267-272.

IMMKE, D., WOOD, M., KISS, L. \& KORN, S.J. (1999). Potassium-dependent changes in the conformation of the Kv2.1 potassium channel pore. Journal of General Physiology 113, 819-836.

ISACOFF, E.Y., JAN, Y.N. \& JAN, L.Y. (1990). Evidence for the formation of heteromultimeric potassium channels in Xenopus oocytes. Nature 345, 530-534. 
ISACOFF, E.Y., JAN, Y.N. \& JAN, L.Y. (1991). Putative receptor for the cytoplasmic inactivation gate in the Shaker $\mathrm{K}^{+}$channel. Nature 353, 86-90.

JACOBS, E.R. \& DECOURSEY, T.E. (1990). Mechanisms of potassium channel block in rat alveolar epithelial cells. Journal of Pharmacology and Experimental Therapeutics 255, $459-472$.

JAHNEL, U., KLEMM, P. \& NAWRATH, H. (1994). Different mechanisms of the inhibition of the transient outward current in rat ventricular myocytes. Naunyn Schmiedebergs Archives Pharmacology 349, 87-94.

JAN, L.Y. \& JAN, Y.-N. (1989). Voltage-sensitive ion channels. Cell 56, 13-25.

JAN, L.Y. \& JAN, Y.N. (1990). How might the diversity of potassium channels be generated. Trends in Neuroscience 13, 415-419.

JAN, L.Y. \& JAN, Y.N. (1992). Structural elements involved in specific $\mathrm{K}^{+}$channel functions. Annual Review of Physiology 54, 537-555.

JOHNS, D.C., NUSS, H.B. \& MARBAN, E. (1997). Suppression of neuronal and cardiac transient outward currents by viral gene transfer of dominant-negative $\mathrm{Kv} 4.2$ constructs. Journal of Biological Chemistry 272, 31598-31603.

KAMB, A., TSENG-CRANK, J. \& TANOUYE, M.A. (1988). Multiple products of the Drosophila Shaker gene may contribute to potassium channel diversity. Neuron 1,421 430. 
KASS, R.S. \& ARENA, J.P. (1989). Influence of pH on calcium channel block by amlodipine, a charged dihydropyridine compound. Implications for location of the dihydropyridine receptor. Journal of General Physiology 93, 1109-1127.

KASS, R.S., ARENA, J.P. \& CHIN, S. (1991). Block of L-type calcium channels by charged dihydropyridines. Sensitivity to side of application and calcium. Journal of General Physiology 98, 63-75.

KASS, R.S. \& FREEMAN, L.C. (1993). Potassium channels in the heart: Cellular, molecular, and clinical implications. Trends Cardiovascular Medicine 3, 149-159.

KIRSCH, G.E. \& SHIEH, C.-C. (1997). Regulation of ion-dependent gating and block by conserved aromatic amino acid residues in the pore of voltage gated $\mathrm{K}^{+}$channels. Biophysical Journal 72, A232

KUKULJAN, M., LABARCA, P. \& LATORRE, R. (1995). Molecular determinants of ion conduction and inactivation in $\mathrm{K}^{+}$channels. American Journal of Physiology Cell Physiology 268, C535-C556

LIU, D.W., GINTANT, G.A. \& ANTZELEVITCH, C. (1993). Ionic bases for electrophysiological distinctions among epicardial, midmyocardial, and endocardial myocytes from the free wall of the canine left ventricle. Circulation Research 72, 671687.

LOOTS, E. \& ISACOFF, E.Y. (1998). Protein rearrangements underlying slow inactivation of the Shaker $\mathrm{K}^{+}$channel. Journal of General Physiology 112, 377-389. 
LOPEZ-BARNEO, J., HOSHI, T., HEINEMANN, S.H. \& ALDRICH, R.W. (1993). Effects of external cations and mutations in the pore region on C-type inactivation of Shaker potassium channels. Receptors and Channels 1, 61-71.

MANNUZZU, L.M., MORONNE, M.M. \& ISACOFF, E.Y. (1996). Direct physical measurement of conformational rearrangement underlying potassium channel gating. Science 271, 213-216.

MARCHAIS, D. \& MARTY, A. (1979). Interaction of permeant ions with channels activated by acetylcholine in Aplysia neurons. Journal of Physiology 297, 9-45.

MARWICK, C. (1996). FDA gives calcium channel blockers clean bill of health but warns of short-acting nifedipine hazards. Journal of the American Medical Association 275, 423424.

MCALLISTER, R.G., Jr. (1986). Kinetics and dynamics of nifedipine after oral and sublingual doses. American Journal of Medicine 81, 2-5.

MCCORMACK, K., JOINER, W.J. \& HEINEMANN, S.H. (1994). A characterization of the activating structural rearrangements in voltage-dependent Shaker $\mathrm{K}^{+}$channels. Neuron $12,301-315$.

MILLER, C. (1991). 1990: Annus mirabilis of potassium channels. Science 252, 1092-1096.

MINES G.R. (1913). On dynamic equilibrium in the heart. Journal of Physiology 46, 350-383.

MITTERDORFER, J., SINNEGGER, M.J., GRABNER, M., STRIESSNIG, J. \&

GLOSSMANN, H. (1995). Coordination of $\mathrm{Ca}^{2+}$ by the pore region glutamates is 
essential for high-affinity dihydropyridine binding to the cardiac $\mathrm{Ca}^{2+}$ channel alpha 1 subunit. Biochemistry 34, 9350-9355.

MITTERDORFER, J., WANG, Z., SINNEGGER, M.J., HERING, S., STRIESSNIG, J., GRABNER, M. \& GLOSSMANN, H. (1996). Two amino acid residues in the IIIS5 segment of L-type calcium channels differentially contribute to 1,4-dihydropyridine sensitivity. Journal of Biological Chemistry 271, 30330-30335.

NAKAYAMA, K., TAKI, M., STREISSNIG, J., GLOSSMAN, H., CATTERALL, W.A. \& KANAOKA, Y. (1991). Identification of 1,4 dihydropyridine binding regions within the $\alpha 1$ subunit of skeletal muscle $\mathrm{Ca}^{2+}$ channels by photoaffinity labelling with diazepine. Proceedings of the National Academy of Sciences of the USA 88, 9203-9207.

NGUYEN, A., KATH, J.C., HANSON, D.C., BIGGERS, M.S., CANNIFF, P.C., DONOVAN, C.B., MATHER, R.J., BRUNS, M.J., RAUER, H., AIYAR, J., LEPPLE-WIENHUES, A., GUTMAN, G.A., GRISSMER, S., CAHALAN, M.D. \& CHANDY, K.G. (1996). Novel nonpeptide agents potently block the c-type inactivated conformation of Kv1.3 and suppress T cell activation. Molecular Pharmacology 50, 1672-1679.

OGIELSKA, E.M., ZAGOTTA, W.N., HOSHI, T., HEINEMANN, S.H., HAAB, J. \& ALDRICH, R.W. (1995). Cooperative subunit interactions in C-type inactivation of K channels. Biophysical Journal 69, 2449-2457.

PAK, M.D., BAKER, K., COVARRUBIAS, M., BUTLER, A., RATCLIFFE, A. \& SALKOFF, L. (1991). mShal, a subfamily of A-type $\mathrm{K}^{+}$channel cloned from mammalian brain. Proceedings of the National Academy of Sciences of the USA 88, 4386-4390. 
PANYI, G., SHENG, Z., TU, L. \& DEUTSCH, C. (1995). C-type inactivation of a voltage-gated $\mathrm{K}^{+}$channel occurs by a cooperative mechanism. Biophysical Journal 69, 896-903.

PAPAZIAN, D.M., TIMPE, L.C., JAN, Y.N. \& JAN, L.Y. (1991). Alteration of voltagedependence of Shaker potassium channel by mutations in the S4 sequence. Nature 349, 305-310.

PARDO, L.A., HEINEMANN, S.H., TERLAU, H., LUDEWIG, U., LORRA, C., PONGS, O. \& STÜHMER, W. (1992). Extracellular $\mathrm{K}^{+}$specifically modulates a rat brain $\mathrm{K}^{+}$channel. Proceedings of the National Academy of Sciences of the USA 89, 2466-2470.

PEROZO, E., MACKINNON, R., BEZANILLA, F. \& STEFANI, E. (1993). Gating currents from a non-conducting mutant reveal open-closed conformation in Shaker $\mathrm{K}^{+}$channels. Neuron 11, 353-358.

PEROZO, E., PAPAZIAN, D.M., STEFANI, E. \& BEZANILLA, F. (1992). Gating currents in Shaker $\mathrm{K}^{+}$channels. Implications for activation and inactivation models. Biophysical Journal 62, 160-171.

PETERSON, B.Z. \& CATTERALL, W.A. (1995). Calcium binding in the pore of L-type calcium channels modulates high affinity dihydropyridine binding. Journal of Biological Chemistry 270, 18201-18204.

PETERSON, B.Z., JOHNSON, B.D., HOCKERMAN, G.H., ACHESON, M., SCHEUER, T. \& CATTERALL, W.A. (1997). Analysis of the dihydropyridine receptor site of L-type calcium channels by alanine-scanning mutagenesis. Journal of Biological Chemistry 272, $18752-18758$. 
PETERSON, B.Z., TANADA, T.N. \& CATTERALL, W.A. (1996). Molecular determinants of high affinity dihydropyridine binding in L-type calcium channels. Journal of Biological Chemistry 271, 5293-5296.

PÉREZ-CORNEJO, P. \& BEGENISICH, T. (1994). The multi-ion nature of the pore in Shaker $\mathrm{K}^{+}$channels. Biophysical Journal 66, 1929-1938.

PHILIPSON, L.H., HICE, R.E., SCHAEFER, K., LAMENDOLA, J., BELL, G.I., NELSON, D.J. \& STEINER, D.F. (1991). Sequence and functional expression in Xenopus oocytes of a human insulinoma and islet potassium channel. Proceedings of the National Academy of Sciences of the USA 88, 53-57.

PO, S., SNYDERS, D.J., BAKER, R., TAMKUN, M.M. \& BENNETT, P.B. (1992). Functional expression of an inactivating potassium channel cloned from human heart. Circulation Research 71, 732-736.

PONGS, O. (1992). Structural basis of voltage-gated $\mathrm{K}^{+}$channel pharmacology. Trends in Pharmacology Science 13, 359-365.

PONGS, O., KECSKEMETHY, N., MULLER, R., KRAH-JENTGENS, I., BAUMANN, A., KILTZ, H., CANAL, I., LLAMAZARES, S. \& FERRUS, A. (1988). Shaker encodes a family of putative potassium channel proteins in the nervous system of Drosophila. EMBO Journal 7, 1087-1096.

RAEMSCH, K.D. \& SOMMER, J. (1983). Pharmacokinetics and metabolism of nifedipine. Hypertension 5, II18-II24 
RAMPE, D., WIBLE, B., FEDIDA, D., DAGE, R.C. \& BROWN, A.M. (1993). Verapamil blocks a rapidly activating delayed rectifier $\mathrm{K}^{+}$channel cloned from human heart. Molecular Pharmacology 44, 642-648.

RASMUSSON, R.L., MORALES, M.J., WANG, S., LIU, S., CAMPBELL, D.L., BRAHMAJOTHI, M.V. \& STRAUSS, H.C. (1998). Inactivation of voltage-gated cardiac $\mathrm{K}^{+}$channels. Circulation Research 82, 739-750.

RAUER, H. \& GRISSMER, S. (1996). Evidence of an internal phenylalkylamine action on the voltage- gated potassium channel Kv1.3. Molecular Pharmacology 50, 1625-1634.

REES, D.C., CHANG, G. \& SPENCER, R.H. (2000). Crystallographic analyses of ion channels: lessons and challenges. Journal of Biological Chemistry 275, 713-716.

RENWICK, A.G., ROBERTSON, D.R., MACKLIN, B., CHALLENOR, V., WALLER, DG \& GEORGE, C.F. (1988). The pharmacokinetics of oral nifedipine--a population study. British Journal of Clinical Pharmacology 25, 701-708.

ROBERDS, S.L., KNOTH, K.M., PO, S., BLAIR, T.A., BENNETT, P.B., HARTSHORNE, R.P., SNYDERS, D.J. \& TAMKUN, M.M. (1993). Molecular biology of the voltagegated potassium channels of the cardiovascular system. Journal of Cardiovascular Electrophysiology 4, 68-80.

ROBERDS, S.L. \& TAMKUN, M.M. (1991). Cloning and tissue-specific expression of five voltage-gated potassium channel cDNAs expressed in rat heart. Proceedings of the National Academy of Sciences of the USA 88, 1798-1802. 
SALINAS, M., DUPRAT, F., HEURTEAUX, C., HUGNOT, J.P. \& LAZDUNSKI, M. (1997).

New modulatory $\alpha$ subunits for mammalian Shab $\mathrm{K}^{+}$channels. Journal of Biological Chemistry 272, 24371-24379.

SANGUINETTI, M.C., CURRAN, M.E., ZOU, A., SHEN, J., SPECTOR, P.S., ATKINSON, D.L. \& KEATING, M.T. (1996). Coassembly of $\mathrm{K}_{\mathrm{v}}$ LQT1 and minK (IsK) proteins to form cardiac $I_{\mathrm{Ks}}$ potassium channel. Nature 384, 80-83.

SANGUINETTI, M.C., JIANG, C., CURRAN, M.E. \& KEATING, M.T. (1995). A mechanistic link between an inherited and an acquired cardiac arrhythmia: $H E R G$ encodes the $\mathrm{I}_{\mathrm{Kr}}$ potassium channel. Cell 81, 299-307.

SCHLIEF, T., SCHÖNHERR, R. \& HEINEMANN, S.H. (1996). Modification of C-type inactivating Shaker potassium channels by chloramine-T. Pflugers Archiv 431, 483-493.

SCHUSTER, A., LACINOVA, L., KLUGBAUER, N., ITO, H., BIRNBAUMER \& HOFMANN, F. (1996). The IVS6 segment of the L-type calçium channel is critical for the action of dihydropyridines and phenylalkylamines. EMBO Journal 15, 2365-2370.

SHENG, M., LIAO, Y.J., JAN, Y.N. \& JAN, L.Y. (1993). Presynaptic A-current based on heteromultimeric $\mathrm{K}^{+}$channels detected in vivo. Nature 365, 72-75.

SHIBATA, E.F., DRURY, T., REFSUM, H., ALDRETE, V. \& GILES, W. (1989). Contributions of a transient outward current to repolarization in human atrium. American Journal of Physiology 257, H1773-H1781

SLAWSKY, M.T. \& CASTLE, N.A. (1994). $\mathrm{K}^{+}$channel blocking actions of flecainide compared with those of propafenone and quinidine in adult rat ventricular myocytes. Journal of Pharmacology and Experimental Therapeutics 269, 66-74. 
SNYDERS, D.J. (1999). Structure and function of cardiac potassium channels. Cardiovascular Research 42, 377-390.

STARKUS, J.G., KUSCHEL, L., RAYNER, M.D. \& HEINEMANN, S.H. (1997). Ion conduction through C-type inactivated Shaker channels. Journal of General Physiology $110,539-550$.

STEFANI, E., TORO, L., PEROZO, E. \& BEZANILLA, F. (1994). Gating of Shaker K ${ }^{+}$ channels: I. Ionic and gating currents. Biophysical Journal 66, 996-1010.

STRIESSNIG, J., GRABNER, M., MITTERDORFER, J., HERING, S., SINNEGGER, M.J. \& GLOSSMANN, H. (1998). Structural basis of drug binding to $\mathrm{L} \mathrm{Ca}^{2+}$ channels. Trends in Pharmacological Sciences 19, 108-115.

STUHMER, W., RUPPERSBERG, J.P., SCHROTER, K.H., SAKMANN, B., STOCKER, M., GIESE, K.P., PERSCHKE, A., BAUMANN, A. \& PONGS, O. (1989). Molecular basis of functional diversity of voltage-gated potassium channels in mammalian brain. EMBO Journal 8, 3235-3244.

STÜHMER, W., CONTI, F., STOCKER, M., PONGS, O. \& HEINEMANN, S.H. (1991). Gating currents of inactivating and non-inactivating potassium channel expressed in Xenopus oocytes. Pflugers Archiv 410, 423-429.

SWENSON, R.P. \& ARMSTRONG, C.M. (1981). $\mathrm{K}^{+}$channels close more slowly in the presence of external $\mathrm{K}^{+}$and $\mathrm{Rb}^{+}$. Nature 291, 427-429.

TABURET, A., SINGLAS, E., COLIN, J., BANZET, O., THIBONNIER, M. \& CORVOL, P. (1983). Pharmacokinetic studies of nifedipine tablet: correlation with antihypertensive effects. Hypertension 5 supp II, II-29-II-33 
TAMKUN, M.M., KNOTH, K.M., WALBRIDGE, J.A., KROEMER, H., RODEN, D.M. \& GLOVER, D.H. (1991). Molecular cloning and characterization of two voltage-gated $\mathrm{K}^{+}$ channel cDNAs from human ventricle. FASEB Journal 5, 331-337.

TEMPEL, B.L., PAPAZIAN, D.M., SCHWARZ, T.L., JAN, Y.N. \& JAN, L.Y. (1987). Sequence of a probable potassium channel component encoded at Shaker locus of Drosophila. Science 237, 770-775.

TRUDEAU, M.C., WARMKE, J.W., GANETZKY, B. \& ROBERTSON, G.A. (1995). HERG, a human inward rectifier in the voltage-gated potassium channel family. Science 269, $92-$ 95.

TSÉNG, G.N. \& HOFFMAN, B.F. (1989). Two components of transient outward current in canine ventricular myocytes. Circulation Research 64, 633-647.

TSIEN, R.W., HESS, P., MCCLESKEY, E.W. \& ROSENBERG, R.L. (1987). Calcium channels: mechanisms of selectivity, permeation, and block. Annual Review of Biophysics and Biophysical Chemistry 16, 265-290.

UEBELE, V.N., ENGLAND, S.K., CHAUDHARY, A., TAMKUN, M.M. \& SNYDERS, D.J. (1996). Functional differences in Kv1.5 currents expressed in mammalian cell lines are due to the presence of endogenous $\operatorname{Kv} \beta 2.1$ subunits. Journal of Biological Chemistry 271, 2406-2412.

VAUGHAN WILLIAMS, E.M. (1970). Classification of antiarrhythmic drugs. In Symposium on Cardiac Arrhythmias, eds. SONDOE E, FLENSTED-JENSEN E \& OLSEN EH, pp. 449501. The Netherlands: Elsevier. 
VEGA-SAENZ DE MIERA, E., WEISER, M., KENTROS, C., LAU, D., MORENO, H., SERODIO, P. \& RUDY, B. (1994). Shaw-related $\mathrm{K}^{+}$channels in mammals. In Membrane channels: molecular and cellular physiology, ed. PERACCHIA, C., pp. 4178. San Diego: Academic Press.

WANG, H., KUNKEL, D.D., MARTIN, T.M., SCHWARTZKROIN, P.A. \& TEMPEL, B.L. (1993). Heteromultimeric $\mathrm{K}^{+}$channels in terminal and juxtaparanodal regions of neurons. Nature 365, 75-79.

WANG, Z., FERMINI, B. \& NATTEL, S. (1993a). Delayed rectifier outward current and repolarization in human atrial myocytes. Circulation Research 73, 276-285.

WANG, Z., FERMINI, B. \& NATTEL, S. (1993b). Sustained depolarization-induced outward current in human atrial myocytes: Evidence for a novel delayed rectifier $\mathrm{K}^{+}$current similar to Kv1.5 cloned channel currents. Circulation Research 73, 1061-1076.

WANG, Z., ZHANG, X. \& FEDIDA, D. (1999). Gating current studies reveal both intra- and extracellular cation modulation of $\mathrm{K}^{+}$channel deactivation. Journal of Physiology 515, $331-339$.

WEI, A., COVARRUBIAS, M., BUTLER, A., BAKER, K., PAK, M. \& SALKOFF, L. (1990). $\mathrm{K}^{+}$current diversity is produced by an extended gene family conserved in Drosophila and mouse. Science 248, 599-603.

WIBLE, B. \& FEDIDA, D. (1994). Expression system affects the steady-state kinetics of human $\mathrm{K}^{+}$channel Kv1.5. Biophysical Journal 66, A108

WIT, A.L., ROSEN, M.R. \& HOFFMAN, B.F. (1974). Electrophysiology and pharmacology of cardiac arrhythmias. II. Relationship of normal and abnormal electrical activity of cardiac 
fibers to the genesis of arrhythmias B. Re-entry. Section I. American Heart Journal 88, 664-670.

WIT, A.L., ROSEN, M.R. \& HOFFMAN, B.F. (1974). Electrophysiology and pharmacology of cardiac arrhythmias. II. Relationship of normal and abnormal electrical activity of cardiac fibers to the genesis of arrhythmias b. Re-entry. Section II. American Heart Journal 88, 798-806.

XU, H.D., DIXON, J.E., BARRY, D.M., TRIMMER, J.S., MERLIE, J.P., MCKINNON, D. \& NERBONNE, J.M. (1996). Developmental analysis reveals mismatches in the expression of $\mathrm{K}^{+}$channel $\alpha$ subunits and voltage-gated $\mathrm{K}^{+}$channel currents in rat ventricular myocytes. Journal of General Physiology 108, 405-419.

YANG, J., ELLINOR, P.T., SATHER, W.A., ZHANG, J.F. \& TSIEN, R.W. (1993). Molecular determinants of $\mathrm{Ca}^{2+}$ selectivity and ion permeation in L-type $\mathrm{Ca}^{2+}$ channels. Nature 366, 158-161.

YELLEN, G., SODICKSON, D., CHEN, T.-Y. \& JURMAN, M.E. (1994). An Engineered cysteine in the external mouth of a $\mathrm{K}^{+}$channel allows inactivation to be modulated by metal binding. Biophysical Journal 66, 1068-1075.

YOKOYAMA, S., IMOTO, K., KAWAMURA, T., HIGASHIDA, H., IWABE, N., MIYATA, T. \& NUMA, S. (1989). Potassium channels from NG108-15 neuroblastoma-glioma hybrid cells. Primary structure and functional expression from cDNAs. FEBS Letters 259, 37-42.

YUSUF, F. (1995). Calcium antagonists in coronary artery disease and hypertension.

Circulation 92, 1079-1082. 
ZAGOTTA, W.N., HOSHI, T. \& ALDRICH, R.W. (1990). Restoration of inactivation in mutants of Shaker potassium channels by a peptide derived from ShB. Science 250, 568571.

ZAGOTTA, W.N., HOSHI, T., DITTMAN, J. \& ALDRICH, R.W. (1994). Shaker potassium channel gating. II: Transitions in the activation pathway. Journal of General Physiology 103, 279-319.

ZHABYEYEV, p., MISSAN, S., JONES, S. \& MCDONALD, T. (2000). Low-affinity block of cardiac K+ currents by nifedipine. European Journal of Pharmacology 401(2), 137-143.

ZHANG, S., ZHOU, Z., GONG, Q., MAKIELSKI, J.C. \& JANUARY, C.T. (1999). Mechanism of block and identification of the verapamil binding domain to $H E R G$ potassium channels. Circulation Research 84, 989-998.

ZHANG, X., ANDERSON, J.W. \& FEDIDA, D. (1997). Characterization of nifedipine block of the human heart delayed rectifier, hKv1.5. Journal of Parmacology and Experimental Therapeutics 281, 1247-1256.

ZHANG, X. \& FEDIDA, D. (1998). Potassium channel-blocking actions of nifedipine: a cause for morbidity at high doses? Circulation 97, 2098

ZOU, A.R., CURRAN, M.E., KEATING, M.T. \& SANGUINETTI, M.C. (1997). Single $H E R G$ delayed rectifier $\mathrm{K}^{+}$channels expressed in Xenopus oocytes. American Journal of Physiology Heart Circulation Physiology 272, H1309-H1314 